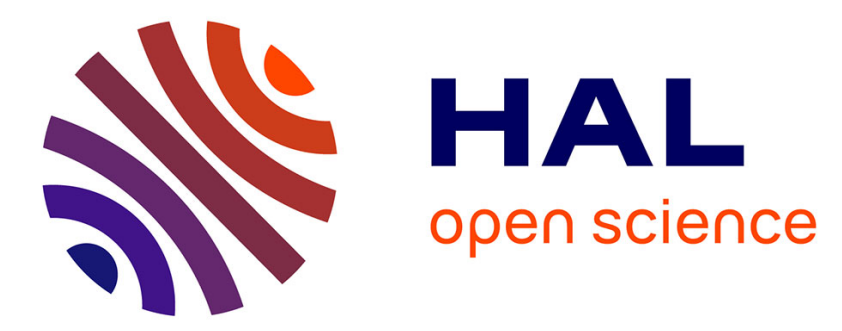

\title{
Sainte-Croix d'Alt'amar. Sens symbolique, architectural et iconographique de la dédicace
}

\author{
Patrick Donabédian
}

\section{To cite this version:}

Patrick Donabédian. Sainte-Croix d'Alt'amar. Sens symbolique, architectural et iconographique de la dédicace. Zaroui Poghossian; Edda Vardanyan. The Church of the Holy Cross of Alt'amar. Politics, Art, Spirituality in the Kingdom of Vaspurakan, Brill, 2019, 978-90-04-40038-2. halshs-02283550

\section{HAL Id: halshs-02283550 \\ https://shs.hal.science/halshs-02283550}

Submitted on 10 Sep 2019

HAL is a multi-disciplinary open access archive for the deposit and dissemination of scientific research documents, whether they are published or not. The documents may come from teaching and research institutions in France or abroad, or from public or private research centers.
L'archive ouverte pluridisciplinaire HAL, est destinée au dépôt et à la diffusion de documents scientifiques de niveau recherche, publiés ou non, émanant des établissements d'enseignement et de recherche français ou étrangers, des laboratoires publics ou privés. 
Article

\title{
«Sainte-Croix d'Alt'amar. Sens symbolique, architectural et iconographique de la dédicace »
}

in

\author{
The Church of the \\ Holy Cross of Att'amar \\ Politics, Art, Spirituality \\ in the Kingdom of Vaspurakan
}

Edited by

Zaroui Poghossian and Edda VARDANYAN

Leiden - Boston

BRILL

2019

p. $291-346$ 


\section{The Church of the Holy Cross of Alt'amar}

Politics, Art, Spirituality

in the Kingdom of Vaspurakan

\section{Edited by}

ZAROUI POGOSSIAN AND EDDA VARDANYAN

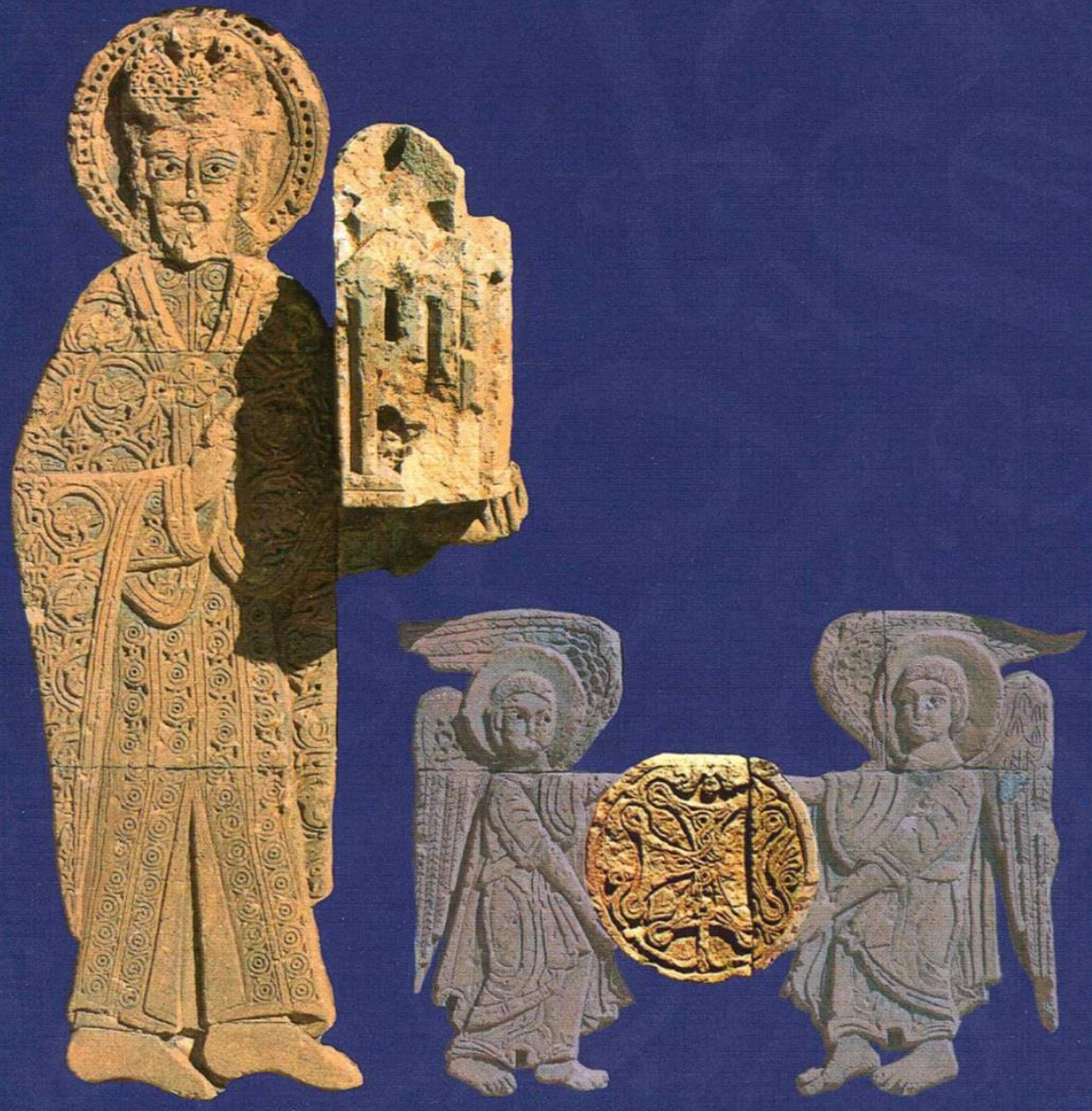

B R I L L 


\title{
Sainte-Croix d'Alt'amar. Sens symbolique, architectural et iconographique de la dédicace
}

\author{
Patrick Donabédian \\ Aix Marseille Université, CNRS, LA3M, Aix-en Provence, France
}

\section{$1 \quad$ Objectifs du présent article}

Monument majeur de l'art médiéval et phénomène hors du commun, l'église palatine d'Ałt'amar, sans doute depuis sa construction au début du $\mathrm{X}^{\mathrm{e}}$ siècle, est consacrée à la Sainte Croix, mais aussi abritait une relique du Saint Bois. Selon la lecture proposée ici, cette dédicace et cette fonction de reliquaire ont une signification particulière et une traduction tangible.

Nous proposerons d'abord d'y voir une manifestation de la popularité du culte de la croix en Arménie et particulièrement au Vaspurakan, et la marque de l'éminente personnalité du commanditaire de l'église, le roi Gagik Arcruni, dont le programme politico-spirituel réservait une place de choix aux sanctuaires dédiés à la Croix, comme une récente étude l'a souligné ${ }^{1}$.

Nous examinerons ensuite dans quelle mesure le vocable de l'église d'Ałt'amar permet d'éclairer les choix qui, on peut le supposer, ont guidé les concepteurs du monument, tant pour sa structure planimétrique et volumétrique que pour la décoration de sa façade occidentale. Nous porterons brièvement notre attention également sur le symbole et l'image de la croix, qui occupent une place centrale dans la spiritualité et l'art des Arméniens. Cette étude nous fournira en outre l'occasion d'évoquer succinctement la dédicace des églises, sujet important mais peu traité par les historiens de l'architecture arménienne ${ }^{2}$. Enfin, cet exercice nous orientera vers quelques parallèles, que nous croyons utiles, avec la Géorgie voisine.

\section{$2 \quad$ Authenticité de la dédicace}

Avant d'aborder la question de la portée symbolique, architecturale et iconographique de la dédicace, commençons par considérer le doute qui plane sur l'authenticité ou plus exactement l'ancienneté de cette dédicace. En effet, l'église n'a pas conservé d'inscription relative à sa fondation et la seule source dont nous disposions à ce sujet, l'Histoire de T'ovma Arcruni et de son continuateur anonyme, certes précieuse pour les renseignements détaillés qu'elle nous fournit sur cet édifice et sur les autres constructions de l'île, n'évoque pas vraiment sa dédicace. Seul un bref passage énonce le vocable de la Sainte Croix, mais il mentionne Ałt'amar de manière incidente et semble résulter d'une interpolation. Ce passage se trouve à la fin du chapitre XX de la section III de la première partie de l'ouvrage, après l'évocation de la mort du prince Derenik et de son épouse Sop'i, enterrés au monastère Sainte-Croix d'Ałbak, et bien avant la partie consacrée à la construction d'Ałt'amar. Ce passage mentionne les donations faites au sanctuaire d'Ałbak, qui sont déclarées transmises plus tard par les fils de Sop'i et Derenik (dont le futur roi Gagik) « pour les besoins de la Sainte-Croix d'Att'amar ${ }^{3}$ :

\footnotetext{
${ }^{1}$ Pogossian 2017. Voir aussi les commentaires à ce sujet de Vardanyan 2014, 735-736.

${ }^{2}$ Hormis quelques travaux sur le rite de dédicace (Findikyan 1998), on ne trouve dans les ouvrages spécialisés que de brèves remarques sur cette question, comme dans : Thierry et Donabédian 1987, 33-34.

${ }^{3}$ T'ovma Arcruni 2010, 237-238.
} 


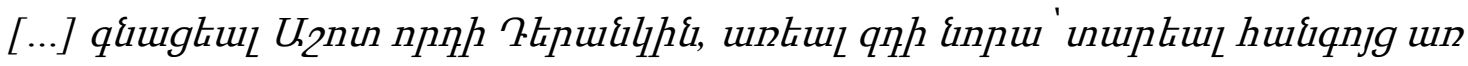

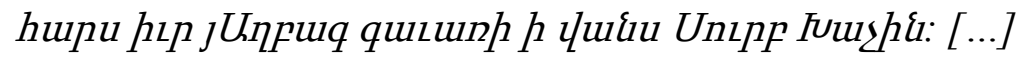

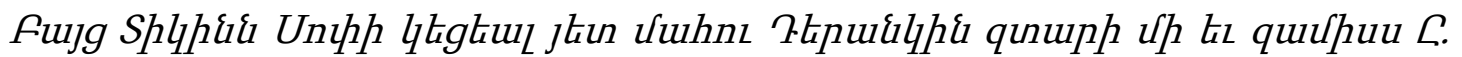

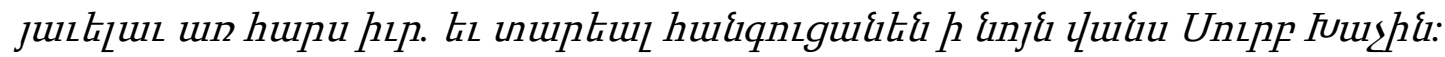

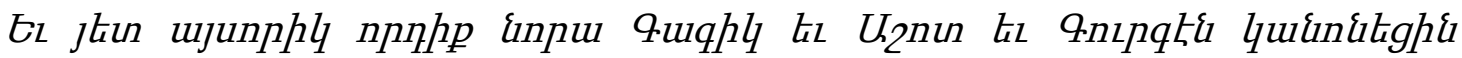

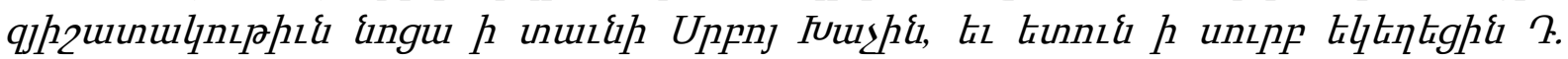

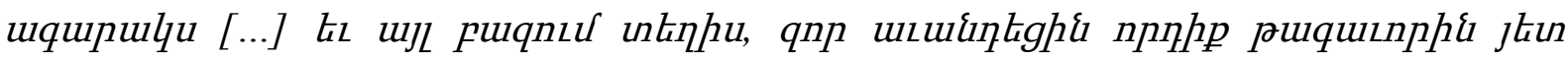

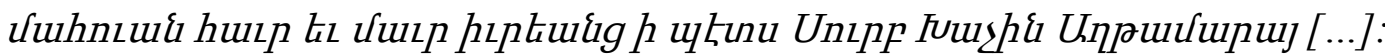

[...] Ašot, fils de Derenik, partit, prit son corps, l'emporta [et] le déposa près de ses pères, dans le district d'Atbag [= Atbak], au monastère de la Sainte-Croix. [...]

Mais dame Sop 'i vécut un an et huit mois après la mort de Derenik [puis] rejoignit ses pères ; on l'emporta [et on la] déposa dans le même monastère de la Sainte-Croix.

Et après cela, ses fils Gagik, Ašot et Gurgēn fixèrent leur commémoration à la fête de la sainte Croix, et donnèrent à la sainte église 4 fermes [...] et beaucoup d'autres lieux, que les fils du roi,

après la mort de leurs père et mère, transmirent pour les besoins de la Sainte-Croix d'Att' 'amar [...].

Le soupçon d'interpolation postérieure est suggéré par une certaine incohérence dans la rédaction du passage ci-dessus, relatif à ce deuxième transfert des donations, et surtout par le fait que, plus loin, dans le texte du Continuateur, au chapitre IX où est relatée la construction et où de nombreux détails sont donnés sur l'église d'Ałt'amar, la dédicace, elle, n'est pas mentionnée $e^{4}$ :

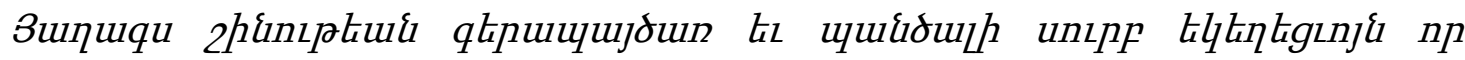

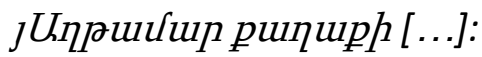

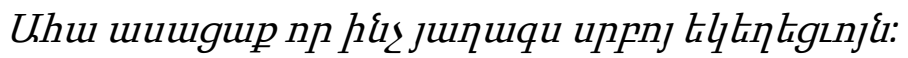

A propos de la construction d'une très brillante et glorieuse sainte église dans la ville d'Att'amar [...].

Nous avons ainsi dit [tout] ce qui concernait la sainte église.

Néanmoins, le vocable est cité plus loin dans cette source, d'abord dans des passages de l'appendice qui relatent des événements du XI et du XII ${ }^{\mathrm{e}}$ siècle ${ }^{5}$, puis dans le colophon, certes postérieur à l'édification de l'église de près de quatre siècles $(1303)^{6}$ :

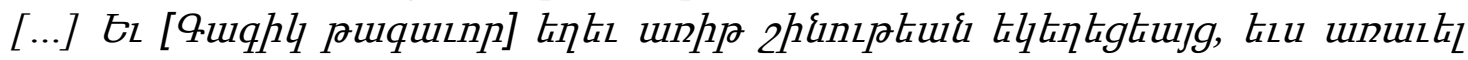

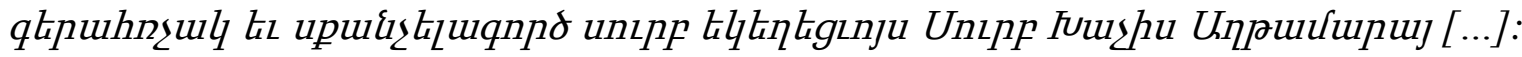

[...] Et il [le roi Gagik] fut à l'origine de la construction d'églises et surtout de cette très célèbre et merveilleuse sainte église, la Sainte-Croix d'Att'amar [...].

La dédicace figure également dans l'épigraphie du monument, en particulier dans l'inscription du catholicos Step'anos, probablement de $1325^{7}$, ainsi que dans des sources tardives. C'est pourquoi elle peut être considérée comme authentique et sans doute contemporaine de la construction de l'église.

\footnotetext{
${ }^{4}$ Ibid., 290, 292. V. Vardanyan, auteur de la traduction en arménien oriental de l'Histoire de T'ovma Arcruni et de son continuateur (T'ovma Arcruni 1978, 367, note 448), veut y voir la preuve de l'existence antérieure, à Ałt'amar, d'une autre église ayant eu la même dédicace, mais on ne connaît pas d'autre argument confirmant une telle hypothèse.

${ }^{5} \mathrm{~T}^{6}$ ovma Arcruni 2010, 300, 304.

${ }^{6}$ Ibid., 307.

${ }^{7}$ Orbeli 1963, 226, 228.
} 
Etant entendu que le vocable de la Sainte Croix s'attache dès sa fondation à l'église $\mathrm{d}^{\prime} \mathrm{A} \mathrm{tt}{ }^{\prime}$ amar, considérons à présent la profondeur et la force du culte de la croix dans cette région de frontière que constitue l'Arménie. De fait, la croix occupe une place majeure dans la tradition arménienne, où, selon l'expression de Jean-Michel Thierry, elle constitue « l'objet de culte par excellence $»^{8}$. Dans le calendrier liturgique arménien, certes fondé sur celui de Jérusalem mais l'enrichissant sensiblement pour ce qui est du culte de la croix, pas moins de cinq (voire six) célébrations et fêtes lui sont consacrées ${ }^{9}$; une grande partie du mois de septembre, en particulier, est placée sous son signe.

1) La première célébration de la croix se déroule le vendredi saint, en fin de matinée et surtout à la sixième heure ${ }^{10}$.

2) La première véritable fête a lieu le $5^{\mathrm{e}}$ dimanche après Pâques (le 7 mai dans l'Église grecque), sous le nom de Fête de l'Apparition de la Sainte Croix / Sol Epluนû́ Uppnj Iuußh. Elle commémore l'apparition miraculeuse de la croix à Jérusalem en 351.

3) La seconde, célébrée le dimanche le plus proche du $14^{\mathrm{e}}$ jour de septembre, est la fête

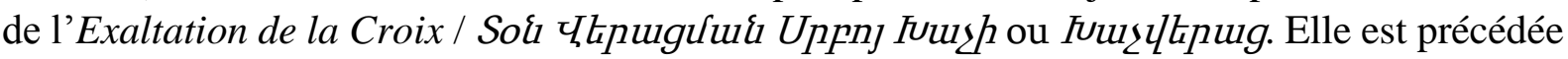
d'une semaine de carême et est suivie, le lundi, d'un deuxième jour dédié simultanément à la croix et au souvenir des morts ${ }^{11}$. C'est l'une des plus importantes fêtes de l'année. Elle commémore à la fois trois événements : a) la première vénération de la croix par l'apôtre Jacques (dont le chef est conservé dans la cathédrale arménienne de Jérusalem), b) la consécration du Saint-Sépulcre de Jérusalem par Constantin le 13 septembre 335, puis l'exposition de la croix le lendemain, 14 septembre ; c) la seconde invention de la croix, reprise aux Perses en 628 par l'empereur Héraclius, avec, selon certaines traditions, la participation de contingents arméniens, et alors que l'empereur traverse l'Arménie pour apporter la relique de la croix à Jérusalem. Ce passage arménien semble avoir laissé un reflet sur le linteau nord de l'église de

[p. 295]

Mren ${ }^{12}$ et dans diverses traditions populaires relatives à des actions miraculeuses accomplies par la relique de la croix.

4a) Le dimanche suivant l'Exaltation de la Croix, la croix est à nouveau fêtée, de même

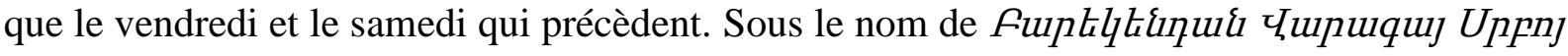
Fuuzh, ces trois jours introduisent la semaine de jeûne qui conduit à la fête suivante.

4b) Le troisième dimanche après l'Exaltation de la croix, vers la fin du mois de septembre, est célébrée une fête propre au calendrier arménien, celle de la Sainte Croix de Varag / So\{ પupuiquu Uppnj Fuush. Il s'agit de l'invention d'une relique de la croix, en 653, sur le mont Varag, précisément dans la province de l'Arménie du Sud qui nous intéresse ici, le Vaspurakan : déposée sur ce mont par sainte Hrip'simē et ses compagnes avant le baptême de l'Arménie, la relique fut alors retrouvée miraculeusement. A cet emplacement fut bâti le monastère de la Croix de Varag.

\footnotetext{
${ }^{8}$ Thierry et Donabédian 1987, 34. Dans Thierry 2000, 47, cet auteur écrit encore : « la croix ... a toujours été l'objet d'un culte privilégié de la part des Arméniens ».

${ }^{9}$ Renoux 1969, 125-133 ; Ōrmanean 1979, 24-25, 29-30, 35-38, 61-62 ; K`H, 429, sv. « Tuu々 h unnulip » (= Fêtes de la Croix).

${ }^{10}$ Renoux 1969, 129-130.

${ }^{11}$ Ibid., 126, précise : «durant sept jours, du dimanche de l'Exaltation de la croix au samedi suivant, le rite arménien célèbre l'Église et la croix ».

12 Thierry 1971, 69-76 ; Maranci 2015, 67-77.
} 
5) Le $7^{\mathrm{e}}$ dimanche après la fête de $1^{\prime}$ Exaltation de la Croix, donc vers la fin du mois d'octobre, est célébrée la fête de l'Invention de la Croix / Qhzun Fuu々h, en souvenir de la découverte à Jérusalem en 326 de la vraie croix par Hélène, mère de l'empereur Constantin. L'Église orthodoxe grecque célèbre cette fête en même temps que celle de l'Exaltation de la Croix, le 14 septembre.

A tout ce qui précède s'ajoute un bref rite appelé Repos de la croix / Fuuzuhuuqqhuun qui marque, dans les sanctuaires possédant une relique de la Vraie Croix ou un Saint Signe précieux, la fin des messes festives et met à nouveau à l'honneur la force protectrice de la croix $^{13}$.

\section{Importance de la croix dans la tradition arménienne. B. En architecture}

Il ne faut donc pas s'étonner de l'omniprésence de l'image de la croix dans l'environnement monumental et artistique arménien. Après l'époque initiale paléochrétienne $\left(\mathrm{IV}^{\mathrm{e}}-\mathrm{VI}^{\mathrm{e}} \mathrm{s}\right.$.) où prédominaient les compositions oblongues (chapelles à nef unique, basiliques à trois nefs), à compter de la fin du $\mathrm{VI}^{\mathrm{e}}$ siècle, la croix, couronnée à l'intersection de ses bras par la coupole sur tambour, est un élément fondamental de l'architecture chrétienne de l'Arménie. Qu'elle se manifeste librement, c'est-à-dire dégagée, ou qu'elle s'inscrive dans

un périmètre rectangulaire, polygonal ou rond, la croix couronnée de la coupole précédée du tambour constitue l'axe principal de cette école d'architecture. La formule «coupole sur croix », conjuguant le rayonnement à partir de la croix et l'élan vertical, a donné naissance, grâce au remarquable esprit créateur des architectes, à une grande diversité de compositions, et notamment à de nombreuses structures rayonnantes ${ }^{14}$. Parmi cette diversité, nous nous intéresserons ici aux compositions cruciformes-rayonnantes apparentées à celle d'Ałt'amar.

L'église-mère Sainte-Ējmiacin de Vałaršapat a une importance majeure en tant que lieu de la vision fondatrice de saint Grégoire ; or dans cette vision, comme le rappelle Charles Renoux, une place d'honneur est faite à la croix ${ }^{15}$. Selon le plan hypothétique reflétant probablement l'état du sanctuaire à la fin du $\mathrm{V}^{\mathrm{e}}$ siècle (fig. 1a), la croix se manifeste par la saillie des quatre conques sur les côtés d'un cube au centre duquel se dresse, sur quatre piliers, dès cette époque, semble-t-il, une coupole. Dans la formule nettement recentrée de Mastara (milieu $\mathrm{du} \mathrm{VII}^{\mathrm{e}} \mathrm{s}$.), la combinaison à coupole sur cube élargi de quatre conques saillantes laisse plus clairement apparaître le principe cruciforme (fig. 1b).

La composition des églises à coupole sur tétraconque-tétraniche (fin $\mathrm{VI}^{\mathrm{e}}-\mathrm{VII}^{\mathrm{e}} \mathrm{s}$.), qui annonce celle d'Ałt'amar, est plus complexe ; la cathédrale d'Awan (années 590) en est le premier spécimen daté et l'église Sainte-Hrip'simē (entre 617 et les années 620), l'exemple le plus célèbre. Le principe cruciforme marqué par les quatre conques axiales est associé au rayonnement que traduisent à l'intérieur les quatre niches diagonales aux trois-quarts cylindriques (fig. 2a). Dans ces compositions sophistiquées, la jonction des quatre conques et des quatre niches constitue les huit points d'appui pour la base du tambour porteur de la coupole, et en même temps, les niches diagonales donnent accès aux quatre chambres angulaires, le tout étant strictement englobé dans une masse extérieurement quadrangulaire.

Créée simultanément avec l'arménienne, la variante ibère (géorgienne) de cette composition présente une plus grande transparence et une plus nette articulation, ce qui permet à la structure cruciforme de s'exprimer plus fortement. L'édifice emblématique de cette version

\footnotetext{
${ }^{13}$ Č‘ ēpēyan 1986, 63-64. Renoux 1969, 132, conclut sa présentation de la place de la croix dans le rite arménien par la formule « il y a une présence continuelle de celle-ci au cours de l'année liturgique ».

${ }^{14}$ Sur les compositions architecturales évoquées ici, voir notamment : Hasratian 2000 ; Donabédian 2008.

${ }^{15}$ Renoux 1969, 123.
} 
géorgienne est l'église qui domine la métropole religieuse Mcxeta et qui est dédiée précisément à la croix : J̌vari (fig. 3a). Autre église de Géorgie appartenant à ce groupe, At'eni, bien que construite par l'architecte arménien $T^{\prime}$ odosak, reprend les caractéristiques

[p. 297 - fig. 1]

planimétriques de J̌vari (fig. 3b). A noter que J̌vari est la seule église de l'époque paléochrétienne et préarabe, et de la région arméno-ibère, qui soit consacrée à la croix. Rappelons que jusqu'au $\mathrm{VII}^{\mathrm{e}}$ siècle inclus, nous disposons de peu de dédicaces assurément anciennes.

Dans la région du Vaspurakan ${ }^{16}$, la composition Awan-Hripip'simē est déjà présente bien avant Ałt'amar. Toujours inscrite dans un périmètre rectangulaire, elle s'observe à Arcuaber, probablement contemporaine de Sainte-Hripis'simē et très proche d'elle pour ce qui est de la planimétrie (fig. 2b). On la retrouve vers l'an mil à la Sainte-Mère de Dieu de Varagavank' (fig. 4), à propos de laquelle deux observations peuvent être faites. A) Son plan présente une particularité qui pourrait être, au moins en partie, liée au sujet de notre étude : la paire de niches diagonales ouest ne conduit pas aux deux chambres angulaires ouest et, de ce fait, perd une partie de sa justification fonctionnelle (que conservent cependant les deux niches diagonales est) ; nous verrons plus loin que l'on peut envisager, à Ałbak et Ałt'amar, pour ces quatre niches diagonales, l'hypothèse d'une fonction symbolique qui concurrence la fonction de passage vers les espaces angulaires. B) Au monastère de Varag, célèbre pour sa relique, le vocable de la croix s'attache au couvent tout entier et non à l'une ou l'autre des églises de l'ensemble. Nous observerons à nouveau ce phénomène, toujours au Vaspurakan, à Aparank'.

Une variante plus originale de la composition Awan-Hrip'simē, presqu'entièrement dégagée, presque sans chambres angulaires, est illustrée par

[p. 298 - fig. 2]

l'église-mausolée dynastique des Arcruni située à Ałbak, rebaptisée au XVII ${ }^{\mathrm{e}}$ siècle Sainte$\bar{E}$ j̆miacin de Soradir ${ }^{17}$ (fig. 5). Elle n'est pas datée avec précision,

[p. 299 - fig. 3] mais pourrait remonter à la deuxième moitié du VII ${ }^{\mathrm{e}}$ ou au $\mathrm{IX}^{\mathrm{e}}$ siècle. Il est important de souligner que, comme l'atteste T'ovma Arcruni, le sanctuaire d'Ałbak, mausolée dynastique des Arcruni, est dédié à la Sainte Croix. Or c'est, jusqu'au X $X^{\mathrm{e}}$ siècle, jusqu'à la construction d'Ałt'amar, le seul spécimen arménien de cette famille planimétrique où l'agencement interne des volumes autour du cercle central surmonté par la coupole n'est presque pas masqué par l'enveloppe externe, et où, au contraire, la composition cruciforme-rayonnante s'exprime à l'extérieur. En effet, grâce à l'absence de volumes angulaires, à l'exception des étroites sacristies de part et d'autre de l'abside, non seulement la structure cruciforme est nettement visible de l'extérieur, mais aussi, du moins à l'ouest, la saillie des niches diagonales se manifeste clairement ${ }^{18}$.

Il est permis de penser que ce parti cruciforme-rayonnant est lié à la dédicace et aussi peut-être, comme nous l'envisagerons infra, à la présence d'une relique de la Croix du type Bois de Vie / Ykiuug Фujun. Nous verrons un peu plus loin que la Sainte-Croix d'Ałbak a sans doute servi de modèle à l'église d'Ałt'amar et lui a en même temps légué sa dédicace, qui remonterait finalement à la Croix de Varag.

\footnotetext{
${ }^{16}$ Sur l'architecture du Vaspurakan, voir : Thierry 1989.

${ }^{17}$ Sur ce monument, voir notamment : Breccia Fratadocchi 1971; Thierry et Donabédian 1987, 577.

${ }^{18}$ A l'est, les deux niches aux trois-quarts cylindriques sont englobées dans le bloc absidal jusqu'au toit en appentis couvrant chacune des sacristies, qui sont basses car elles n'ont qu'un niveau ; au-dessus, ces volumes prennent la forme d'une saillie en angle droit. Voir Breccia Fratadocchi 1971, fig. 3, 7-9, 11.
} 


\section{5 Importance de la croix dans la tradition arm. C. Dans les formes « mineures »}

La croix de pierre ou sur pierre, en tant que monument « mineur » indépendant, a eu une présence considérable en Arménie tout au long des siècles. Après l'adoption du christianisme, l'un des premiers types correspondait à des monuments en forme de grande croix de pierre, dressés isolément (unuidihq quiqquud huurkp), dont seuls quelques exemplaires, les plus anciens

[p. $301-$ fig. 5]

[p. $302-$ fig. 6]

restaurés (recollés), nous sont parvenus ${ }^{19}$ (fig. 6a). Cette typologie a été progressivement abandonnée, probablement en raison de sa vulnérabilité, même si quelques spécimens médiévaux et plus tardifs attestent sa présence ici ou là jusqu'au bas Moyen Âge.

Bien plus nombreux, des monuments crucifères en pierre ont été érigés, là encore dès les premiers temps chrétiens, en Arménie comme en Ibérie (Géorgie), formés pour l'essentiel de cinq éléments superposés : un podium à degrés, une base cubique, une stèle quadrilatérale ou une colonne, un chapiteau, et enfin, dans la très grande majorité des cas, une petite croix dégagée $^{20}$ (fig. $6 \mathrm{~b}$ ). En raison de la présence quasi obligatoire de la croix à leur sommet, Hamlet

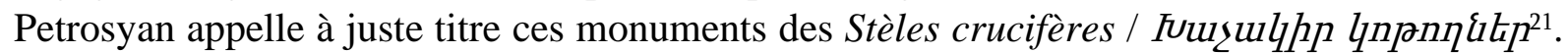
Ces monuments sont eux aussi mal conservés, d'une part parce qu'ils étaient fragiles, d'autre part parce que beaucoup d'entre eux ont sans doute été détruits au VIII ${ }^{\mathrm{e}}$ siècle lors de l'occupation arabe. Près de la

basilique d'Ereruyk', on relève les traces d'un nombre particulièrement élevé : six à huit monuments de ce type se dressaient sur le côté sud de la grande église ${ }^{22}$.

Les $x a c c^{\prime} k$ 'ars, pierres-croix apparues à partir de la fin de l'occupation arabe ( $2^{\mathrm{e}}$ moitié du IX ${ }^{\mathrm{e}} \mathrm{s}$.), peuvent être vus comme l'étape ultérieure de ces monuments paléochrétiens, même s'ils correspondent à une typologie différente ${ }^{23}$ (fig. 6c). Sculptée en saillie méplate sur la face ouest de ces plaques de pierre qui couvrent littéralement le pays par milliers, et ainsi consolidée, la croix est désormais omniprésente sur le sol de l'Arménie et en constitue l'un des emblèmes, peut-être le plus représentatif, le plus éloquent.

\section{Importance de la croix dans la tradition arménienne. D. Dans l'enluminure et (jusqu'au VII ${ }^{\mathrm{e}}$ s. inclus) dans la sculpture monumentale}

Au début des évangiles enluminés arméniens, surtout les plus anciens, la croix est souvent peinte isolée en pleine page, dressée sur un podium à gradins (fig. 7). Comme le précise Dickran Kouymjian, on en recense une quarantaine d'occurrences, dont la moitié sur des codex antérieurs au XII ${ }^{\mathrm{e}}$ siècle $^{24}$.

La croix est aussi l'un des motifs les plus importants du répertoire décoratif sculpté de l'Arménie chrétienne. Durant les premiers siècles chrétiens en Arménie (IV $-\mathrm{VI}^{\mathrm{e}} \mathrm{s}$.), c'est surtout la croix « de Malte» («grecque ») dans un médaillon circulaire qui a été sculptée, marquant et protégeant en particulier les linteaux des portes des églises (fig. 8a), ainsi que quelquefois les

\footnotetext{
${ }^{19}$ Sur ces croix dégagées et isolées, voir : Mnac'akanyan 1982, 41-46.

${ }^{20}$ Sur ces mémoriaux verticaux, voir : Grigorian 2012. Cet auteur signale (p. 50) quelques cas où le monument pouvait ne pas être surmonté d'une croix. Voir aussi Tchakerian 2016.

${ }^{21}$ Petrosyan 2008, 10, 12,13..., 44 et passim.

${ }^{22}$ Voir une restitution schématique dans Donabédian 2014, 247, fig. 5.

${ }^{23}$ Petrosyan 2008.

${ }^{24}$ Khatchadourian et Basmadjian 2014, introduction par D. Kouymjian, p. 8.
} 
bases et impostes ${ }^{25}$. Ce médaillon est parfois bordé d'une stylisation de palme qui renvoie à la couronne laurée, un attribut sans doute destiné à souligner la portée sémantique de la croix en tant que signe de victoire sur la mort et aussi de protection de l'église. Assez souvent, sur des linteaux et des bases et impostes, la « croix de Malte » apparaît au centre d'une composition à trois médaillons dont les deux latéraux renferment une rosace ou une marguerite (fig. $8 \mathrm{~b}$ ), substitut/complément rayonnant de la croix.

À partir du $\mathrm{VII}^{\mathrm{e}}$ siècle, un schéma différent se répand: celui d'une croix oblongue (« latine »), peut-être introduit en Arménie par l'imagerie impériale

[p. 304 - fig. 7] byzantine, en particulier par les monnaies byzantines du $\mathrm{VI}^{\mathrm{e}}-\mathrm{VII}^{\mathrm{e}}$ siècle qui en font un signe de victoire, comme l'attestent les inscriptions qui l'accompagnent. Désormais présentée comme un arbre de vie, avec deux grandes feuilles recourbées en $\mathrm{S}$ poussant de son pied, parfois un globe et un piédestal

[p. 305 - fig. 8]

à degrés en-dessous, elle s'impose, dans un cadre rectangulaire, sur les linteaux du VII siècle $^{26}$ (fig. 9). La même croix victorieuse, longitudinale, arborescente, à piédestal et médaillon, est sculptée sur les milliers de $x a c c^{`} k$ 'ars qui couvrent le pays à partir du IX ${ }^{\mathrm{e}}$ siècle (fig. $6 \mathrm{c}$ ).

[p. 306 - fig. 9]

Dans certains cas au VII ${ }^{\mathrm{e}}$ siècle, la croix reste réservée au décor du linteau ou du tympan, mais y acquiert une importance particulière. C'est le cas à Mren, on l'a vu, sur le linteau nord (fig. 10). C'est le cas aussi à J̌vari où l'élévation de la croix fait l'objet d'une grande composition sur le tympan de la porte sud, la principale de l'église, elle-même dédiée à la Croix (fig. 11).

Dans de rares cas encore, la croix se fraie même un chemin en dehors du strict cadre du linteau ou tympan de la porte, ou encore des bases et chapiteaux. Les premiers exemples apparaissent à la période paléochrétienne $\left(\mathrm{V}^{\mathrm{e}}-\mathrm{VI}^{\mathrm{e}} \mathrm{s}\right.$. $)$

[p. 307 - fig. 10, 11] avec une sobre croix à l'écoinçon des fines arcatures surmontant les fenêtres supérieures de la façade occidentale, à la chapelle mononef de Lernakert et sur les basiliques d'Aštarak (fenêtre double - fig. 12) et d'Ereruyk' (fenêtre triple). On trouvait aussi une croix en médaillon, un peu plus marquée, en haut de la façade ouest de Tekor, entre les deux fenêtres supérieures. Ce principe est repris dans l'architecture de l'âge d'or du VII ${ }^{\mathrm{e}}$ siècle, où une timide tendance à l'ostentation de la croix se fait jour, par exemple à la chapelle arménienne

[p. 308 - fig. 12]

dite Karmrawor d'Aštarak et à l'église ibère de C'romi : la croix est placée non seulement sur le linteau mais aussi au sommet du pignon (fig. 13). Elle reste toutefois pour l'heure modeste, car sa taille et sa visibilité sont encore réduites ; de plus, dans les deux cas, on ignore si la plaque la portant est à son emplacement originel.

[p. 309 - fig. 13]

Deux autres monuments du VII ${ }^{\mathrm{e}}$ siècle, les églises de Mastara (années 640-650) et d'Aruč (années 660), font une place un peu plus notable à la croix. À Saint-Jean de Mastara, la croix, bien que petite, est au centre d'une composition insolite, encadrée en haut de la conque occidentale, liée au contenu de

\footnotetext{
${ }^{25}$ Ces décors sculptés sont présentés notamment dans : Hasratian 2000 et Donabédian 2008, 35-59, $234,236$.

${ }^{26}$ A propos de cette croix « latine », son iconographie et sa sémantique victorieuse, voir : Donabédian 2009, 155157.
} 
[p. 310]

l'inscription qui y est gravée ${ }^{27}$ (fig. 14a). La croix y est mise en parallèle avec l'image de l'église, fiancée du Christ, inspirée de l'évangile selon Jean, 3, 29, et de l'épître de Paul 2 Corinthiens, 11, 2. L'inscription dit : "Cette cathédrale, fiancée coiffée du signe de la croix comme d'une couronne, a pour fiancé le Christ, pour parrains de mariage les apôtres et pour témoins les prophètes ». À Aruč, la croix, bien que de taille modeste, domine la façade est, sur laquelle un accent particulier est mis à travers le décor sculpté et l'inscription dédicatoire ${ }^{28}$ (fig. 14b). On le voit, les solutions novatrices adoptées à Mastara et Aruč produisent certes un certain effet, mais ne réservent pas à la croix une place véritablement marquante ${ }^{29}$.

Moins fréquemment, la croix est aussi sculptée, au VII ${ }^{\mathrm{e}}$ siècle, à l'intérieur des coupoles (fig. 15), combinée au motif du rayonnement de la Pentecôte, motif peut-être emprunté, dans cet emploi-là, à l'architecture constantinopolitaine du $\mathrm{VI}^{\mathrm{e}}$ siècle $^{30}$. Ce dispositif connaît quelques échos au Moyen Âge (plafonds de gawit) et au bas Moyen Âge (bichromie à l'intérieur de la coupole de Saint-Georges de Mułni). La chapelle cruciforme de Lmbat (VII ${ }^{\mathrm{e}} \mathrm{s}$.) donne une interprétation originale de ce dispositif avec une assez grande croix sculptée au centre de la voûte en berceau du bras occidental. Un principe assez différent, mais qui fait à nouveau apparaitre la croix à l'intérieur de coupoles, s'observe sur les plaques orientales, à décor de $x a c ̌ c k$ ' $a r$, de la calotte pyramidale qui couvre l'espace central de plusieurs gawit's médiévaux (Horomos ${ }^{31}$, Gošavank', Keč‘ariis, Sałmosavank', Tełer), évoquant peut-être la fonction partiellement funéraire de ces «narthex ».

\section{$7 \quad$ La croix sur la façade ouest d'Alt'amar}

Il en est autrement, au début du $\mathrm{X}^{\mathrm{e}}$ siècle, sur la façade occidentale d'Alt'amar. Sur cette façade éclairée par les rayons du soir, la dédicace et sans doute aussi l'idéologie royale du commanditaire, Gagik Arcruni, se traduisent par une extériorisation exceptionnelle de la croix (fig. 16). Premièrement, dans une

[p. $311-$ fig. 14]

[p. 312 - fig. 15]

certaine mesure, celle-ci peut être perçue dans la disposition générale du décor sculpté sur la façade, qui obéit grosso modo à un schéma cruciforme : marqué par la figure de l'évangéliste sur le pignon et par le panneau rectangulaire à cep de vigne au-dessus de la fenêtre centrale, puis plus bas par les deux croix médianes, l'axe vertical coupe le bras horizontal dessiné par la frise végétale, malgré un décrochement au-dessus de la fenêtre centrale ${ }^{32}$.

Mais surtout, la dédicace du sanctuaire se traduit par la figuration de la croix quatre fois, de manière à la fois diversifiée et harmonieuse, au sein du principal registre sculpté de l'église ${ }^{33}$ (fig. 17). Les deux schémas évoqués supra y coexistent au sein d'une grande composition dédicatoire. En bas, le médaillon circulaire emprunté au répertoire paléochrétien, avec une croix

\footnotetext{
${ }^{27}$ Donabédian 2008, 155-156 et fig. 285.

${ }^{28}$ Ibid., 127-128 et fig. 207, 212.

${ }^{29}$ Il est possible toutefois que la croix sculptée dans le cadre surmontant la fenêtre ouest de Mastara ait été « doublée » d'une seconde croix placée dans la niche arrondie creusée juste au-dessus de ce cadre cintré. On peut y imaginer une petite croix de pierre dégagée, du type de celles qui surmontaient les stèles quadrilatérales.

${ }^{30}$ Donabédian 2008, 269-270.

${ }^{31}$ Ce décor d'Horomos est minutieusement étudié et superbement illustré dans : Vardanyan (éd.) 2015, articles d'E. Vardanyan et de J.P. Mahé.

${ }^{32}$ Dans son étude innovante sur la frise à vigne de l'église d'Ałt'amar, Vardanyan E. 2014, 719-720, propose de voir sur la partie centrale de cette frise, sur la façade ouest, un épisode de l'Hospitalité d'Abraham où ce dernier est montré nettement en-dessous du chêne de Mambré, ce qui expliquerait ce décrochement, donc intentionnel.

${ }^{33}$ Sauf erreur, S. Der Nersessian (Der Nersessian 1965, 21 ; Der Nersessian 1977, 88) est la seule à avoir observé que l'ensemble formé par le médaillon à croix que portent les anges et par le rang de trois croix, disposé plus haut « rappelle le vocable de l'église » (« remind us that the church was dedicated to the Holy Cross »).
} 
à quatre bras égaux (détruite à la fin du $\mathrm{XX}^{\mathrm{e}} \mathrm{s}$.), est tenu par deux anges (fig. 17b). Pour cette scène, une iconographie bien connue est adaptée, attestée déjà en Arménie, par exemple sur la reliure (sans doute constantinopolitaine)

[p. 313 - fig. 16]

de l'évangile d'Ējmiacin. On suppose que la couronne qui l'entoure et les anges qui la portent soulignent le caractère victorieux de la croix ${ }^{34}$. Cette iconographie est placée au-dessus de la porte principale (pas immédiatement sur elle,

[p. 314 - fig. 17] mais un peu plus haut), selon un principe assez proche de celui appliqué, deux siècles plus tôt, au tympan de la porte, sur la façade sud de la Sainte-Croix de J̌vari, en Ibérie (fig. 11).

Plus haut, trois croix « latines », dont l'allongement vertical, sans être très marqué, est tout de même bien perceptible, sont sculptées sur des panneaux rectangulaires (au centre, le contour du rectangle n'est pas dessiné - fig. 17a). Cette verticalité et l'iconographie de ces trois panneaux peuvent être vues comme un écho de l'essor naissant, depuis la deuxième moitié du $\mathrm{IX}^{\mathrm{e}}$ siècle, des $x a c^{\prime} k$ 'ars. L'extrémité (chacun des angles) des bras de la croix en forme de boule unique est propre aux $x a c c^{\prime} k$ 'ars les plus anciens, du IX ${ }^{\mathrm{e}}-\mathrm{X}^{\mathrm{e}}$

siècle ${ }^{35}$. Sur le panneau central, l'image est, comme sur la majeure partie des reliefs de l'église, en saillie méplate, caractéristique de la sculpture arménienne médiévale en bas-relief. En revanche, sur les deux côtés, l'image est détachée par évidement du fond, à l'intérieur du cadre rectangulaire évidé dans la surface murale, ce qui est l'autre technique traditionnelle employée par la sculpture arménienne depuis les premiers temps chrétiens, moins fréquente au Moyen Âge et qui encore une fois évoque les $x a c c^{\prime} k$ 'ars. Nous la trouvons aussi sur les linteaux de l'église (voir infra). Quelques disparités s'observent dans la technique : la croix médiane se distingue par une facture moins soignée, des bras de la croix, plus larges, une absence de trous dans les boules des extrémités des bras, ce qui donne à penser qu'elle n'est pas de la même main que les deux croix latérales.

Il ne faut pas voir dans cette différence de traitement la preuve d'une distance temporelle entre les panneaux latéraux et la croix centrale, car dans l'ensemble, les trois sculptures sont homogènes. Le panneau central présente deux colombes de part et d'autre de la croix, symbole bien connu de l'aspiration des âmes humaines au salut. On en relève de nombreuses variantes dans la sculpture des premiers siècles chrétiens, avec souvent d'autres animaux (notamment d'autres oiseaux) à la place des colombes (fig. 12). Sur les trois croix, les deux feuilles latérales inférieures ont la traditionnelle double courbure en $\mathrm{S}$, omniprésente en particulier sur les $x a c c^{\prime} k$ 'ars ; mais ces feuilles se distinguent ici par la longueur inhabituelle de la foliole terminale recourbée, dédoublée sur le panneau central. Une telle ampleur dans le recourbement extérieur de ces deux feuilles est, sauf erreur, exceptionnelle, de même que la greffe d'une grappe de raisin sur chacune des demi-palmes latérales ${ }^{36}$.

Faut-il voir une différence sémantique entre ces deux iconographies de la croix, celle de la croix en médaillon tenu par deux anges, et celle, trois fois répétée au milieu de la façade occidentale de l'église, dans un cadre rectangulaire ? Il semble plutôt que l'on ait voulu, de deux façons légèrement différentes, en faisant appel au répertoire iconographique de deux périodes successives, exprimer le même message de victoire triomphale de la croix ; par là même on a traduit en images légèrement diversifiées, mais dans le fond, sémantiquement

\footnotetext{
${ }^{34}$ Thierry 2000, 47, rappelle que ce thème reprend celui des Victoires ailées hellénistiques (Palmyre) ou sassanides (Taq-i Bostan).

${ }^{35}$ Petrosyan 2008, 90-110.

${ }^{36}$ Signalons toutefois une grappe de raisin accrochée à un ruban sassanide, lui-même attaché au cou d'un paon, sur une imposte d'Ereruyk', provenant sans doute de la basilique.
} 
homogènes, la dédicace de l'église. En effet, en haut, est trois fois sculptée la croix arbre de vie, sans doute perçue, on l'a signalé supra, comme un symbole

de victoire depuis la fin $\mathrm{du} \mathrm{VI}^{\mathrm{e}}$ siècle $^{37}$, tandis qu'en bas est montrée l'élévation triomphale de la croix que les anges emportent dans le $\operatorname{ciel}^{38}$.

Aux quatre croix du registre principal sculpté, il faut en ajouter trois qui timbrent le linteau de la porte ouest, aujourd'hui visible seulement depuis l'intérieur du gawit ' (= žamatun, « narthex »). Ce sont des croix « latines » dans des cadres rectangulaires évidés, comme au VII ${ }^{\mathrm{e}}$ siècle, la centrale un peu plus grande, les deux latérales dans un cadre arqué (fig. 18a). En outre, deux croix séparées par un gros médaillon à marguerite polylobée, ornent/ornaient également le linteau de la porte sud, en partie couvert par les appuis du campanile / clocher (fig. 18b). On ignore si, dans la conception initiale, l'installation d'un indispensable accès à la loge royale ménagée dans la conque sud permettait ou empêchait que le linteau sud et son décor fussent bien visibles de l'extérieur ${ }^{39}$.

On notera que les deux linteaux, ouest et sud, sont taillés dans un tuf gris sombre qui tranche vivement sur l'ocre-rose de l'appareil de l'église. Mais cela ne signifie probablement pas une distance chronologique puisque, bien que plus modestes, et sculptées plus superficiellement par évidement du fond, les cinq croix des linteaux sont, iconographiquement et stylistiquement, étroitement apparentées à celles de la façade ouest et sans doute contemporaines (début $\mathrm{X}^{\mathrm{e}} \mathrm{s}$.). On y relève en effet la même tresse sur le corps de la croix, les mêmes boules uniques à double liséré aux extrémités des bras, et sur le linteau sud, les mêmes feuilles latérales à long replis, semblablement agrémentées de petites grappes de raisin.

\section{Dédicace et présence d'une relique de la Vraie Croix à Alt'amar}

Revenons au vocable de l'église palatine d'Ałt'amar. A propos de la dédicace à la croix en Arménie, deux observations peuvent être faites : a) comparé à la très forte dévotion des Arméniens pour la croix et comparé aux autres vocables, très populaires en Arménie, comme la Sainte-Mère de Dieu, Saint-Serge, Saint-Jean, Saint-Etienne ou Saint-Georges, il peut paraître étonnant que le nombre de sanctuaires et couvents arméniens consacrés à la Sainte Croix ne soit pas

[p. 317 - fig. 18]

très élevé ; b) (ce deuxième point expliquant en partie le premier) la dédicace à la Sainte Croix est concurrencée en Arménie par celle au Saint Signe : les sanctuaires et monastères dédiés au Saint Signe sont à peu près aussi nombreux ${ }^{40}$.

[p. 318]

Sans pouvoir étudier ici les raisons de ce phénomène, contentons-nous d'émettre l'hypothèse que la dédicace à la Sainte Croix pouvait être réservée à des sanctuaires très importants qui abritaient un rare et précieux fragment de la relique de la Vraie Croix, tandis que dans celles dédiées au Saint Signe on vénérait peut-être des images de la croix : des croix de bois, de métal ou de pierre, créées et consacrées selon le canon du catholicos Jean d'Ōjun et du

\footnotetext{
37 Thierry 2000, 141, qualifie ces trois croix de «xač $k$ 'ars » et les caractérise comme des « objets de conviction et de vénération », mais, curieusement, ne les lie pas à la dédicace de l'église.

${ }^{38}$ Thierry 1989, 277, semble considérer que seule cette croix portée par les anges est liée à la dédicace de l'église.

${ }^{39}$ Compte tenu de la présence, dans la conque sud, d'une loge royale, assurément contemporaine de la construction de l'église, il faut imaginer, sur la façade sud, un dispositif d'accès depuis l'extérieur, peut-être en forme d'escalier en encorbellement, ensuite remplacé par l'actuel campanile / clocher.

${ }^{40}$ Dans son répertoire des monastères arméniens (et non des églises) Thierry 1993, index, p. 233-234 et 237-238, recense vingt-quatre occurrences de la Sainte-Croix et vingt du Saint-Signe. Melik'-Baxšyan 2009, 177-184, 312316, de son côté relève, parmi les monastères et les églises, 103-120 (avec des doublons) occurrences pour la SteCroix et 102 pour le St-Signe.
} 
Rituel ou Maštoc ${ }^{41}$. L'Église arménienne a en effet adopté au VIII $-\mathrm{IX}^{\mathrm{e}}$ siècle le rite de la consécration de la croix par onction, rite qui lui est propre (et que l'Église grecque réprouve). Conformément à ce rite, la croix consacrée devient un réceptacle de l'Esprit saint. C'est pourquoi les objets sacrés appelés Saint Signe bénéficiaient d'une popularité équivalente à celle des reliques de la Croix. Les Arméniens avaient une profonde vénération pour ce substitut d'icône qu'était le « Saint Signe de la Croix (Surb Nšan - Unıpp ¿zuuq) », dont une forme très connue et omniprésente en Arménie est le xač 'k'ar ; sur ces innombrables stèles, le Saint Signe donne en principe une image abstraite de la croix - arbre de vie, d'où est exclue la figuration du sacrifice humain du Christ, et qui évoque, non les souffrances humaines du Christ sur la croix, mais la voie conduisant au salut et l'espoir de rédemption et de vie éternelle.

Nuançons tout de suite ce qui vient d'être énoncé en notant que, dans certains cas, les deux termes, Surb Xač ' et Surb Nšan ou Tẽrunakan Surb Nšan (= Saint Signe du Seigneur), pouvaient être équivalents, voire carrément synonymes. Ainsi, dans l'appendice à l'Histoire de la maison des Arcruni, la relique de la Sainte Croix d'Aparank', fameuse staurothèque (voir infra), est dite «signe de la croix du Seigneur / nšan tērunakan xač ‘n, Saint Signe / Surb $N \check{s} a n »^{42}$. Dans l'épigraphie des $x a c c^{\prime} k$ 'ars également, les deux termes semblent interchangeables ${ }^{43}$.

Quoi qu'il en soit, il faut reconnaître qu'il existe peu de témoignages précis sur la présence d'une relique de la Vraie Croix en lien avec une dédicace à la croix et encore moins sur la présence d'une croix confectionnée et consacrée, en lien avec une dédicace au Saint Signe. D'une façon générale, il ne paraît pas possible de lier systématiquement un vocable à la présence de reliques du saint dédicataire : il ne pouvait certainement pas y avoir de reliques de saint Georges ou de saint Serge dans chacune des innombrables églises d'Arménie dédiées à ces saints. Mais le Vaspurakan bénéficiait à cet égard de conditions

particulières, car ici, s'agissant des reliques, il existait un terreau encore plus propice au développement du culte de la croix que dans les autres parties de l'Arménie. C'est la raison pour laquelle il est possible, dans cette région, d'établir, pour quelques églises, un lien entre la dédicace à la Sainte Croix et la présence d'une relique ; on peut même, nous le verrons, déceler un reflet de la dédicace et peut-être de la présence d'une relique dans la composition architecturale des sanctuaires d'Ałbak et d'Ałt'amar ; enfin, pour l'église d'Ałt'amar qui nous intéresse en particulier, on peut aussi observer un effet direct sur la composition décorative de sa façade occidentale.

En effet, comme l'a montré Zaroui Pogossian dans une analyse détaillée du témoignage de $\mathrm{T}^{\text {'ovma }}$ Arcruni $^{44}$, un vif culte de la croix s'était développé ici, peut-être dès la fin du VII ${ }^{\mathrm{e}}$ siècle, notamment autour de la fameuse relique de la Vraie Croix réapparue au monastère de Varag, voire dès le début du VII ${ }^{\mathrm{e}}$ avec la relique peut-être offerte par l'empereur Héraclius à la princesse Biwreł, qui aurait fondé pour l'abriter le monastère de Hac'uneac ${ }^{645}$, et ce culte s'aviva encore sous le règne de Gagik qui le plaça au cœur de son action publique. Il se pourrait que ce fût à cette même croix de Varag qu'ait été dédiée l'église d'Ałbak ${ }^{46}$ et, « par ricochet », finalement, l'église d'Ałt'amar. Souvenons-nous aussi (voir supra) que la messe de requiem des parents du roi Gagik avait été fixée le jour de la fête de la croix (sans doute la fête de l'Exaltation de la Croix).

\footnotetext{
${ }^{41}$ Renoux 1969, 133-136; K'H, 423, s.v. « Juu々» (Croix) ; Donabédian 2009, 160.

42 T'ovma Arcruni 2010, 300.

${ }^{43}$ Voir par exemple Khatchadourian et Basmadjian 2014, corpus iconographique et épigraphique, 332-415.

${ }^{44}$ Pogossian 2017.

${ }^{45}$ Outre les sources citées par Z. Pogossian, signalons à ce sujet Č'amč‘eanc' 1784, II, 532.

${ }^{46}$ S'appuyant sur Inčičean 1822, 207, Thierry 1989, 133 et 470, admet que, dans la $2^{\mathrm{e}}$ moitié du IX ${ }^{\mathrm{e}}$ s., la fameuse relique de Varag a pu être transférée à Ałbak.
} 
Plusieurs décennies après l'érection de l'église du roi Gagik, nous relevons d'ailleurs au Vaspurakan un nouveau témoignage éclatant de la profondeur de cette dévotion pour la croix. L'occasion en est fournie par la consécration, en 983, dans le monastère d'Aparank', de l'église Sainte-Mère-de-Dieu et par l'installation dans ce sanctuaire d'une relique de la Vraie Croix offerte par l'empereur de Byzance Basile II : une grande cérémonie fut alors organisée en présence des plus hauts dignitaires de la région, cérémonie pour laquelle Grégoire de Narek composa un panégyrique ${ }^{47}$. Cette relique est ainsi qualifiée par le Continuateur anonyme de

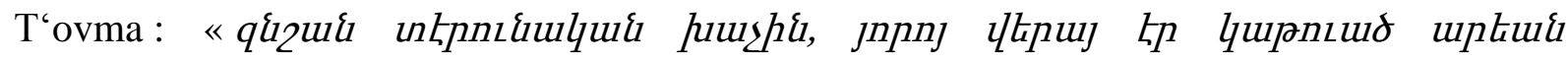

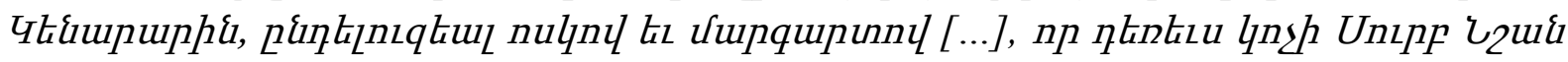
Uuqupuing / le signe de la Croix du Seigneur, orné d'or et de gemmes, sur lequel avait goutté le sang du Sauveur [...], qui s'appelle encore Saint Signe d'Aparank“ ${ }^{48}$. De son côté,

Grégoire de Narek qualifie la relique de « bois salutaire, trône glorieux de Notre Seigneur » ${ }^{49}$.

Une observation peut être faite ici concernant les relations entre présence d'une relique de la Croix, dédicace et composition architecturale : bien que destinée à abriter la précieuse relique, l'église d'Aparank' n'obéit pas à un plan plus cruciforme que dans l'écrasante majorité des églises monastiques arméniennes $d u X^{\mathrm{e}}-\mathrm{XI}^{\mathrm{e}}$ siècle, puisqu'il s'agit d'une ordinaire croix inscrite cloisonnée $^{50}$ (fig. 19) ; en outre, elle est dédiée à la sainte Mère de Dieu et non à la Croix, et, à l'instar de ce que nous avons observé à Varag, le vocable Sainte Croix est attaché non à l'une de ses composantes, mais à l'ensemble du monastère d'Aparank'.

Compte tenu de tout ce qui précède, il serait logique de supposer que, dans la splendide église palatine qu'il a fait ériger, le roi Gagik avait déposé une relique de la Vraie Croix. Toutefois les sources ne nous disent rien à ce sujet. T'ovma Arcruni nous raconte l'histoire, qu'il qualifie de merveilleuse, du sauvetage d'une croix de bois revêtue d'argent, brisée en mille morceaux par un voleur hérétique, et somptueusement restaurée par le futur roi Gagik. Mais cela se passait avant la construction d'Ałt'amar, à l'époque où Gagik était encore général, et cela concernait l'église de Ostan, si l'on en croit du moins le titre du chapitre XXVII de T'ovma où ce récit est noté ${ }^{51}$. Quant à son continuateur, il n'évoque pas l'installation d'une relique dans l'église bâtie par le roi Gagik à Ałt'amar.

Heureusement, nous disposons du témoignage de l'ethnologue Eruand Lalayean qui vit au début du XX ${ }^{\mathrm{e}}$ siècle, dans la sacristie sud-est de l'église d'Att'amar, «le Bois de Vie / Ykinug Tuujun $»^{52}$. Or ce nom désigne une relique de la Vraie Croix ${ }^{53}$. Il nous est donc permis d'affirmer que la Sainte-Croix d'Ałt'amar abritait effectivement une relique de la Vraie Croix. C'est bien ainsi

\footnotetext{
${ }^{47}$ Thierry 1989, 425 ; Dasnabédian 1995, 9-11 ; Mahé 2000, 78-80.

48 T'ovma Arcruni 2010, 300.

${ }^{49}$ Mahé 2000, 82.

50 Thierry 1989, 430, fig. 133. Seule particularité : la profondeur (longueur et étroitesse) des deux chapelles orientales flanquant l'abside, peut-être due à la présence de reliques (l'une d'elles était d'ailleurs appelée « chapelle des sept reliques » - ibid., 429). Pour comparaison, voir les planches synoptiques de Cuneo 1988, II : 726-727, où le plan de la Mère de Dieu d'Aparank' porte le no 368.

51 T'ovma Arcruni 2010, 249. Comme l'indique Thierry 1989, 269, il ne reste plus aucun monument chrétien à Gevaş, l'ancien Ostan.

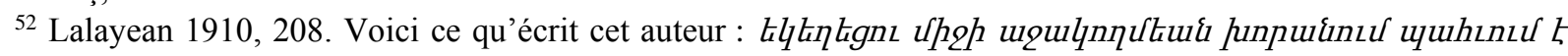

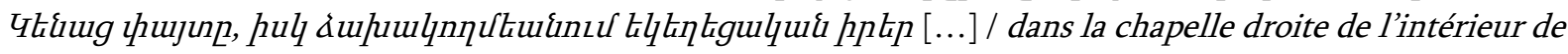
l'église est conservé le Bois de Vie, et dans celle de gauche les objets ecclésiastiques [...].

53 Ōrmanean 1979, 144.
} 
[p. 321 - fig. 19]

d'ailleurs que l'avait compris Sirarpie Der Nersessian ${ }^{54}$. On ne peut pas affirmer que cette relique ait été présente dès la fondation de l'église, mais, compte tenu de la dédicace, cela paraît probable. Notons cependant qu'il peut également s'agir de la relique de la Sainte Croix d'Aparank', mentionnée un peu plus haut; en effet, le continuateur anonyme de T'ovma indique que, avec beaucoup d'autres trésors précieux, elle avait été mise à l'abri à Ałt'amar au $\mathrm{XI}^{\mathrm{e}}$ siècle. ${ }^{55}$

\section{Saintes-Croix d'Albak et d'Alt'amar: une même «composition de reliquaire » ?}

Il semble fort plausible que la dédicace d'Ałt'amar renvoie à celle de son très probable modèle conceptuel, la Sainte-Croix d'Ałbak. Une parenté planimétrique

si évidente lie les deux sanctuaires ${ }^{56}$ que la composition d'Ałt'amar peut être considérée comme inspirée de celle d'Ałbak, dont on a souligné la grande originalité (fig. 20). Il n’y aurait rien d'étonnant à ce que Gagik ait voulu que son église palatine s'inspire du mausolée de ses ancêtres ; la brève mention, évoquée plus haut, de la transmission à Ałt'amar des biens initialement donnés à Ałbak constitue d'ailleurs une allusion à un lien génétique entre les deux sanctuaires.

Comme à Ałbak, à Ałt'amar, la dédicace semble dicter à l'architecte l'élaboration d'un faisceau de volumes nettement cruciforme, mais où s'observe également une claire extériorisation de l'aspect rayonnant. Or cette particularité singularise les deux plans parmi tous ceux de la famille des églises à coupole sur tétraconque tétraniche ${ }^{57}$. Compte tenu de la dédicace et de la présence probable, dès la fondation, d'une relique de la Croix, il est permis de se demander si cette particularité (la combinaison visible des principes cruciforme et rayonnant) n'a pas un lien avec le type de relique de la Vraie Croix vu par Lalayean dans la sacristie sudest d'Ałt'amar et identifié par lui comme un Kenac'P'ayt (Bois de Vie). Comme l'explique l'archevêque Ōrmanean, un Bois de Vie est une relique dans laquelle un petit fragment de la Vraie Croix est placé dans un «magnifique rayonnement ${ }^{58}$. Il précise en outre que l'un des types de croix les plus caractéristiques de l'Église arménienne est celui appelé Seraknajew Xač (Croix rayonnante) qui possède quatre rayons diagonaux partant des angles de la croix ${ }^{59}$. On peut voir des exemples de telles croix rayonnantes, comportant en leur centre une relique, et munies d'un pied permettant de les dresser sur un autel, attribuées aux XVI ${ }^{\mathrm{e}}-\mathrm{XVIII}{ }^{\mathrm{e}}$ siècles, au musée du catholicossat d'Ë̌̆miacin ${ }^{60}$. Le même type de croix figure également dans les

[p. 323 - fig. 20]

\footnotetext{
${ }^{54}$ Der Nersessian 1965, 7.

55 T'ovma Arcruni 2010, 300. Thierry 1989, 425, note 115, n'avait sans doute pas pensé à faire le rapprochement avec le témoignage de Lalayean, puisqu'il ajoute que, après son transfert à Ałt'amar, on ignore le sort ultérieur de la relique.

56 Plusieurs auteurs ont noté que le plan d'Ałt'amar avait pour modèle celui d'Ałbak/Soradir, notamment : Der Nersessian 1969, 107-108, 111 ; Breccia Fratadocchi 1971, 18, 40-41 (cet auteur note aussi que les deux églises ont presque les mêmes dimensions), 46-47 ; Der Nersessian et Vahramian 1974, 10 ; Der Nersessian 1977, 86 ; Mnac'akanyan 1983, 34-35, 149 ; Thierry et Donabédian 1987, 172, 476 ; Thierry 1989, 273, 469 ; Thierry 2000, 137-138.

${ }^{57}$ Pour s'en rendre compte, consulter la double planche synoptique de Cuneo 1988, II, 722-723. Seules l'église atypique de Sarakap en Arménie et en particulier la chapelle de Kvetera en Géorgie peuvent être rapprochées de nos deux églises pour ce qui est de la saillie des rayons diagonaux.

${ }^{58}$ Ōrmanean 1979, 144, s.v. « YGiuug huujun » (= Bois de Vie).

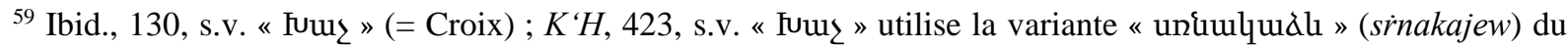
même adjectif, qui signifie au sens propre « axial » mais doit être compris ici comme « rayonnant».

${ }^{60}$ Treasures of Etchmiadzin 1984, passim.
} 
enluminures d'évangiles ; un exemple orne la première page d'un évangile copié au monastère de Narek en $1069^{61}$ (fig. 7).

Ceci nous conduit à avancer l'hypothèse, déjà suggérée par Edda Vardanyan ${ }^{62}$, que l'église Sainte-Croix d'Ałt'amar tout entière avait été conçue par son commanditaire le roi Gagik et par son bâtisseur l'architecte Manuel comme un «sanctuaire reliquaire », ce qu'était peut-être déjà son très probable prototype Ałbak. C'est bien ce que paraît traduire la volumétrie générale de la construction. Il ne semble d'ailleurs pas exclu que le modèle réduit, représentation assez fidèle de l'église ${ }^{63}$, sculpté en un relief très saillant, placé sur la main gauche du roi Gagik dans un geste d'offrande au Christ, figure le type de cassette reliquaire qu'amplifie le volume entier de l'église (fig. 21). Dans l'harmonieuse composition cruciformerayonnante à coupole de l'église, ses concepteurs semblent avoir voulu souligner, à travers la saillie marquée des niches diagonales, comme dans le prototype d'Ałbak et même encore davantage, l'aspect de rayonnement qui caractérise les croix-reliquaires dites Kenac' $P^{\prime}$ 'ayt (fig. 22). Cette conjecture ne peut bien sûr être prise en considération que si l'on accepte l'hypothèse qu'une telle relique ait été déposée à Ałt'amar dès sa fondation et que sa présence ait été prise en compte dans la conception de l'édifice.

L'idée en était peut-être également présente à la Sainte-Mère de Dieu de Varag, où l'on a aussi opté pour une composition cruciforme-rayonnante, avec une certaine autonomie des niches diagonales, mais atténuée par l'enveloppe murale quadrangulaire. Il est révélateur que le même principe compositionnel avec la même particularité concernant les niches diagonales ouest est reproduit à l'église, elle aussi dédiée à la Mère de Dieu, du monastère consacré au Saint Signe (autrement dit, à la Sainte Croix), construit près de Sébaste dans la première moitié $\mathrm{du} \mathrm{XI}^{\mathrm{e}}$ siècle par le dernier roi du Vaspurakan Senek'erim, ou par son fils Atom, après la cession de son royaume à Byzance ${ }^{64}$. Il est raisonnable de supposer qu'un fragment de la relique de Varag avait dû être transféré dans le nouveau monastère.

Revenons à la volumétrie rayonnante, possible reflet d'une « fonction de reliquaire ». Le caractère «cristallin » de la silhouette des églises d'Arménie, volumes compacts aux lignes pures, assemblés autour de leur coupole, souligné notamment par Adriano Alpago Novello, les apparente à des objets taillés dans un bloc de pierre ${ }^{65}$ et incite à ce genre d'associations d'idées. Quant au

[p. 325 - fig. 21]

modèle réduit de l'église tenu par le roi, nous verrons un peu plus loin que le continuateur de $\mathrm{T}^{\prime}$ 'ovma Arcruni le compare à « une cassolette d'or emplie de parfum ». Que de telles sculptures de pierre en ronde bosse aient pu servir de reliquaires est confirmé par les caractéristiques relevées sur plusieurs des nombreux modèles réduits en pierre d'églises arméniennes qui nous

[p. 326 - fig. 22] sont parvenus ${ }^{66}$. Les modèles qui nous intéressent en particulier ici se distinguent en ce qu'ils sont évidés, largement ouverts par une porte démesurée et n'ont aucune trace d'appartenance à un appareil mural, ce qui conduit à supposer qu'ils avaient la fonction de reliquaires déposés à l'intérieur d'églises ${ }^{67}$.

\footnotetext{
${ }^{61}$ Zakarian et al. 2006, 104, no 40 (Erevan, Matenadaran no 10434, fol. 1v).

62 Vardanyan 2014, 736.

${ }^{63}$ Orbeli 1963, 222-228, a mis en évidence la fidélité du modèle à la construction réelle et son importance en particulier pour l'étude de la forme originelle de sa coupole.

${ }^{64}$ Cuneo 1988, I, 701, n 456.

${ }^{65}$ Alpago Novello 1981 ; Alpago Novello et al. 1986, $42-43$.

${ }^{66}$ Cuneo 1988, II : 760-761.

${ }^{67}$ Durand et al. 2007, 89, $\mathrm{n}^{\circ} 17,146, \mathrm{n}^{\mathrm{o}} 38$ et 39 . On peut voir in situ un tel modèle-reliquaire évidé à l'intérieur de l'église Sainte-Mère de Dieu de Sanahin, sur une tablette placée au-dessus de l'entrée de la sacristie nord-est.
} 
Aux observations formulées supra sur la parenté des deux sanctuaires d'Ałbak et d'Ałt'amar, ajoutons que la composition d'Ałt'amar présente en même temps une importante différence par rapport à celle d'Ałbak : elle est beaucoup plus découpée. La comparaison du plan d'Ałt'amar avec celui d'Ałbak, ainsi d'ailleurs qu'avec tous les autres plans arméniens, fait ressortir une volonté très marquée, tout à fait insolite, de créer le maximum de saillies et de retraits. On devine sans peine que l'objectif du concepteur était, d'une part, de mettre en exergue, d'une façon singulièrement vivante, l'image d'une croix rayonnante. Et d'autre part, que ce rayonnement très découpé offre le plus de surface possible à la décoration sculptée, d'une exceptionnelle richesse, et

que ce polyèdre, sans cesse avivé par le renouvellement des jeux d'ombre et de lumière, mette le mieux possible en valeur le tapis de bas-reliefs qui le couvre.

Notons que la vivacité anguleuse qui anime la volumétrie générale de l'édifice imprime aussi sa marque, à une échelle plus réduite, sur le traitement des paires de niches dièdres qui avivent les deux façades axiales (est et ouest) d'Ałt'amar. Ces niches extérieures présentent, d'une manière encore une fois très originale, dans leur fond, deux entailles dièdres séparées par une arête saillante. A la façade orientale, l'effet de cette double césure est encore amplifié par un ressaut supplémentaire qui marque, sur ses deux bords, l'élargissement de chaque niche.

\section{Un programme au service d'une idéologie royale}

Architecture et décoration, tant sculptée que peinte, tout confirme que l'on a affaire à une église palatine hors normes, au service d'un commanditaire que l'on devine aussi hors du commun. On ne peut détailler ici la description de l'édifice - contentons-nous de mentionner parmi ses traits exceptionnels : la volumétrie que l'on vient d'évoquer, avec le riche message que l'on peut y déceler, et le contour très découpé du polyèdre, la profusion du décor sculpté rangé en registres horizontaux tout autour du polyèdre et rehaussé à l'origine par l'insertion de billes de turquoise dans les prunelles des grands yeux des personnages, la richesse du décor peint sur l'ensemble des parois internes et la présence d'une loge royale à l'intérieur de la conque sud, bordée par une balustrade très originalement sculptée, loge à laquelle on devait accéder, de l'extérieur, par un escalier, peut-être en encorbellement.

La vaste composition dédicatoire sculptée sur la façade ouest donne une illustration éloquente de l'idéologie royale, si forte que quelques auteurs ont, avec nous semble-t-il une certaine pertinence, jugé intentionnelle la différence de hauteur entre la figure du roi portant le modèle de l'église, et celle, plus basse, du Christ ${ }^{68}$, alors que d'autres ont cru y voir une erreur de conception ou une maladresse d'ajustement ${ }^{69}$. Catherine Jolivet l'interprète clairement

\footnotetext{
Cf. Ghalpakhtchian et Alpago Novello 1970, 15, fig. 5. Le modèle de Sanahin est identifié comme un reliquaire par Ieni 1978, 264 et 292, fig. 34. Un reliquaire analogue, mais de forme simplifiée, évoquant moins une église, se trouve à l'intérieur du St-Signe de Haghbat, sur la face ouest de l'appui engagé sud-est de la coupole.

${ }^{68}$ Voir en particulier Mnac'akanyan 1983, 52, 55.

${ }^{69}$ Reprenant le jugement de Der Nersessian 1965, 29 : « a mistake [...] because all the figures were carved before they were set in place », Thierry 1989, 277, impute la différence de taille à « la méthode peu rigoureuse de facture et d'assemblage des blocs sculptés ». Der Nersessian 1965, 29, interprète la différence de hauteur qui s'observe entre les deux séraphins dressés aux extrémités de la scène comme une tentative d'atténuer cette disparité de taille, le séraphin de droite ayant la hauteur du Christ, tandis que celui de gauche est de la hauteur du roi.
} 
[p. 328]

comme « une volonté délibérée de mise en valeur du souverain arménien ${ }^{70}$. La description que donne de cette scène le continuateur de $\mathrm{T}^{\prime}$ ovma est en accord avec la grandeur et la richesse du tableau; elle relève la combinaison de « fierté » et de prière qui s'y exprime, sans manquer de souligner «l'image glorieuse du roi ». Citons le passage en question, au chapitre IX $^{71}$ :

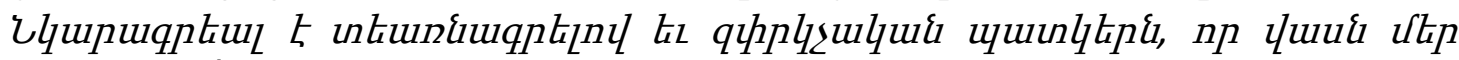

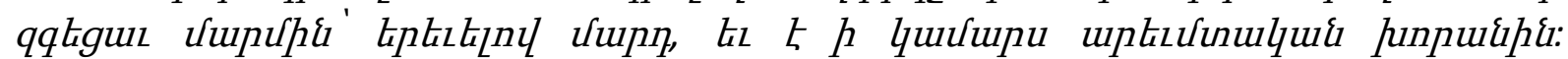

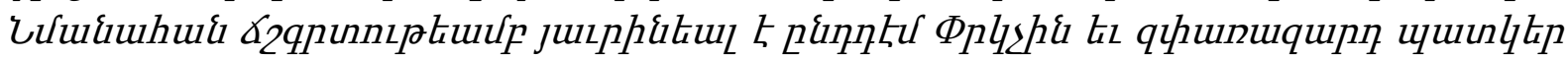

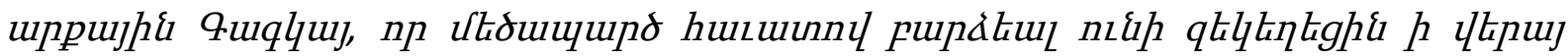

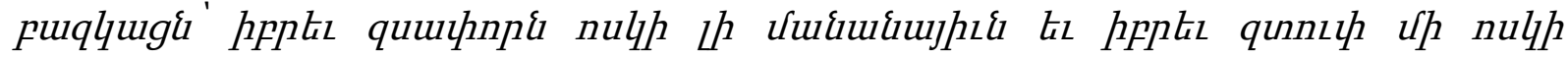

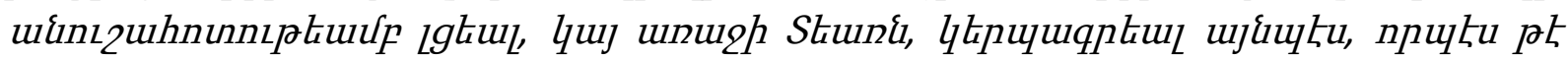

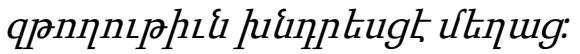

Il représenta aussi, à l'emplacement de la voûte de l'abside occidentale, avec le signe de la croix, l'image du Sauveur qui s'incarna pour nous, prenant une apparence humaine. Avec une exacte ressemblance, il créa aussi, en face du Sauveur, l'image glorieuse du roi Gagik qui, avec une fière foi, a élevé l'église sur ses bras, comme un vase d'or plein de manne ou comme une cassolette d'or emplie de parfum ; il est devant le Seigneur, représenté comme s'il demandait la rémission de ses péchés.

Ce dernier accent mis sur la prière que le roi adresse au Christ semble conférer au message porté par la croix une composante supplémentaire. Quatre fois mise en avant sur la façade occidentale de l'église, éclairée par la lumière du jour finissant ${ }^{72}$, et, de plus, trois fois sculptée sur le linteau ouest, la croix pouvait, en sus de l'évocation du vocable de l'église et de sa contribution à la glorification du souverain du Vaspurakan, servir également à rehausser le message

[p. 329]

eschatologique que comporte, comme l'indique le continuateur de T'ovma Arcruni, l'offrande de l'église au Christ.

\section{Ostentation de la croix sur les façades des églises médiévales de Géorgie et d'Arménie}

Aucune analogie à la forte présence extérieure de la croix sur la façade occidentale de l'église d'Ałt'amar ne peut être trouvée dans l'architecture arménienne, ni aux périodes antérieures, ni au $\mathrm{X}^{\mathrm{e}}$ siècle. Certes, on l'a vu, la croix est couramment employée pour marquer et sans doute protéger les linteaux et tympans des portes depuis la période paléochrétienne, mais il est très rare qu'elle sorte de ce cadre très restreint. Nous avons signalé supra quelques timides tentatives d'une telle « émancipation » à l'époque préarabe. Les exemples en sont toujours très peu nombreux au IX ${ }^{\mathrm{e}}-\mathrm{X}^{\mathrm{e}}$ siècle. Citons la façade sud de Širakawan (fin du IX ${ }^{\mathrm{e}} \mathrm{s}$.) dont le centre s'enrichissait d'une croix finement sculptée placée entre deux fenêtres, mais qui avait sans doute été ajoutée au XI ${ }^{\mathrm{e}}$ siècle en même temps que les deux cadres rectangulaires (fig. 23a).

\footnotetext{
${ }^{70}$ Jolivet 1981, 86. Analysant le décor sculpté figuré du registre principal de l'église dans son ensemble, cette auteure relève une volonté constante de magnifier le roi Gagik et sa dynastie. Elle considère que, non seulement « par le choix et l'emplacement des sujets, l'histoire de la dynastie venait s'insérer dans le plan divin du salut », mais aussi que, compte tenu de ce que l'on sait du roi Gagik, "on s'explique qu'une telle propagande gouvernementale ait pu s'exprimer sur les murs de sa chapelle palatine » (p. 89). Enfin (p. 90), elle suggère d'attribuer à l'ensemble du décor sculpté d'Ałt'amar une « valeur prophylactique », faisant de «l'ensemble d'Aghthamar [une] sorte de talisman devant protéger le royaume du Vaspourakan de ses ennemis ».

${ }^{71}$ T'ovma Arcruni 2010, 291.

${ }^{72}$ Cf. Aubert 1947, 166 : «[...] l'Ouest, touché par les derniers rayons du soleil couchant, [est consacré] au Jugement dernier et aux fins dernières de l'homme $[\ldots] »$.
} 
Citons encore les assez petites croix en médaillon sur la façade ouest de Saint-Ménas de Horomos (première moitié du $\mathrm{X}^{\mathrm{e}} \mathrm{s}$.) et sous la corniche de la cathédrale de Kars (c. 930-943 fig. 23b). Présentant une lointaine analogie avec la solution adoptée à Ałt'amar, la façade ouest de l'abbatiale Saints-Pierre-et-Paul de Tat'ew (895-906) possède une plaque à croix évoquant un $x a c c^{\prime} k$ 'ar, logée au-dessus de l'entrée occidentale (fig. 23c). Portant une inscription dédicatoire de l'évêque Jean, bâtisseur de l'église ${ }^{73}$, elle en est probablement contemporaine, même si son décor semble plutôt renvoyer au XI ${ }^{\mathrm{e}}$ siècle $^{74}$; toutefois l'appareil mural ayant été refait, on ignore si elle se trouve à son emplacement originel. Il s'agit, on le voit, dans ces trois cas, d'une présence bien plus modeste ou plus incertaine qu'à Ałt'amar.

Le seul parallèle (partiel) qui puisse être tracé avec Ałt'amar lui est postérieur d'un siècle. Il se trouve sur l'église Saint-Georges de Horomos, bâtie au début du $\mathrm{XI}^{\mathrm{e}}$ siècle par le roi Gagik Bagratide : sur sa façade ouest, au-dessus du cadre rectangulaire de la fenêtre et près de ses angles supérieurs, trois croix sont sculptées en légère saillie méplate par rapport à la surface du mur (fig. 24). La centrale est reliée au cadre de la fenêtre par une tige à trois brins. Les

[p. 330 - fig. 23] deux latérales sont feuillues et «posées » sur une hampe et un large socle rectangulaire. La croix de gauche s'appuie sur cette haute base par l'intermédiaire d'une insolite boule au pied de sa hampe. Celle de droite présente, nouées sous son pied, deux palmettes à disposition horizontale caractéristique des $x a c c^{`} k$ 'ars du début du XI ${ }^{\mathrm{e}}$ siècle ${ }^{75}$. Malgré la relative petitesse des croix, cette composition a une forte présence sur la façade, puisqu'elle en constitue, avec le cadre de la fenêtre, le seul décor. Ce rang de trois croix au centre de la façade ouest d'une fondation royale peut être regardée comme un écho du décor d'Ałt'amar, mais il n'est pas lié à la dédicace et n'a certainement pas le même sens ; compte tenu de son emplacement au-dessus de la fenêtre, on peut lui attribuer une portée prophylactique et peut-être en partie « votive ${ }^{76}$.

[p. 331 - fig. 24]

Nous laisserons de côté les cas de plaques à croix encastrées postérieurement dans la façade d'une église, ainsi que les $x a c ̌$ ' $k$ 'ars, parfois nombreux, insérés dans les façades bien après l'édification des monuments, comme à Mren, qui constituent des éléments hétérogènes, ou encore les plaques à croix « votives » placées dans la façade ouest du gawit' de Tełer (1221), et celles, tardives, de Ktuc' (1713). Au sommet de la façade occidentale de la cathédrale d'Ani, achevée en 1001, un petit $x a c{ }^{\prime} k$ 'ar probablement contemporain de la construction ou de peu postérieur est encastré presque au centre du pignon, en écho à la tradition que nous avons vu s'esquisser à l'époque préarabe, mais il est assez peu visible (fig. 25a). Le principe en a été vaguement repris sur le pignon ouest de l'église Saint-Grégoire de Tigran Honenc' (1215) à Ani, timbré d'une petite plaque à croix (martelée), à inscription géorgienne, mais il n'est pas certain que cette plaque, difficilement visible, ait été conçue dès l'origine pour cet emplacement (fig. 25b).

On a évoqué plus haut l'affinité qui ressort de la comparaison entre la place accordée à la croix au-dessus de la porte occidentale d'Ałt' amar et la figuration

\footnotetext{
${ }^{73}$ Barxudaryan 1960, 14, n ${ }^{\circ} 3$.

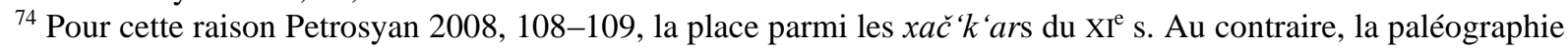
semble plaider en faveur d'une datation contemporaine de l'église, Ibid., 895-906.

${ }^{75}$ Cette composition est décrite dans Mahé 2015, 306, 308-309.

${ }^{76}$ Peut-être y a-t-il eu, pour les croix latérales, une intention initiale «votive », avec un espace destiné à une inscription sur le «piédestal» de la croix, qui est resté inutilisé, du moins du côté gauche. Sur la tablette particulièrement haute de ce piédestal, un bref texte (huu々u Uhpל $\mathrm{W}$ / cette croix de Mik'ēl) a été maladroitement gravé, qui ne semble pas d'origine. Cf. Karapetyan et Mahé 2015, 403, nº 6.
} 
[p. 332 - fig. 25]

sculptée au-dessus de la porte méridionale de J̌vari. Ce parallèle avec la Géorgie ne vient pas à l'esprit par hasard. Dans ce pays, en effet, la mise en valeur de la croix au centre des façades s'opère avec vigueur à partir $\mathrm{du} \mathrm{XI}^{\mathrm{e}}$ siècle. Ce phénomène peut sans doute être rapproché du fort développement de la décoration sculptée à cette période et peut-être également du renforcement de la conscience nationale et de la réunification des terres géorgiennes sous l'égide de la royauté unie des Bagratides géorgiens, mais il n'a apparemment pas de lien avec la dédicace des églises.

Au début de cette époque nouvelle, en Géorgie, c'est surtout sur la façade orientale que la croix est magnifiée ; ce n'est probablement plus tout à fait le même message que sur la façade occidentale d'Ałt'amar, où était mis en valeur le vocable de l'église, en même temps que la personnalité du commanditaire et s'exprimait peut-être l'attente du Jugement dernier. Sur la façade orientale des églises de Géorgie, tournée vers le côté où se lève le soleil et d'où viendra le salut, comme sur les xač 'k'ars d'Arménie (eux aussi orientés), c'est plutôt, sans doute, l'espoir du salut qui est accentué. Les premiers essais sont faits au sortir de l'occupation arabe en Kaxeti (c. VIII ${ }^{\mathrm{e}}-\mathrm{X}^{\mathrm{e}}$ s.) : à Gurjaani et Sanagire (fig. 26a, b) ; à la basilique de Nekresi la même formule est appliquée à la façade occidentale (fig. 26c). Des tentatives analogues sont peut-être faites

[p. 333 - fig. 26]

aussi dans d'autres provinces, mais elles sont modestes et/ou difficiles à dater (Zedazeni, Urbnisi - fig. 26d,e). Les premiers pas vers une vraie ostentation de la croix s'amorcent avec une grande croix placée sous l'arcature aveugle centrale de la façade orientale de quelques églises du XI ${ }^{\mathrm{e}}$ siècle (Nikorc'minda - 1014, Savane - 1046 - fig. 27). La formule élaborée pour la façade est de Samtavisi (1030) est particulièrement innovante et impressionnante (fig. 28). Encadrée par l'arcature aveugle centrale, la croix est placée au sommet d'un puissant corps de moulures partant du bas de la façade; cette forte tige verticale dessine d'abord deux grands losanges, puis forme autour de la fenêtre centrale un chambranle rectangulaire avant de hisser, par l'intermédiaire d'un médaillon rond, la grande croix tout en haut de la façade.

Réservée toujours à la façade orientale, la composition de Samtavisi est reprise au XII ${ }^{\mathrm{e}}$ $\mathrm{XIII}^{\mathrm{e}}$ siècle sur plusieurs monuments géorgiens, avec une modification : l'arcature-colonnade aveugle qui l'encadrait initialement, encore présente à Ik'orta (1172), est abandonnée, peut-être pour mieux mettre en

valeur le vigoureux corps de moulures vertical et surtout la grande croix ainsi fièrement affichée (fig. 29). C'est ce que l'on voit notamment à Gudarexi, K'abeni et Kvataxevi (déb. du XIII s.), ainsi qu'à Met'exi de Tbilisi (1272-1289) ${ }^{77}$ (fig. 29b-30).

Toujours en Géorgie, à partir de la formule de la façade orientale des églises du groupe de Samtavisi, l'idée de l'ostentation de la croix sur une large partie de la façade fait école : à la fin du XII ${ }^{\mathrm{e}}$ siècle et au début du XIII ${ }^{\mathrm{e}}$ siècle, elle marque souvent désormais le centre supérieur de beaucoup de façades autres que l'orientale. Souvent combinée avec une paire de fenêtres, la croix dresse sa haute hampe entre les baies et étend ses bras au-dessus d'elles (Betania,

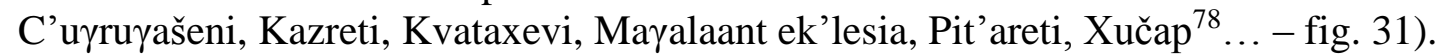

Jusque-là en Arménie, au contraire, comme nous l'avons vu, hormis sur les linteaux ou tympans et pour quelques très modestes médaillons en haut de la façade occidentale, et hormis bien sûr le cas exceptionnel d'Att'amar et, dans une moindre mesure, son écho à Horomos, l'idée de fort «affichage » de la

\footnotetext{
${ }^{77}$ La même composition, mais sans les losanges, est sculptée à Ertac'minda, tandis qu'une version réduite et dénaturée figure à M $\gamma$ vimevi.

78 Situé du côté arménien de la frontière avec la Géorgie, le monastère de Xučap, dont on ignore quelle communauté il desservait, possède les caractéristiques de l'architecture et du décor sculpté géorgiens.
} 
[p. 335 - fig. 28]

croix sur les murs était restée étrangère à la tradition nationale, alors que la croix était omniprésente à travers les innombrables $x a c c^{\prime} k$ 'ars. Il faut attendre le début du XIII ${ }^{\mathrm{e}}$ siècle et le rattachement à la Géorgie pour voir sur les façades de plusieurs églises arméniennes une exposition nettement marquée de l'image de la croix.

[p. 336 - fig. 29, 30] [p. 337 - fig. 31]

Ce phénomène est lié premièrement à l'écho que trouve dans l'Arménie des Mxargrjeli/Zakarides la composition de Samtavisi. Cet écho est toutefois limité, si on le prend au sens d'une reproduction fidèle, puisque ce modèle n'est appliqué que sur deux édifices d'Arménie, même s'il s'agit de sanctuaires importants: les églises des monastères de Płnjahank'/Axt'ala (déb. du XIII ${ }^{\mathrm{e}}$ s.) et de Yovhannavank' (1216-1221 - reprise assez fidèle mais simplifiée - fig. 32). Quant à la deuxième formule, celle de la croix surmontant les deux fenêtres centrales, elle n'est reproduite à l'identique que sur la plus géorgienne des églises d'Arménie, celle de Płnjahank'/Axt'ala, où elle orne les trois façades autres que l'orientale (fig. 33), ainsi qu'à l'église de la branche chalcédonienne des Mxargrjeli, K'obayr, façade est.

Mais si l'on considère, d'une manière plus générale, les deux dispositifs élaborés en Géorgie comme l'expression d'une volonté d' « exposer » une haute croix au centre supérieur des façades, on observe que ce principe a en Arménie un impact assez fort, bien qu'indirect ${ }^{79}$. En effet, ce parti nouveau est souvent adopté dans l'Arménie du XIII ${ }^{\mathrm{e}}$ siècle, mais chaque fois réinterprété, voire

[p. 338 - fig. 32]

totalement repensé. C'est le cas dans l'un des monuments majeurs de l'époque, Hariič (1201 fig. 34), ainsi qu'à Astuacənkal (1244), Ganjasar (1216-1238) (fig. 35), Keč‘arìs (déb. du XIII s.), Mškavank‘ (déb. du XIII s.) (fig. 36), Nor Varagavank‘ (1224-1237), Xoranašat (12111222), Yovhannavank' (1216-1221) (fig. 37), Saint-Grégoire de Tat'ew (1295)... Son écho se laisse également percevoir dans les croix sur haute et longue hampe du campanile de Hałbat (1245), de l'église Sainte-Marianē d'Aštarak ( $2^{\mathrm{e}}$ moitié du XIII ${ }^{\mathrm{e}}$ s.) et peut-être aussi sur la façade ouest du gawit ' de Hałarcin (après 1212) et du campanile / clocher de Sanahin (déb. du $\mathrm{XIII}^{\mathrm{e}}$ s.)..., puis sur les monuments du XIV siècle (Ełvard - déb. du XIV ${ }^{\mathrm{e}}$ s., Spitakawor - 1321, Burt'elašēn de Noravank' - 1339 - fig. 38), et plus tard à la fin du Moyen Âge ${ }^{80}$. De grandes croix sont aussi sculptées et marquées par la bichromie des blocs qui les composent, au XIII ${ }^{\mathrm{e}}$ siècle, sur les remparts d'Ani.

S'agissant de la dédicace des églises et de son rapport avec la figuration de la croix sur les façades et l'éventuelle présence de reliques, notons que, parmi les églises qui obéissent à la nouvelle mode d' « affichage haut et fort de la croix », il n'y en a apparemment pas qui soient consacrées à la Croix ou au Saint

[p. 339 - fig. 33]

Signe. Là encore, l'importante place faite à la croix dans l'image extérieure de l'église semble indépendante de son vocable. Mais il convient d'être prudent, car les dédicaces ne sont pas toutes établies avec certitude, et les monastères Astuacənkal, Keč 'arìs et Nor Varagavank' ont sans doute un lien avec une relique de la Croix ou un Saint Signe - dans les deux premiers existe une chapelle

\footnotetext{
${ }^{79}$ Ces questions d'échanges arméno-géorgiens font l'objet de deux études plus détaillées sur le parallélisme, les convergences et divergences entre les deux écoles, a) jusqu'au XI ${ }^{\mathrm{e}}$ siècle : Donabédian 2012 ; b) au XII ${ }^{\mathrm{e}}-\mathrm{XIV}^{\mathrm{e}}$ siècle : Donabédian 2016.

${ }^{80}$ Voir les planches de Cuneo 1988, II, 806-807.
} 
[p. 340 - fig. 34, 35]

Surb Nšan et dans le troisième, la fameuse Croix de Varag aurait été transférée en 1231, d'où le nom du couvent ${ }^{81}$. Néanmoins l'église principale, porteuse du décor à croix, des deux premiers est appelée Kat'ołikē, et celle du troisième, Sainte-Mère de Dieu.

\section{L'un des vastes champs encore à défricher}

[p. $341-$ fig. 36, 37]

La formule adoptée à Ałt'amar au début du $\mathrm{X}^{\mathrm{e}}$ siècle était audacieuse, novatrice, prémonitoire, puisqu'annonciatrice de ce qui se ferait trois siècles plus tard, mais aussi isolée : elle constitue un phénomène extraordinaire dans l'histoire de cet art, comme est extraordinaire, dans l'ensemble, cette église palatine, monument de prestige, création unique.

[p. 342 - fig. 38]

En même temps, elle s'inscrit dans un groupe, certes très restreint mais caractéristique d'une période et d'une région, groupe auquel appartient son probable prototype Ałbak, ainsi que peut-être la Mère de Dieu de Varag (et son épigone à Sébaste). La composition à coupole sur un volume à la fois cruciforme et rayonnant y reflète, semble-t-il, non seulement la présence d'une relique de la Vraie Croix, mais peut-être aussi la forme rayonnante que revêtait le type spécifique dit « Bois de Vie » de cette relique, et même la nature « de reliquaire » du sanctuaire tout entier. Ce phénomène n'était certainement pas étranger à l'intensité du culte de la croix au Vaspurakan, en particulier sous le règne de Gagik qui, selon le témoignage de T'ovma Arcruni et de son continuateur, lui accordait un rôle primordial dans sa vie et dans la conduite des affaires publiques.

Enfin, la composition du décor de la façade occidentale qui réserve une place considérable à la croix, et le modèle offert au Christ, reproduction en miniature de l'ensemble de l'édifice et probablement symbole de sa «fonction reliquaire», se complètent pour magnifier simultanément la dédicace de l'église et le prestige de son royal commanditaire. Mais il semble que sur ce point également, l'église d'Att'amar, avec probablement auprès d'elle Ałbak et Varag, se tienne en-dehors des usages communs. En effet, le rapide examen, simplement ébauché dans cette brève étude, de la question du rapport entre la dédicace d'une église, sa structure et la présence en son sein d'une relique semble montrer la rareté d'un tel lien. Toutefois pour être véritablement probante, une telle enquête autour de la question des vocables demande à être approfondie et élargie. Elle constitue l'une des nombreuses voies à explorer dans le vaste domaine des arts médiévaux de l'Arménie et de la Géorgie.

\footnotetext{
${ }^{81}$ Thierry et Donabédian 1987, 560.
} 


\section{Bibliographie}

Alpago Novello, A. 1981. "Architettura e territorio in Armenia : le chiese di cristallo", Atlante, Mensile dell'Istituto Geografico de Agostini, juillet 1981, Novara: Istituto Geografico de Agostini, 40-53.

Alpago Novello, A., Ieni, G., Manoukian, A., Pensa, A., Uluhogian, G. et Zekiyan, B.L. 1986. Les Arméniens. Milan : Jaca Book.

Aubert, M. 1947. La sculpture française au Moyen Âge. Paris : Flammarion.

Augé, I., Barkhoudaryan, V., Dédéyan, G., Dokhtourichvili, M., Karaulashvili, I. (éd.). 2016, L'Arménie et la Géorgie en dialogue avec l'Europe du Moyen Âge à nos jours. Paris : Geuthner.

Augé, I. et Dédéyan, G. (éd.). 2009. L'Église arménienne entre Grecs et Latins, fin XI - milieu $X V^{e}$ siècle. Paris : Paul Geuthner.

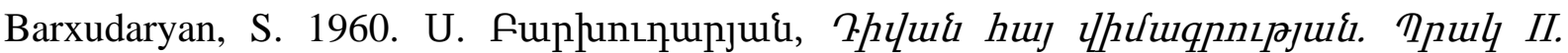

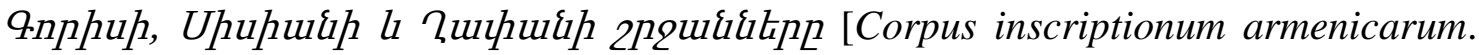
Livre II. Régions de Goris, Sisian et Łap'an]. Erevan : Académie des sciences.

Breccia Fratadocchi, T. 1971. La Chiesa di S. Ejmiacin a Soradir. Rome : De Luca Editore.

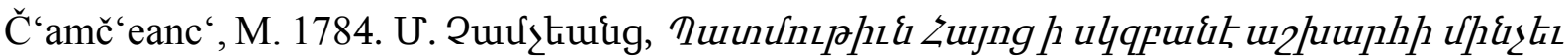
guud Stünzi 1784. Zuunnn $f$. [Histoire de l'Arménie du début du monde jusqu'à l'an du Seigneur 1784. Tome II]. Venise : St-Lazare.

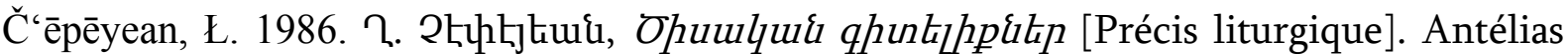
(Liban) : Catholicossat arménien de Cilicie.

Cuneo, P. 1988. Architettura armena dal quarto al diciannovesimo secolo, 2 vol. Rome : De Luca.

Dasnabédian, T. 1995. Le panégyrique de la Sainte Mère de Dieu de Grigor Narekac i Introduction, traduction, commentaire, notes et index. Antélias (Liban) : Catholicossat arménien de Cilicie.

Der Nersessian, S. 1965. Aght'amar. Church of the Holy Cross. Cambridge (Ma.): Harvard University Press.

Der Nersessian, S. 1969. The Armenians. Londres : Thames \& Hudson.

Der Nersessian, S. 1977. L'art arménien. Paris : Arts et Métiers Graphiques.

Der Nersessian, S. et Vahramian, H. 1974. Aght'amar. Documenti di architettura armena 8. Milan : Edizioni Ares.

Dokhtourichvili, M., Dédéyan, G. et Augé, I. (éd.). 2012. L'Europe et le Caucase. Les relations interrégionales et la question de l'identité. Tbilissi : Edition Université d'Etat Ilia.

Donabédian, P. 2008. L'âge d'or de l'architecture arménienne. VII siècle. Marseille: Parenthèses.

Donabédian, P. 2009. «Le khatchkar, un art emblématique de la spécificité arménienne », in Augé et Dédéyan (éd.), 151-167.

Donabédian, P. 2012. «Parallélisme, convergences et divergences entre Arménie et Géorgie en architecture et sculpture architecturale - 1 », in Dokhtourichvili, Dédéyan et Augé (éd.), $215-269$.

Donabédian, P. 2014. «Ereruyk' : nouvelles données sur l'histoire du site et de la basilique », in Mardirossian, Ouzounian et Zuckerman (éd.), 241-284. 
Donabédian, P. 2016. «Parallélisme, convergences et divergences entre Arménie et Géorgie en architecture et sculpture architecturale - $2 »$, in Augé, Barkhoudaryan, Dédéyan, Doukhtourichvili et Karaulashvili (éd.), 19-130.

Durand, J., Rapti, I. et Giovannoni, D. (éd.). 2007. Armenia sacra. Mémoire chrétienne des Arméniens (IV ${ }^{e}-X V I I I^{e}$ siècles), catalogue d'exposition, Paris : Musée du Louvre / Editions Somogy.

Džanberidze, N. et Cicišvili, I. 1996. Н. Джанберидзе, И. Цицишвили, Архитектурньле памятники Грузии [Monuments architecturaux de Géorgie], Moscou : Strojizdat.

Findikyan M. D. 1998. «The Armenian Ritual of the Dedication of a Church: A Textual and Comparative Analysis of Three Early Sources », Orientalia christiana periodica 64, 75121, Rome.

Foletti, I. et Thuno, E. (éd.). 2016. Convivium, Supplementum. The Medieval South Caucasus: Artistic Cultures of Albania, Armenia and Georgia, Lausanne et Brno : Université de Lausanne et Université de Brno.

Ghalpakhtchian, O. et Alpago Novello, A. 1970. Sanahin. Documenti di architettura armena 3. Milan : Edizioni Ares.

Glei, R. et Jaspert, N. (éd.). 2017. Locating Religions: Contact, Diversity and Translocality, Leyde : Brill.

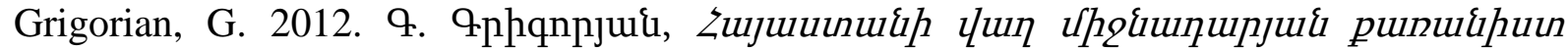
lnpnnitipl / Early Medieval four-sided Stelae in Armenia (en arménien, avec résumé en anglais et en russe), Erevan : Musée d'Histoire de l'Arménie.

Hasratian, M. 2000. Early Christian Architecture of Armenia (en russe et en anglais). Moscou : Inkombuk Publ.

Ieni, G. 1978. «La rappresentazione dell'oggetto architettonico nell'arte medievale con riferimento particolare ai modelli di architettura caucasici », Atti del Primo simposio internazionale di arte armena (1975), 247-292. Venise : Saint-Lazare.

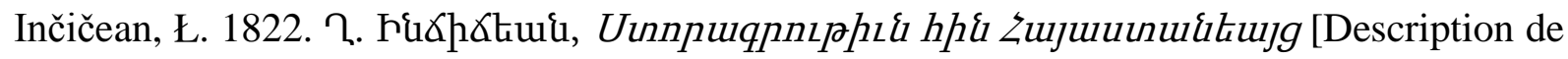
l'Arménie ancienne], Venise : St-Lazare.

Jolivet, C. 1981. «L'idéologie princière dans les sculptures d'Aghthamar », The Second International Symposium on Armenian Art. Collection of Reports. Volume III (1978) : 86-94. Erevan : Académie des sciences.

Karapetyan, S. et Mahé, J.-P. 2015. « The Horomos Inscriptions », in Vardanyan E. (éd.), 363489.

$K^{\prime} H=e_{p h u \imath n}{ }^{\prime}$ 2002. Erevan : Encyclopédie Arménienne.

Khatchadourian, H. et Basmadjian, M. 2014. L'art des khatchkars. Les pierres à croix arméniennes d'Ispahan et de Jérusalem. Paris : Geuthner.

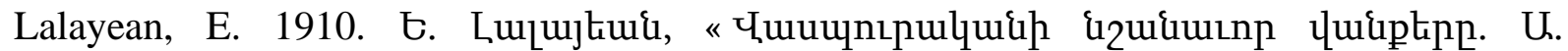
Unpưưup Unıpp IUuı luukpp » [Les monastères célèbres du Vaspurakan. I. Le

monastère Sainte-Croix d'Ałt'amar], Uqquqpulquí ZukinLu, XX qhpp [Revue Ethnographique / Azgagrakan Handēs, 20], 1910/2, 197-212. Tiflis.

Mahé, A. et J.-P. 2000. Grégoire de Narek, Tragédie. Introduction, traduction et notes, Corpus Scriptorum Christianorum Orientalium 584, Subsidia, T. 106. Louvain : Peeters.

Mahé, J.-P. 2015. « Croix et xač‘k'ar de Horomos », in Vardanyan (éd.), 301-324. 
Maranci, C. 2015, Vigilant Powers: Three Churches of Early Medieval Armenia. Turnhout: Brepols.

Mardirossian, A., Ouzounian, A. et Zuckerman, C. (éds.). 2014. Mélanges Jean-Pierre Mahé. Travaux et Mémoires 18. Paris : Association des Amis du Centre d'Histoire et de Civilisation de Byzance.

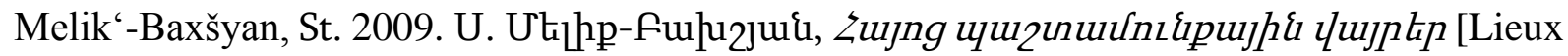
de culte arméniens]. Erevan : Université d'Erevan.

Mépisachvili, R. et Tsintsadzé, V. 1978. L'art de la Géorgie ancienne, Leipzig : Éditions Hier et Demain.

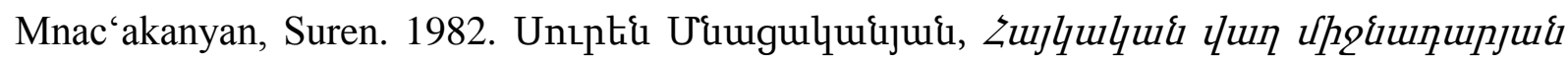
Ukunphuu hnzqupáuiqulpp [Les monuments commémoratifs arméniens du haut Moyen Âge], Erevan : Académie des sciences.

Mnac'akanyan, S. 1983. U. U\{uugulququuid, Unpuufup [Ałt'amar], Erevan : Erebuni.

Orbeli, I. 1963. И. Орбели, Избранные труды [CEuvres choisies]. Erevan : Académie des sciences.

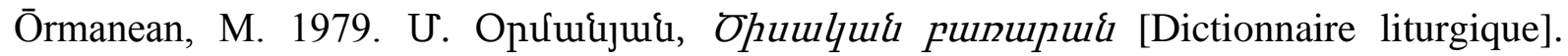
Antélias (Liban) : Catholicossat arménien de Cilicie [1 ${ }^{\mathrm{e}}$ éd. : 1905-1906, 2e éd. : 1957].

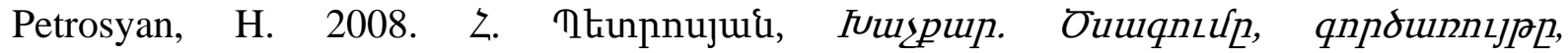

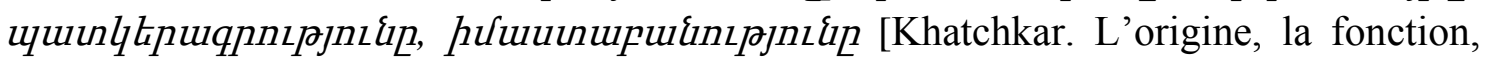
l'iconographie, la sémantique]. Erevan : Printinfo.

Pogossian, Z. 2017. « Locating Religion, Controlling Territory: Conquest and Legitimation in Late Ninth Century Vaspurakan and its Inter-Religious Context », in Glei \& Jaspert (éd.), 173-233.

Renoux, A. 1969. « La croix dans le rite arménien. Histoire et symbolisme », Melto. Recherches orientales V/1, 123-175. Kaslik (Liban) : Université St-Esprit.

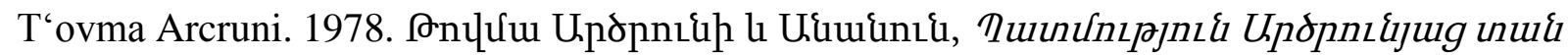
[T'ovma Arcruni et Anonyme, Histoire de la Maison des Arcruni], Introduction, traduction en arménien oriental et notes de V. Vardanyan, Erevan : Sovetakan groł.

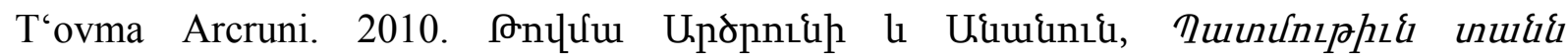
Upдpnzktuug [T'ovma Arcruni et son continuateur anonyme, Histoire de la Maison des Arcruni], éd. G. Tēr-Vardanean, in Uuuntuuuqhp Zuung / MH / Armenian Classical Authors, XI : $10^{\text {th }}$ century, Historiography, Antélias (Liban) : Catholicossat arménien de Cilicie. 46-313. [Consulté sur: http://www.matenadaran.am/ftp/MH/MH/11/2.MHhator-11-2.pdf].

Tchakerian, S. 2016. « Towards a Detailed Typology: Four-Sided Stelae in Early Christian South Caucasus », in Foletti et Thuno (éd.), 124-143.

Thierry, J.-M. 1989. Monuments arméniens du Vaspurakan. Paris : Geuthner.

Thierry, J.-M. 1993. Répertoire des monastères arméniens (Corpus Christianorum). Turnhout : Brepols.

Thierry, J.-M. 2000. L'Arménie au Moyen Âge. Les hommes et les monuments. St-LégerVauban (Abbaye de la Pierre-qui-Vire) : Zodiaque.

Thierry, J.-M. et Donabédian, P. 1987. Les arts arméniens. Paris : Mazenod.

Thierry, M. [J.-M.] et N. 1971. «La cathédrale de Mrèn et sa décoration », Cahiers Archéologiques XXI : 43-77. Paris : Editions Klinsksieck. 
Treasures of Etchmiadzin 1984 (album avec une introduction de S. Der Nersessian, brefs textes de V. Haroutiunian, S. Saghoumian, Kh. Mousheghian, A. Samvelian, M. Khazaryan, S. Davtian, V. Ghazarian, en arménien, russe et anglais, avec pages et illustrations non numérotées), Ējmiacin : Saint-Siège de Ste-Etchmiadzine.

Vardanyan, E. 2014. «Décor sculpté de l'église de la Sainte-Croix d'Ałt'amar: les sujets bibliques de la frise de la vigne », in Mardirossian, Ouzounian et Zuckerman (éd.), 707736.

Vardanyan E. (éd.). 2015. Horomos Monastery: Art and History (Monographies 50), Paris : Association des Amis du Centre d'Histoire et de civilisation de Byzance.

Vardanyan, E. 2015. «The Sculpted Dome of Horomos Monastery Žamatun: an Armenian Apocalypse », in Vardanyan (éd.), 237-300.

Zakarian, L., Drampian, I., Korkhmazian, E., Hacopian, H. 2006. La miniature arménienne. Collection du Maténadaran. Erevan : Naïri. 


\section{Illustrations}

N.b. Les photos dont l'auteur n'est pas indiqué sont de Patrick Donabédian
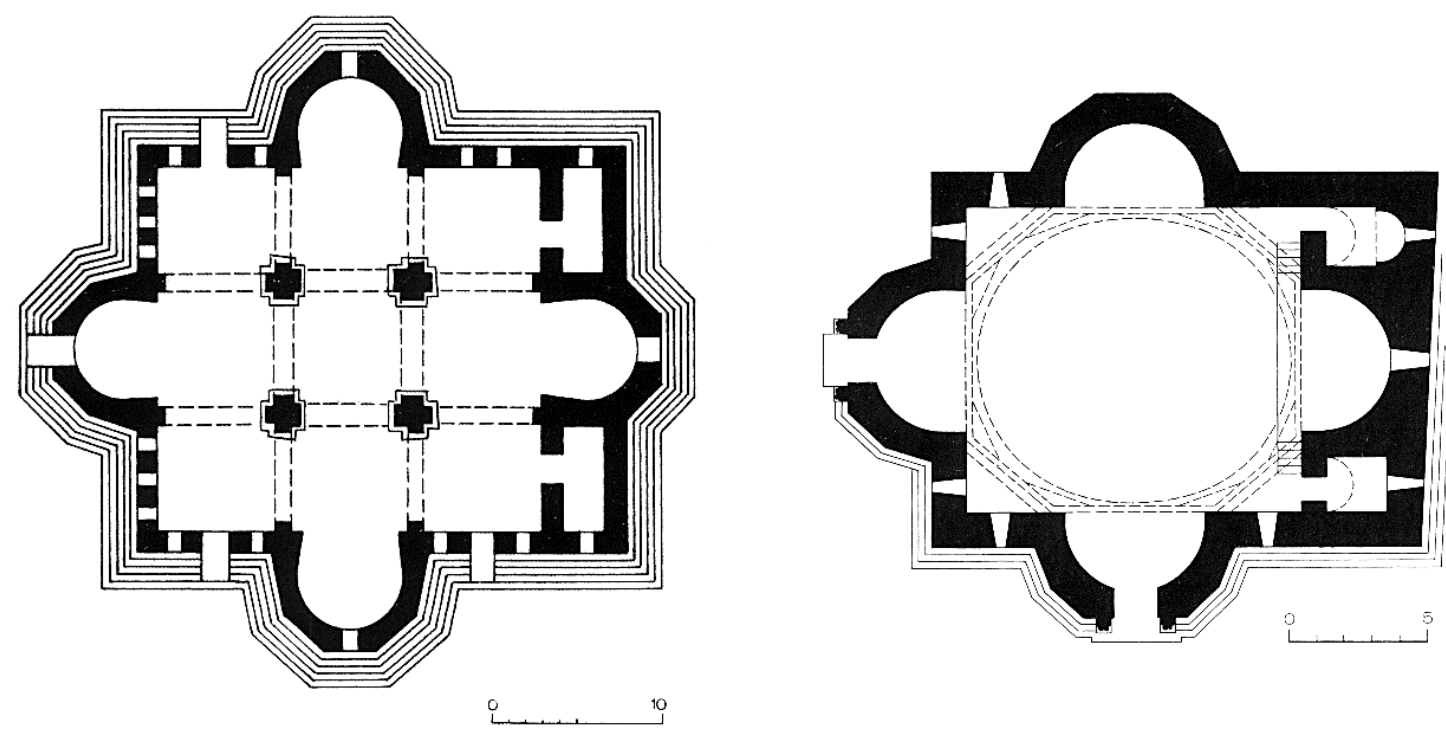

Fig. 1. Plans.

A) Vałaršapat, Sainte-Ē J̆miacin (fin $\mathrm{V}^{\mathrm{e}}$ s.). Plan reconstitué, hypothèse (Hasratian 2000, 117).

B) Mastara, Saint-Jean (années 640). Plan (Hasratian 2000, 288).
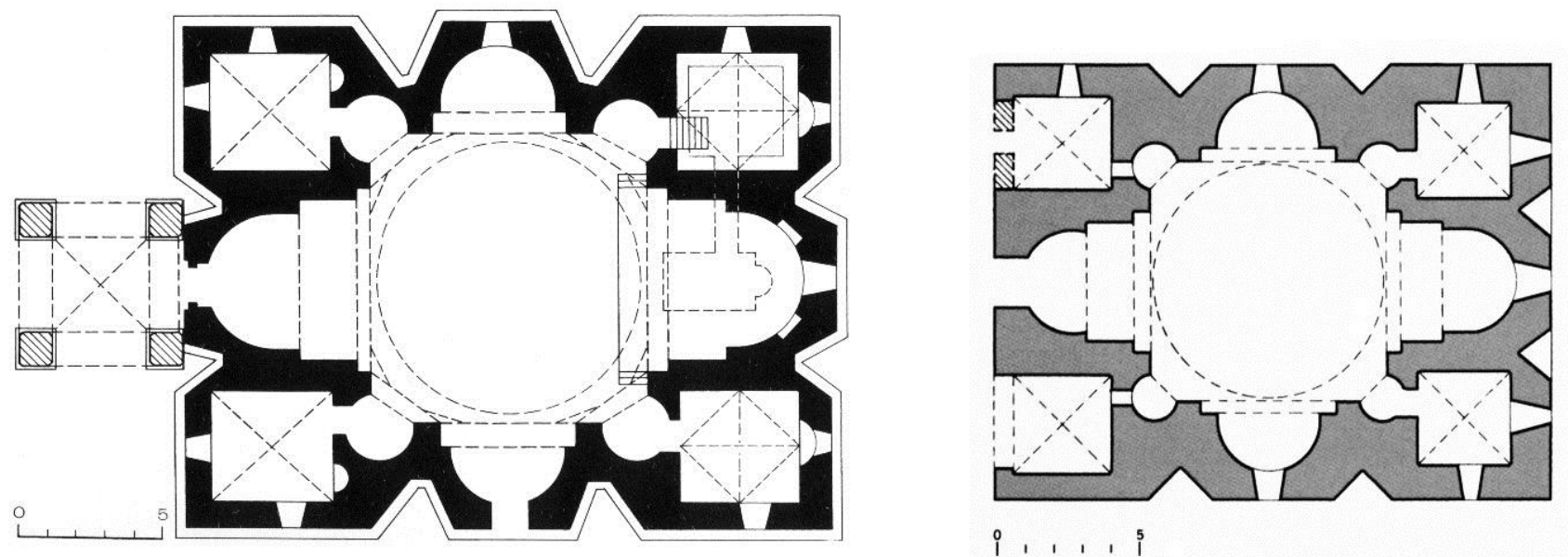

Fig. 2. Eglises arméniennes du début du VII ${ }^{\mathrm{e}}$ s., à coupole sur tétraconque tétraniche inscrite, à quatre chambres angulaires. Plans.

A) Vałaršapat, Ste-Hr̈ip'simē (Hasratian 2000, 307). B) Arcuaber. Plan (Thierry 1989, 202). 

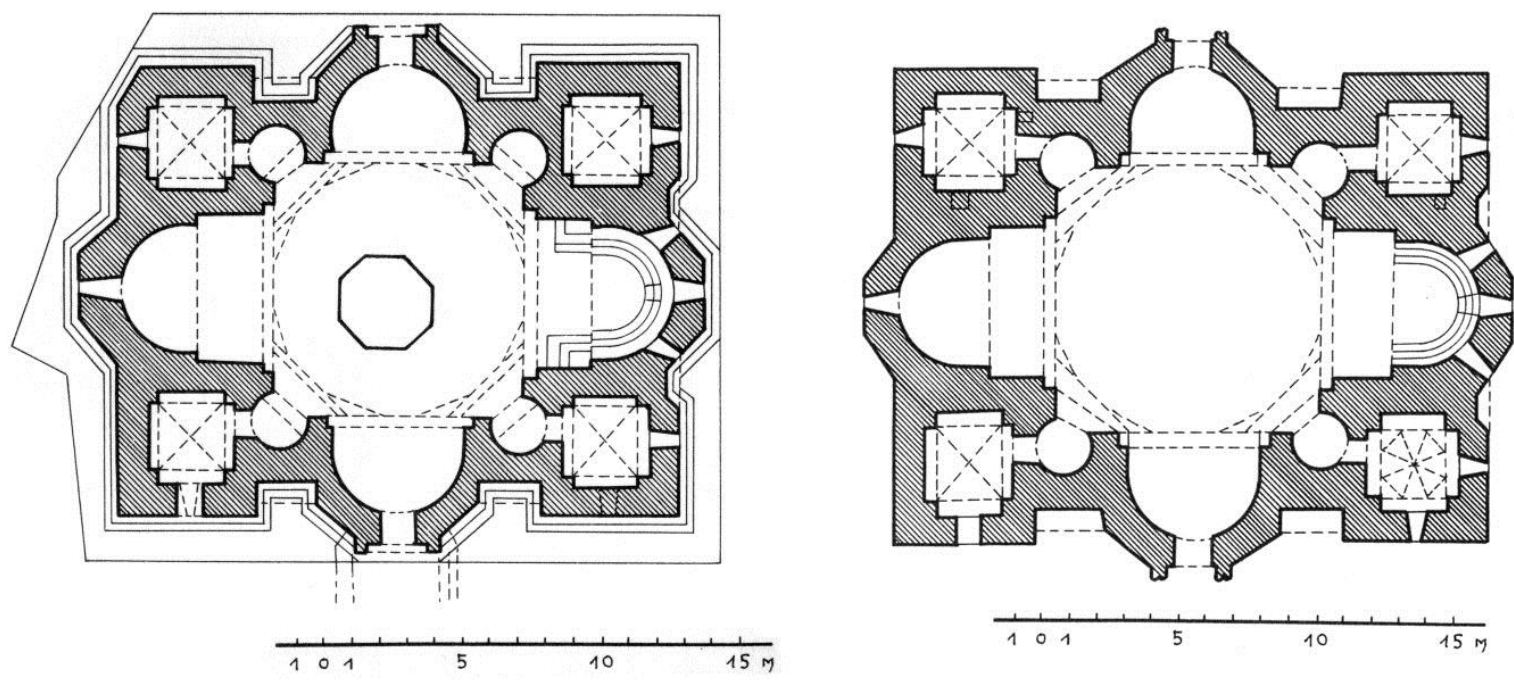

Fig. 3. Eglises géorgiennes (ibères), à coupole sur tétraconque tétraniche, à quatre chambres angulaires. Plans (Mépisachvili et Tsintsadzé 1978, 64).
A) J̌vari, Sainte-Croix (années 590-640).
B) At'eni, Sainte-Sion (c. années 640).

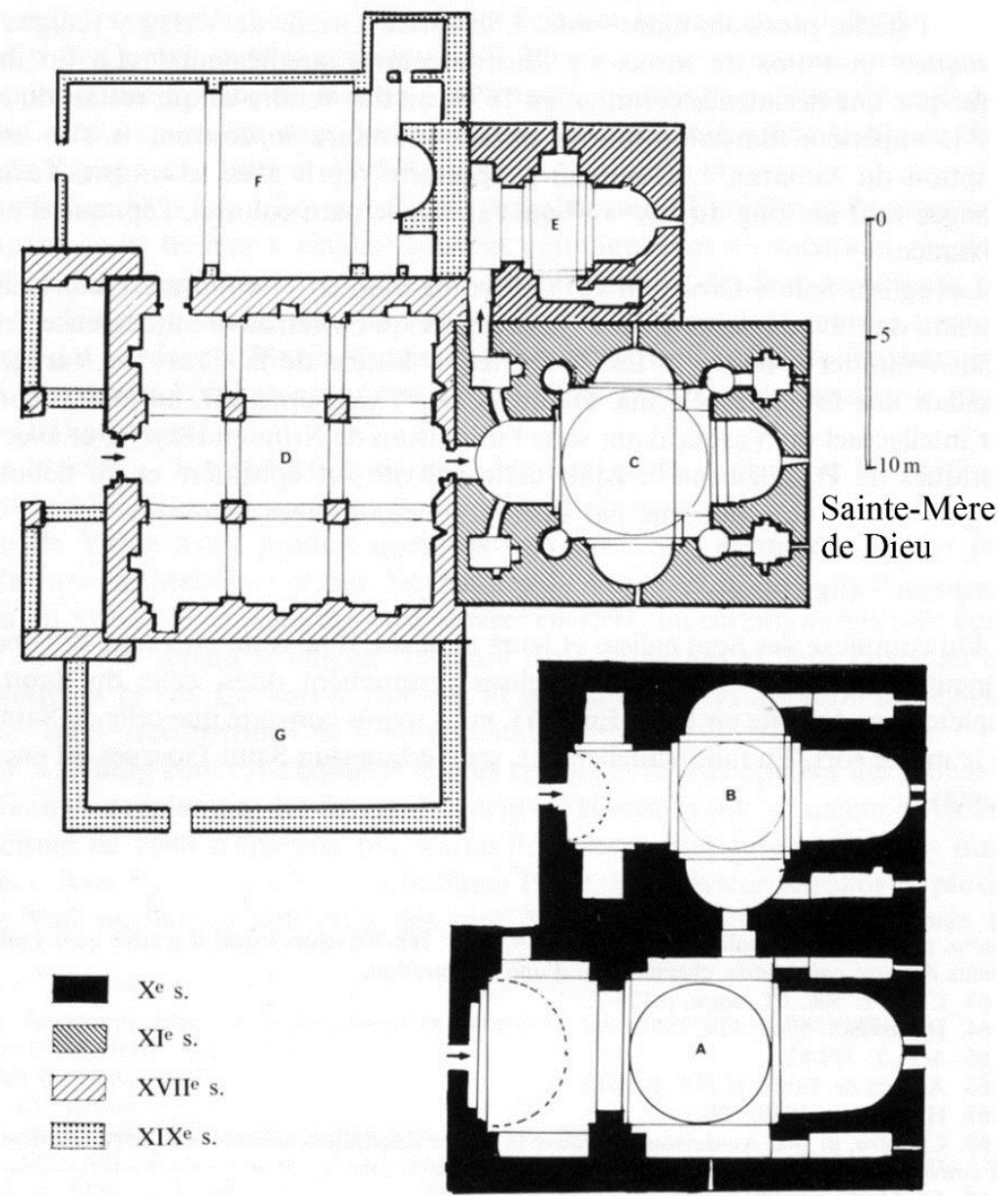

Fig. 4. Varagavank', monastère Sainte-Croix fondé en 981-1003.

Eglise Sainte-Mère de Dieu marquée « $\mathrm{C}$ ».

Plan (Thierry 1989, p. 136, fig. 14). 

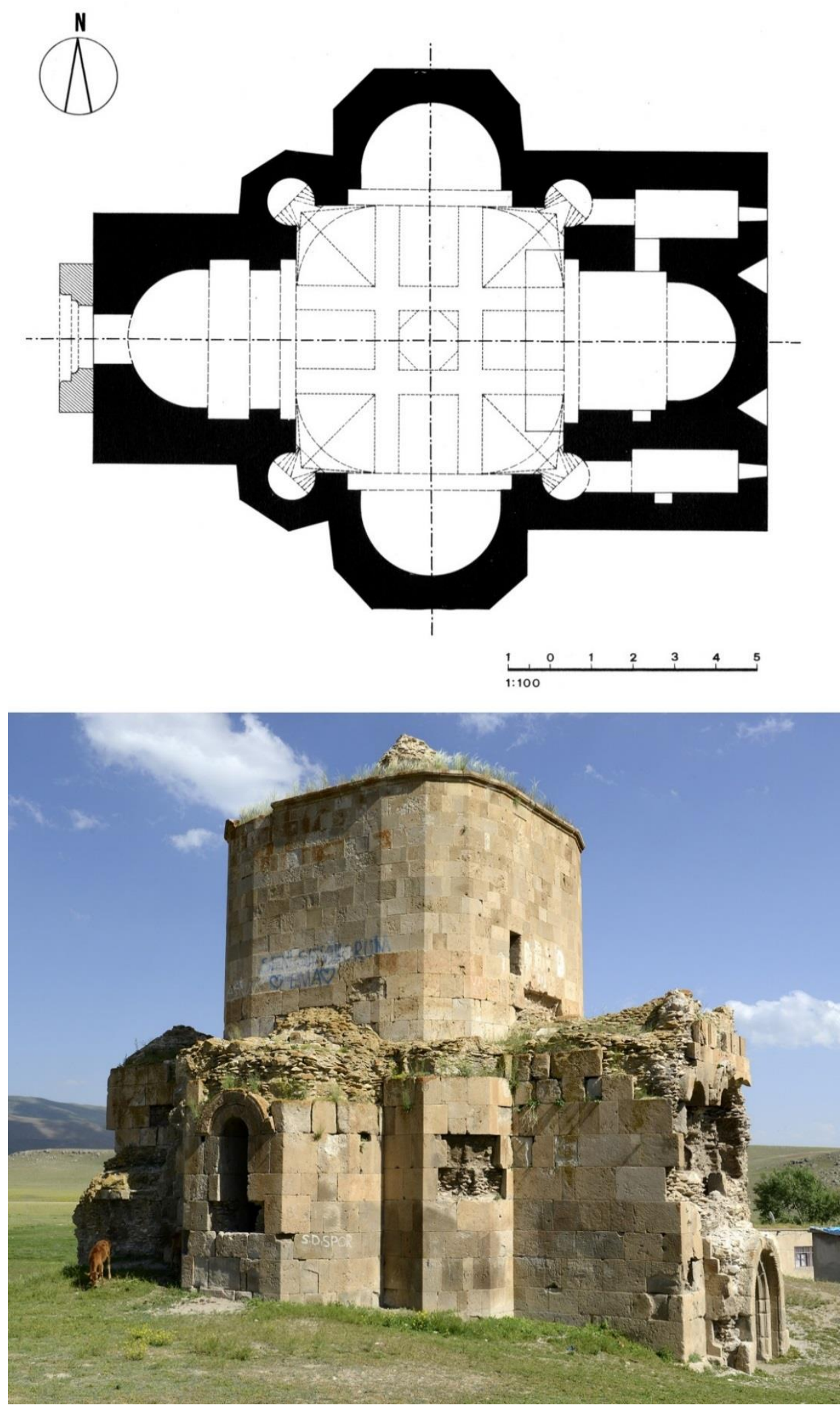

Fig. 5. Ałbak, Sainte-Croix / Soradir, Sainte-Ēj̆miacin (VII ${ }^{\mathrm{e}}$ ou IX ${ }^{\mathrm{e}}$ s.). Plan (Breccia Fratadocchi 1971, fig. 2) et vue générale du NO (photo Hraïr H. Khatcherian). 

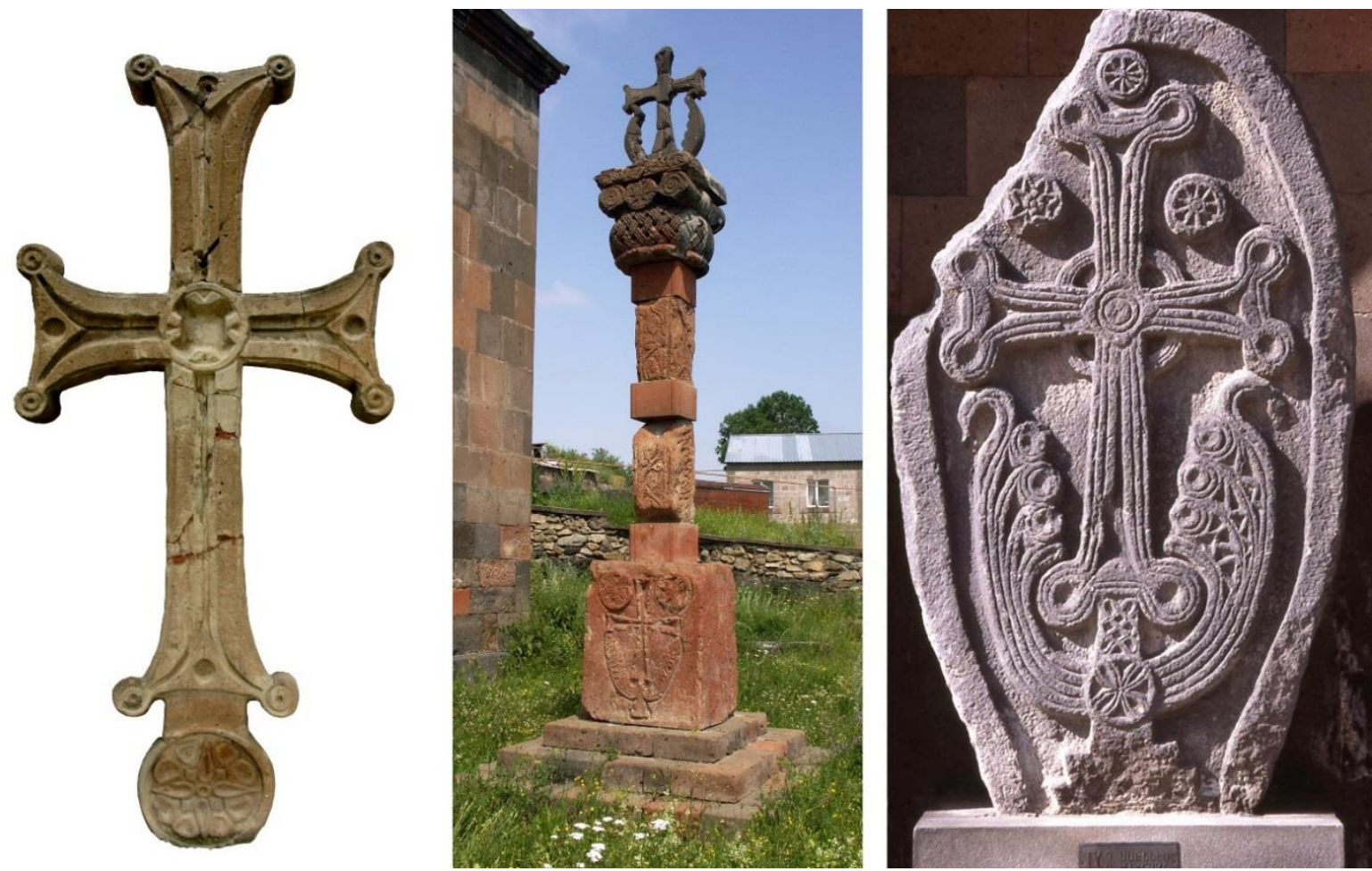

Fig. 6. Croix de pierre et khatchkar.

A) Duin. Croix de pierre isolée (c. VII ${ }^{\mathrm{e}}$ s. ?). Photo Musée d'Histoire d'Arménie.

B) Gogaran. Stèle crucifère reconstituée à partir d'éléments hétérogènes (c. $\mathrm{VI}^{\mathrm{e}}-\mathrm{VII}^{\mathrm{e}} \mathrm{s}$. ?). C) Khatchkar de Mak'enoc' (IX $-\mathrm{X}^{\mathrm{e}} \mathrm{s}$.) aujourd'hui à Ējmiacin.

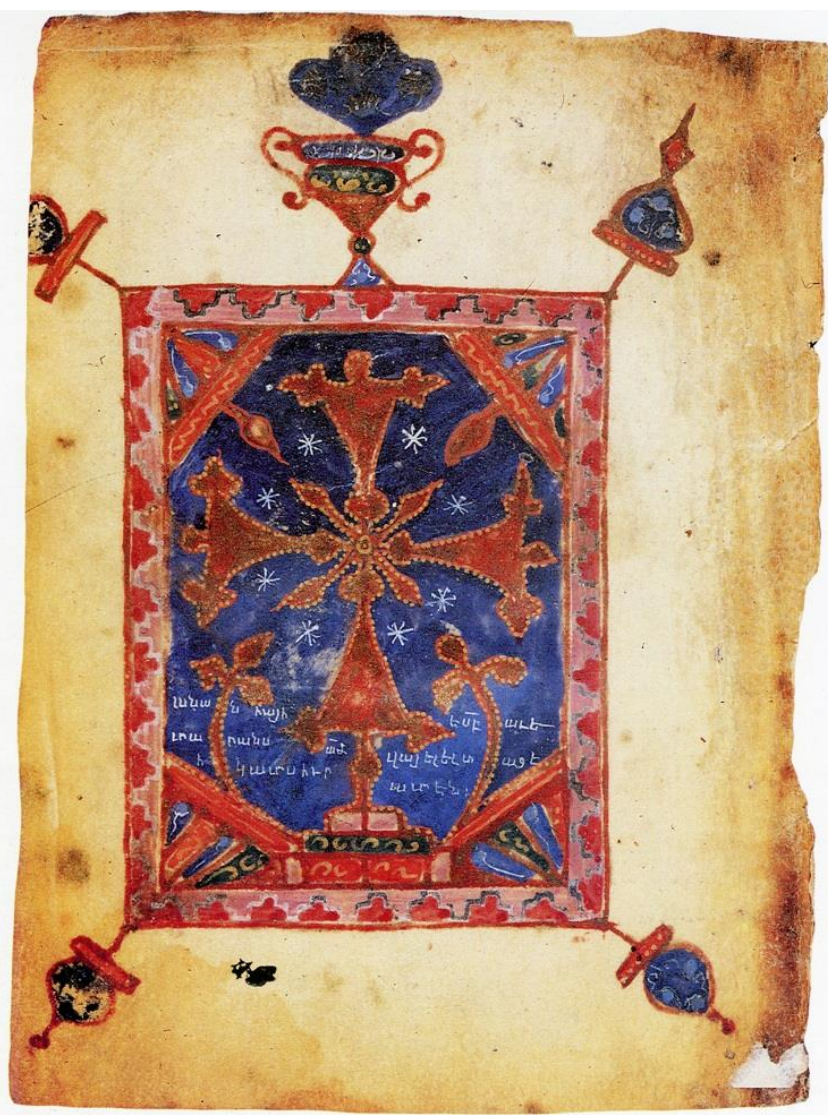

Fig. 7. Evangile copié à Narek en 1069. Matenadaran n 10434, fol. 1v. Photo Matenadaran. 


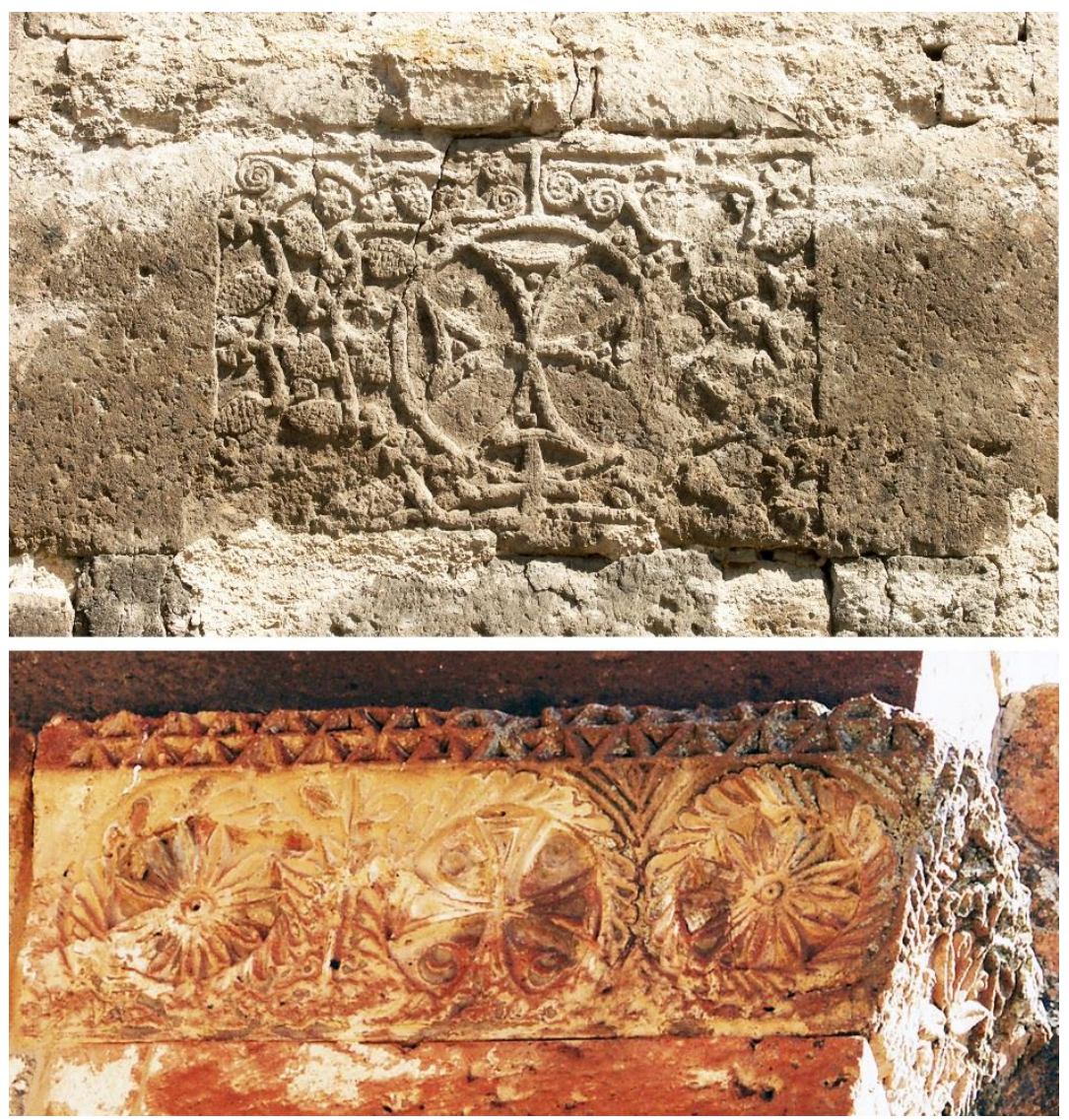

Fig. 8. Croix « de Malte » de l'Arménie paléochrétienne.

A) Aštarak (c. $\mathrm{VI}^{\mathrm{e}} \mathrm{s}$.). Basilique Ciranawor. Linteau de la porte O.

B) Ereruyk' (c. VI s. s. Basilique. Arc triomphal de l'abside principale. Imposte de l'angle SE.

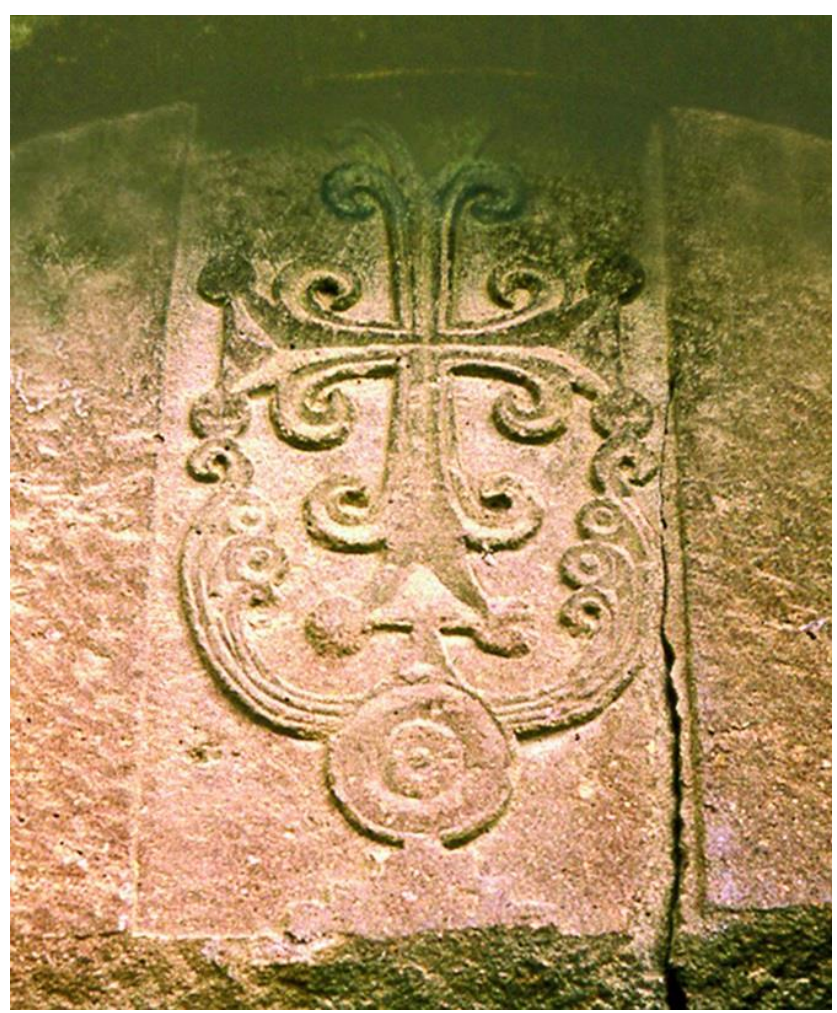

Fig. 9. Oskepar ( $\mathrm{VII}^{\mathrm{e}}$ s.). Linteau de la porte S. 


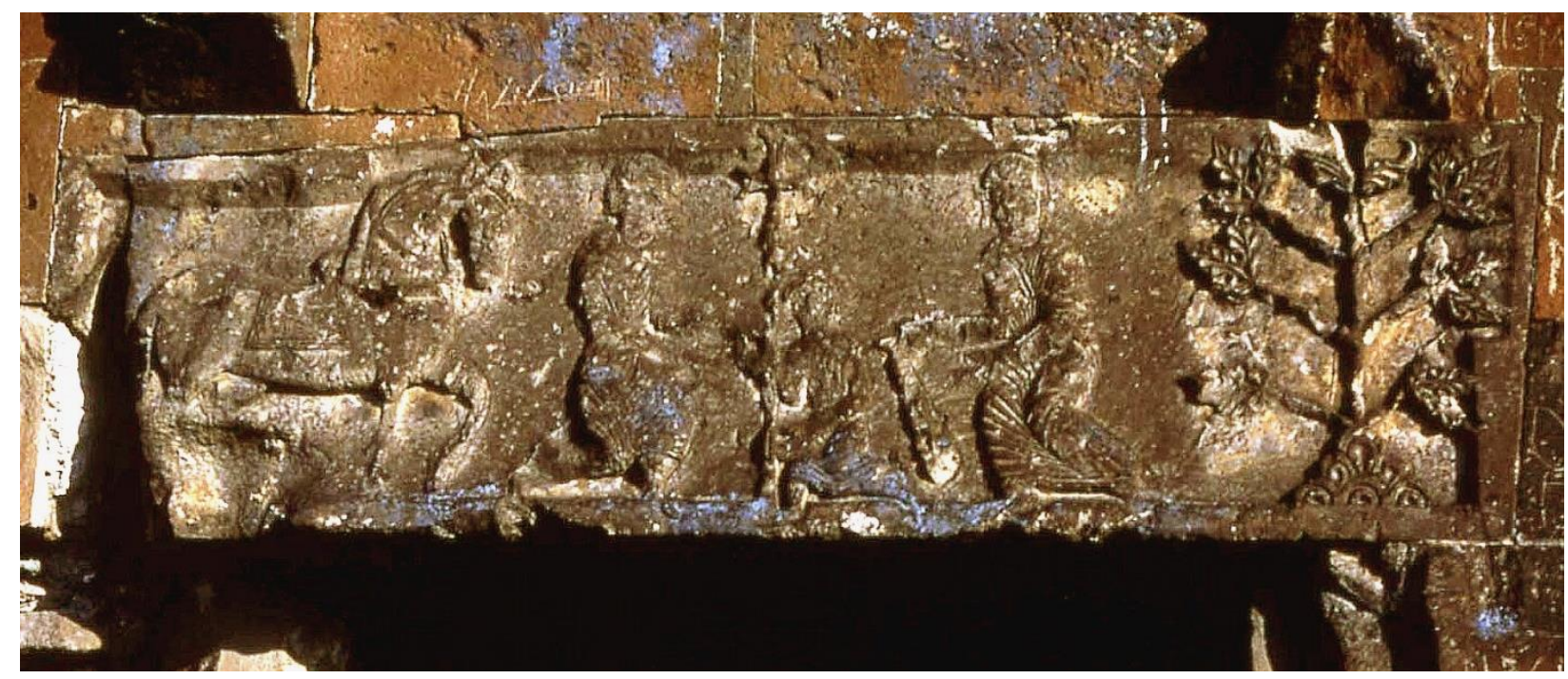

Fig. 10. Mren (années 630). Linteau de la porte N. Photo Zaven Sargsyan.

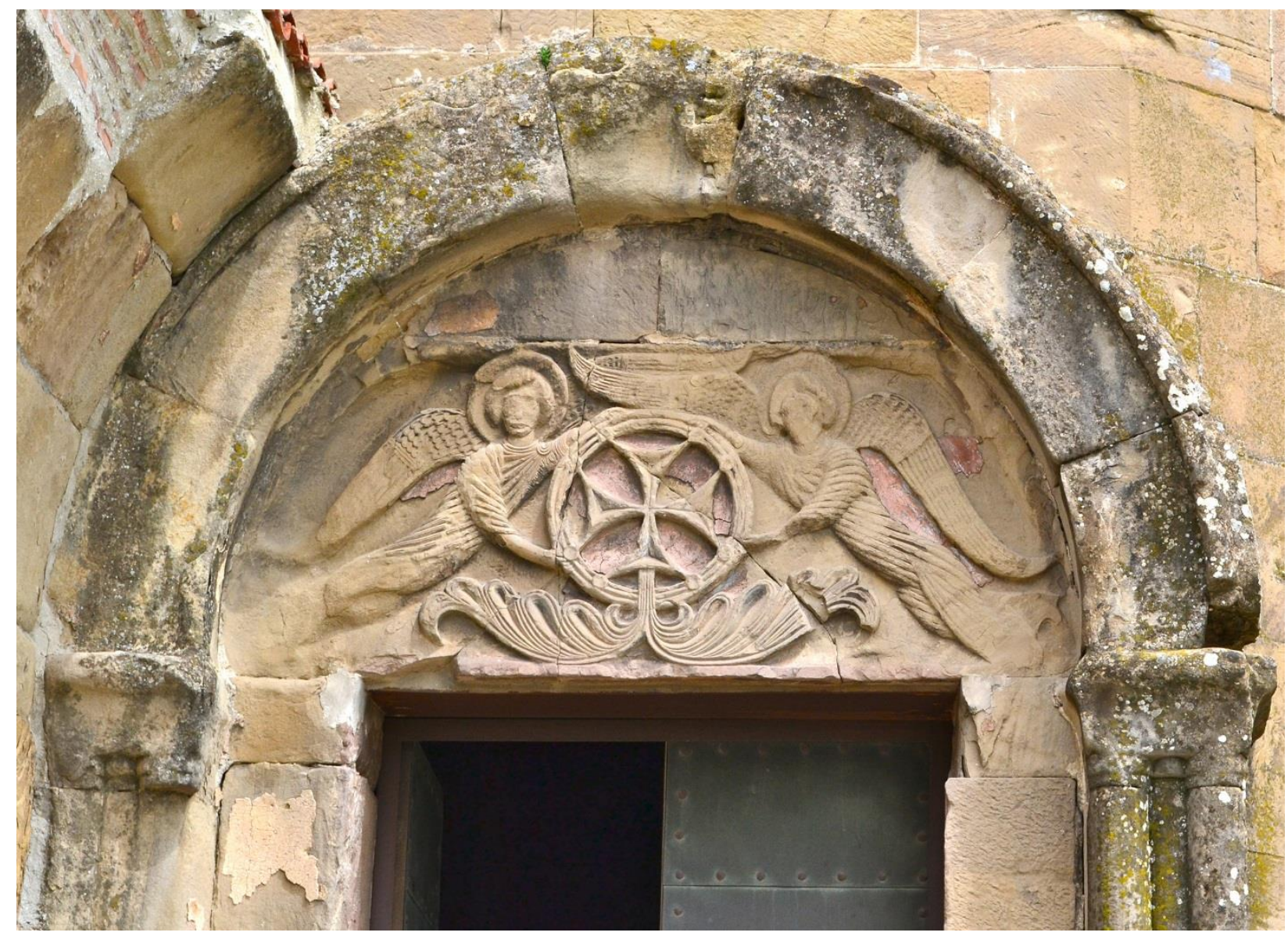

Fig. 11. J̌vari, Sainte-Croix (Ibérie - années 590-640). Tympan de la porte S. 


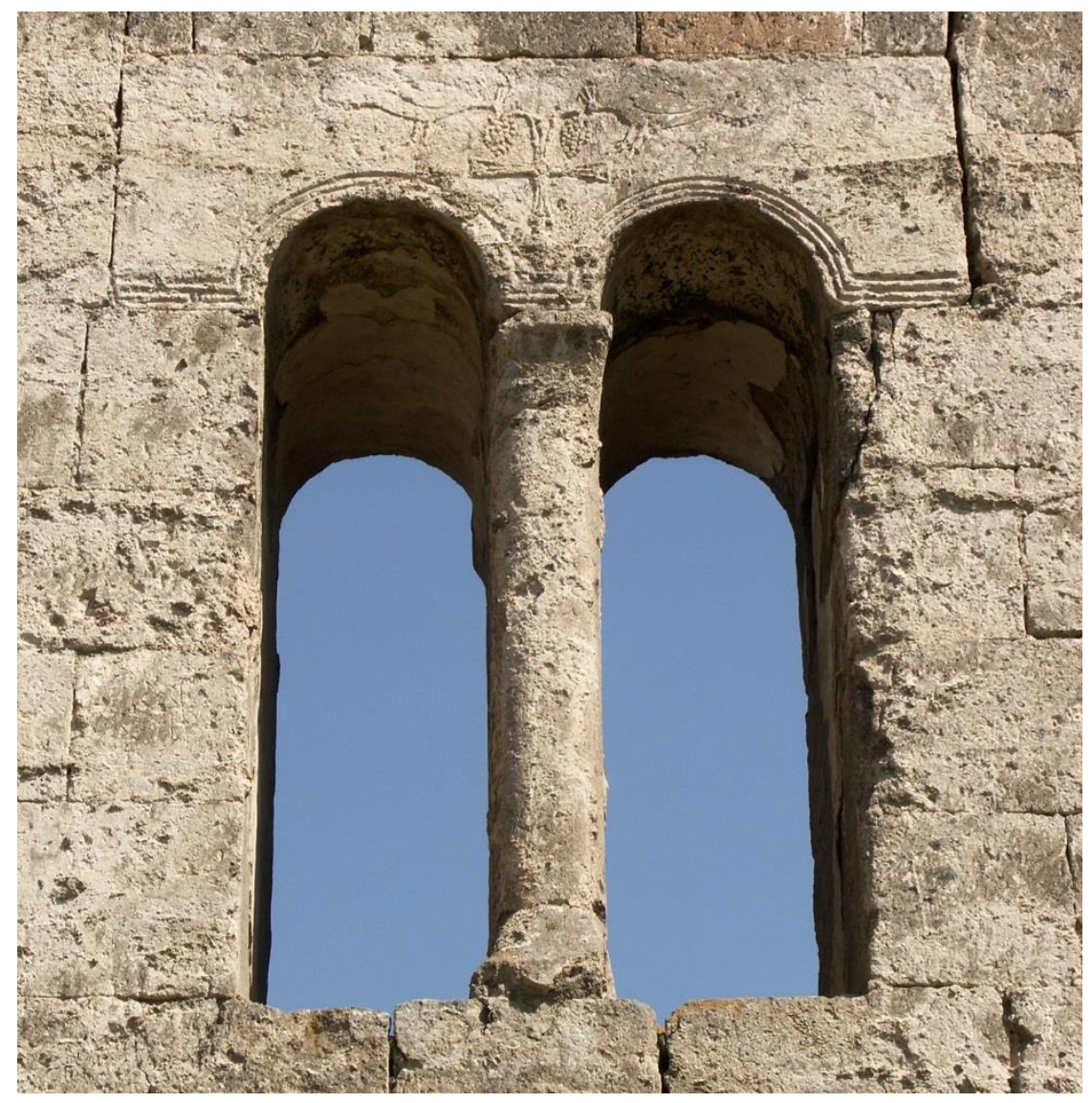

Fig. 12. Aštarak. Basilique Ciranawor (c. $\mathrm{VI}^{\mathrm{e}}$ s.). Fenêtre double de la façade O.

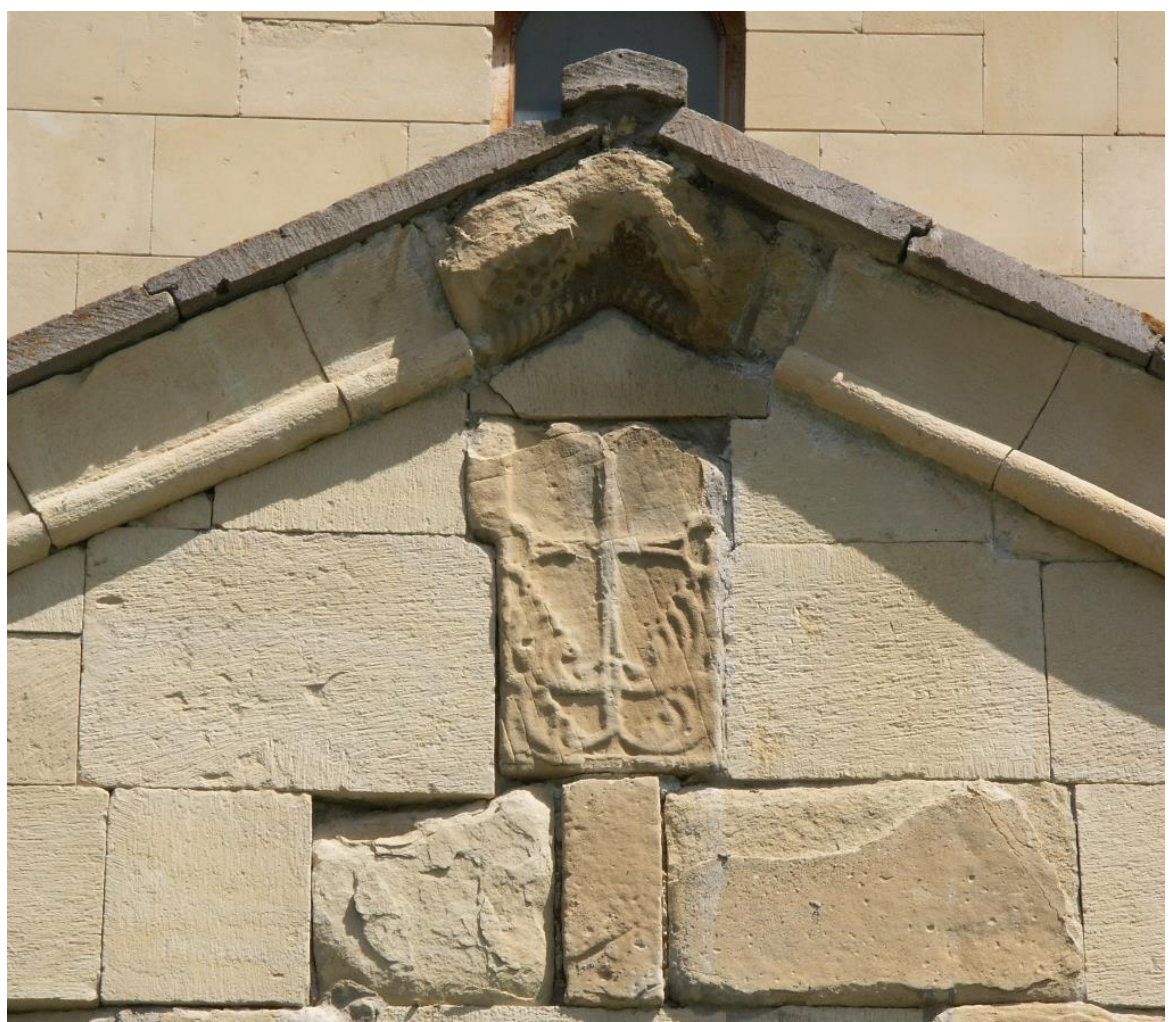

Fig. 13. C'romi (Ibérie - c. années 640). Façade S. Pignon. 

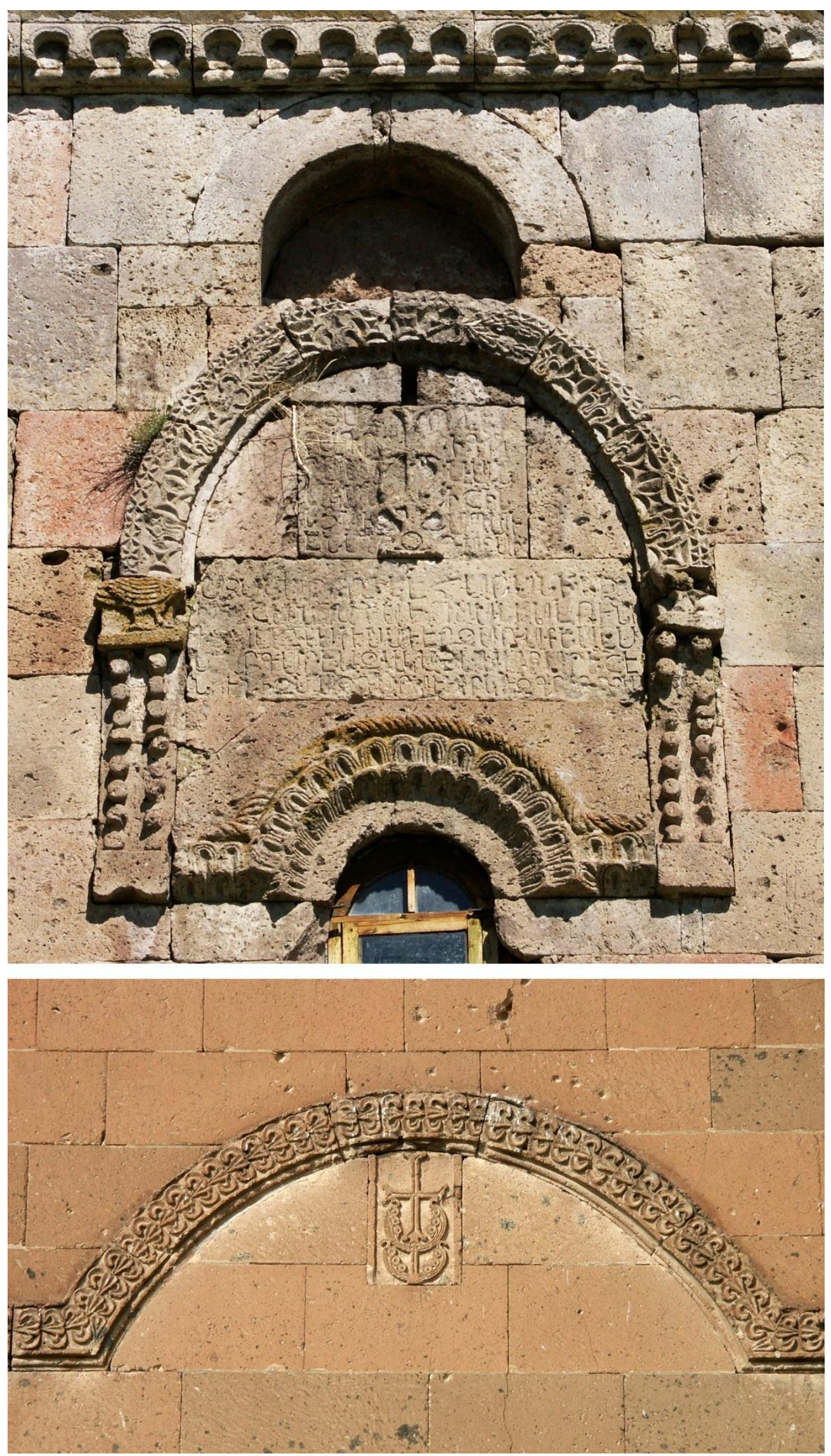

Fig. 14.

A) Mastara, Saint-Jean (années 640). Façade O. B) Aruč (années 660). Centre de la façade E. 


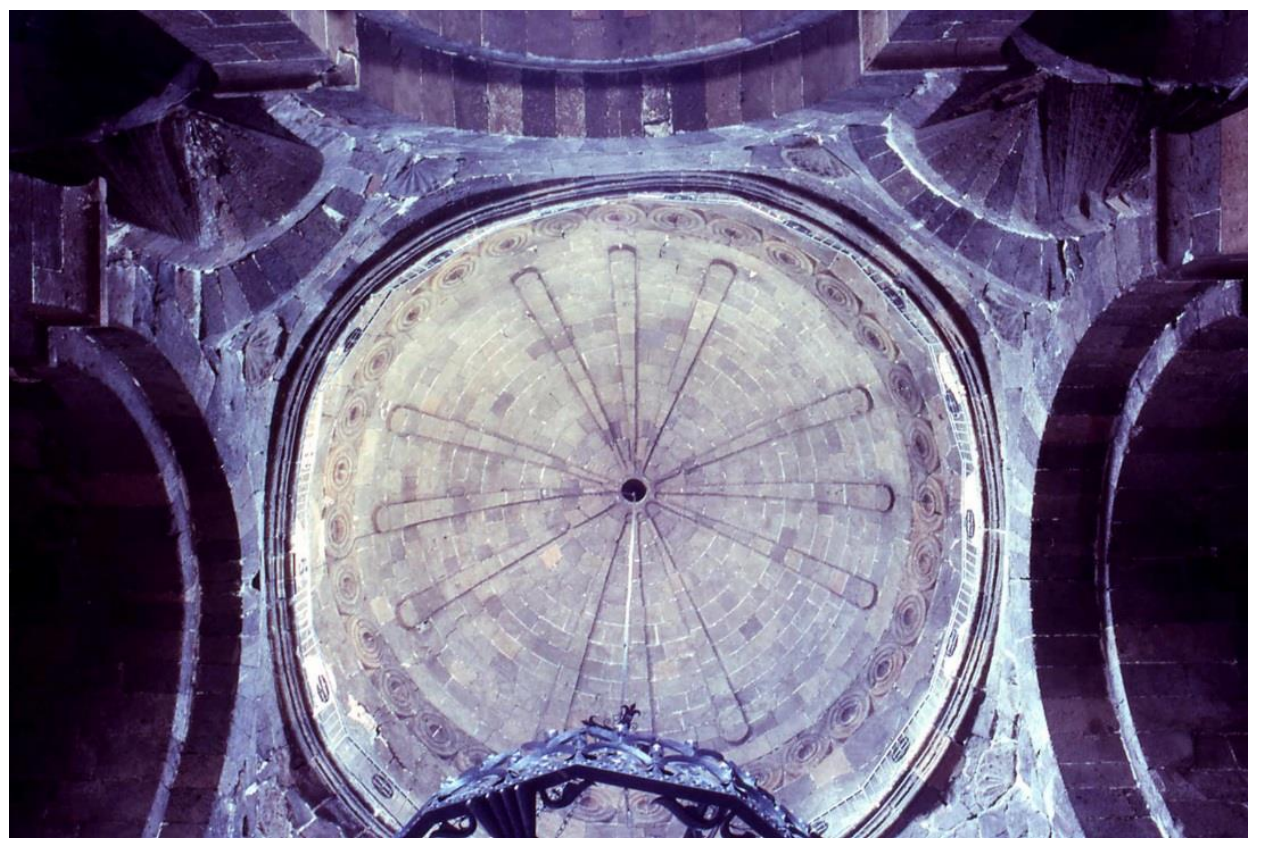

Fig. 15. Vałaršapat, Ste-Hr̈ip‘simē (617-années 620). Vue intérieure zénithale de la coupole.

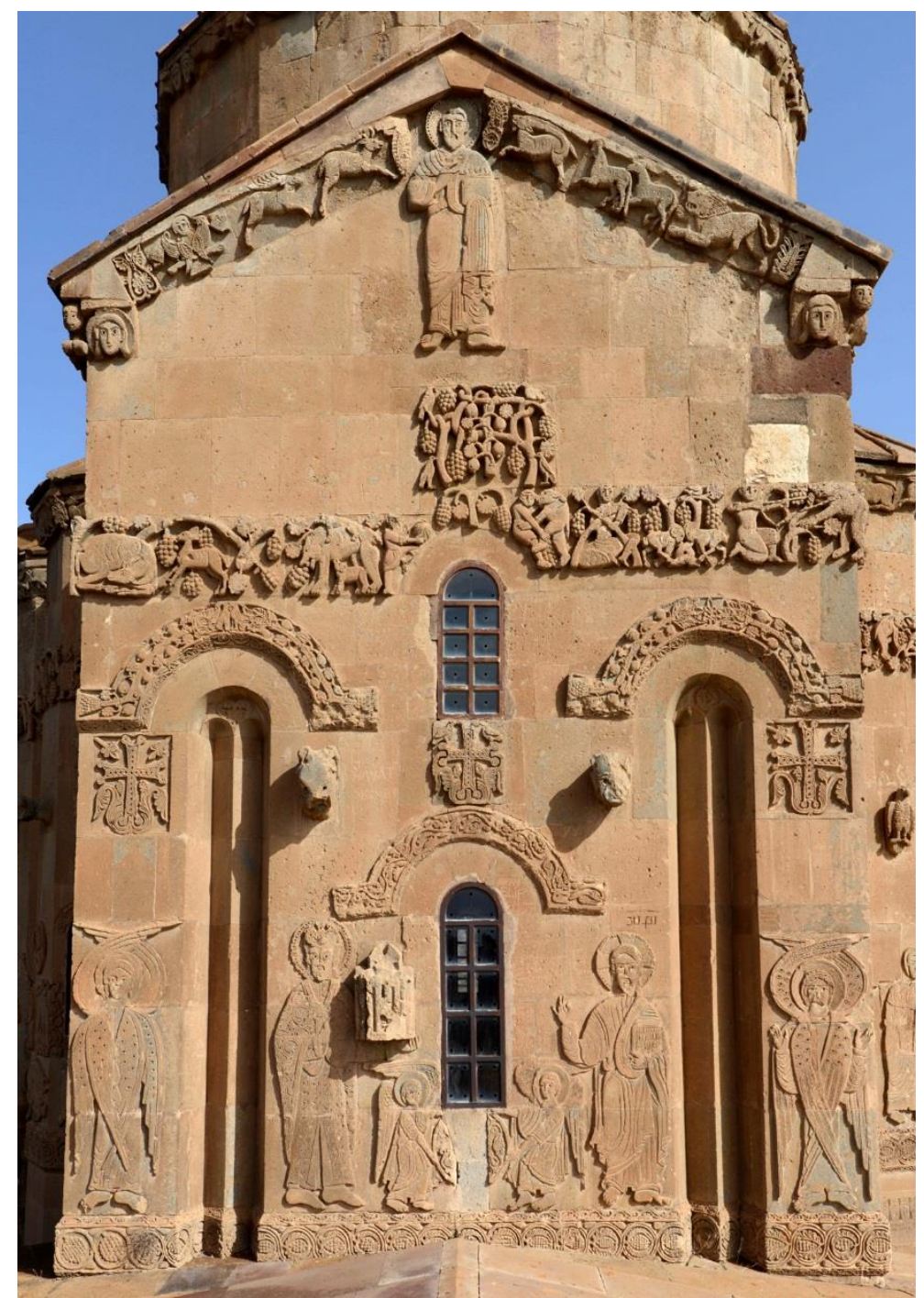

Fig. 16. Ałt‘amar, Sainte-Croix (915-921). Façade O. Photo Hraïr H. Khatcherian. 

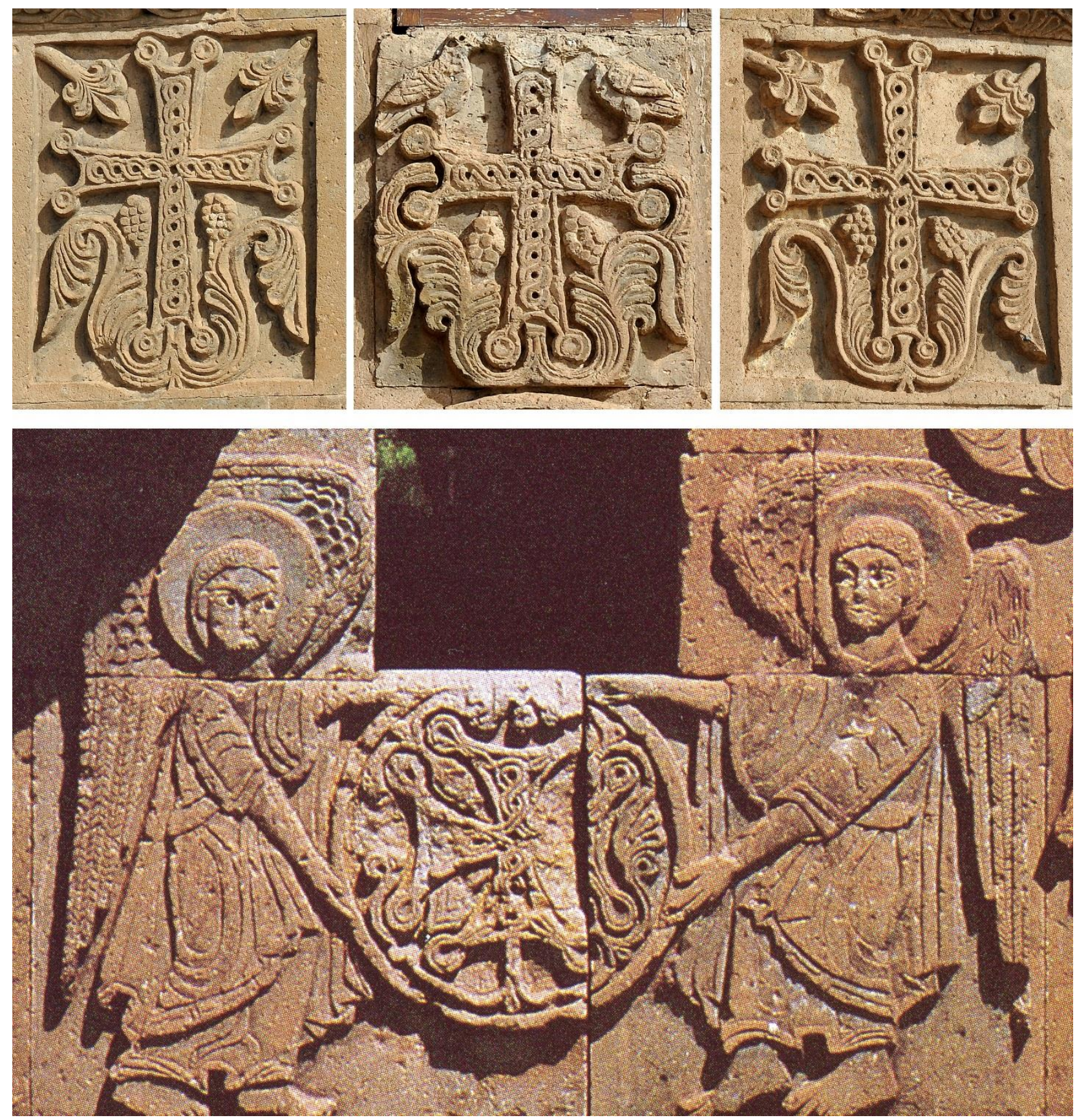

Fig. 17. Ałt'amar, Sainte-Croix. Façade O.

A) Les trois croix sous la fenêtre supérieure. Photo Hraïr H. Khatcherian.

B) La croix sous la fenêtre inférieure. Photo Rainer Laipinen (1985). 

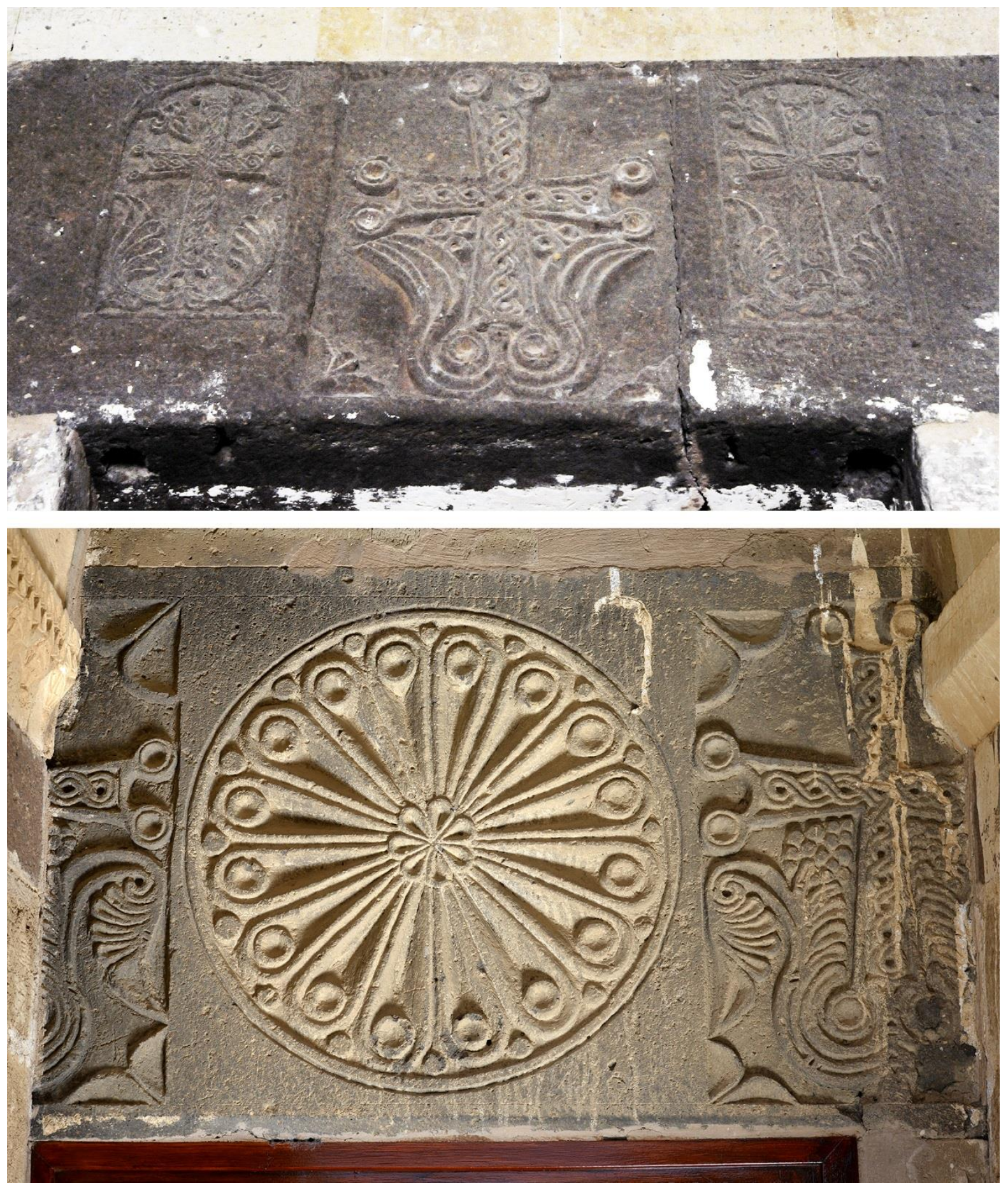

Fig. 18. Ałt'amar, Sainte-Croix, linteaux.

A) Linteau de la porte O. Photo Zaven Sargsyan.

B) Linteau de la porte S. Photo Hraïr H. Khatcherian. 


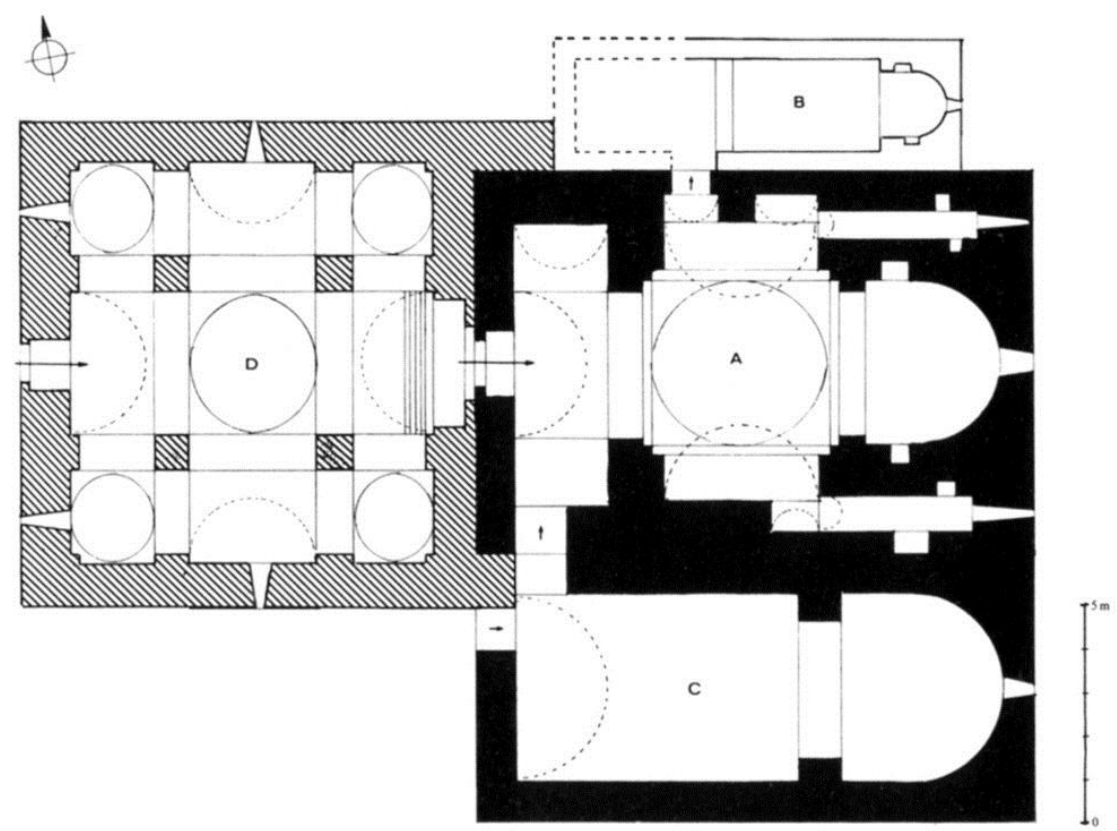

Fig. 19. Aparank', Sainte-Mère de Dieu (édifice central marqué «A»-983). Plan (Thierry 1989, 430, fig. 133).
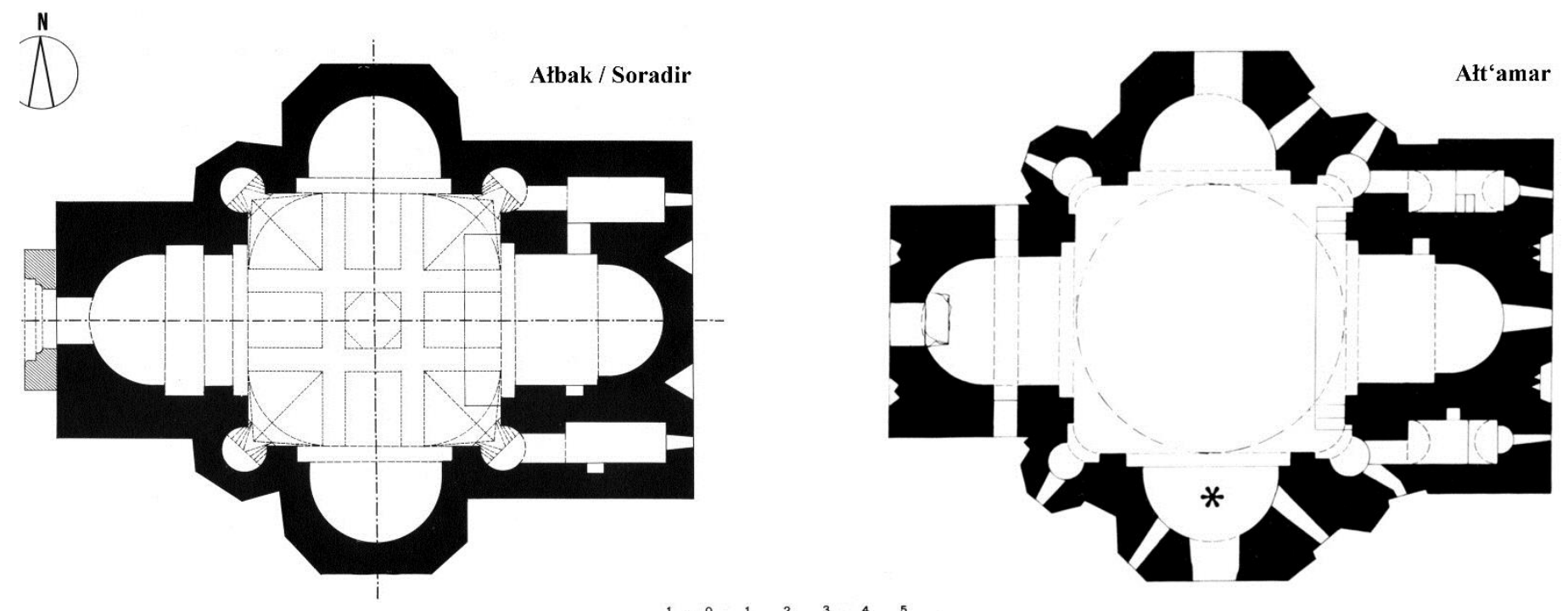

Fig. 20. Ałbak et Ałt'amar. Plans.

A) Ałbak-Soradir (Breccia Fratadocchi 1971, fig. 2).

B) Att'amar (Der Nersessian et Vahramian 1974, 103). $\mathrm{Nb}$. L'astérisque indique la présence de la loge royale. 


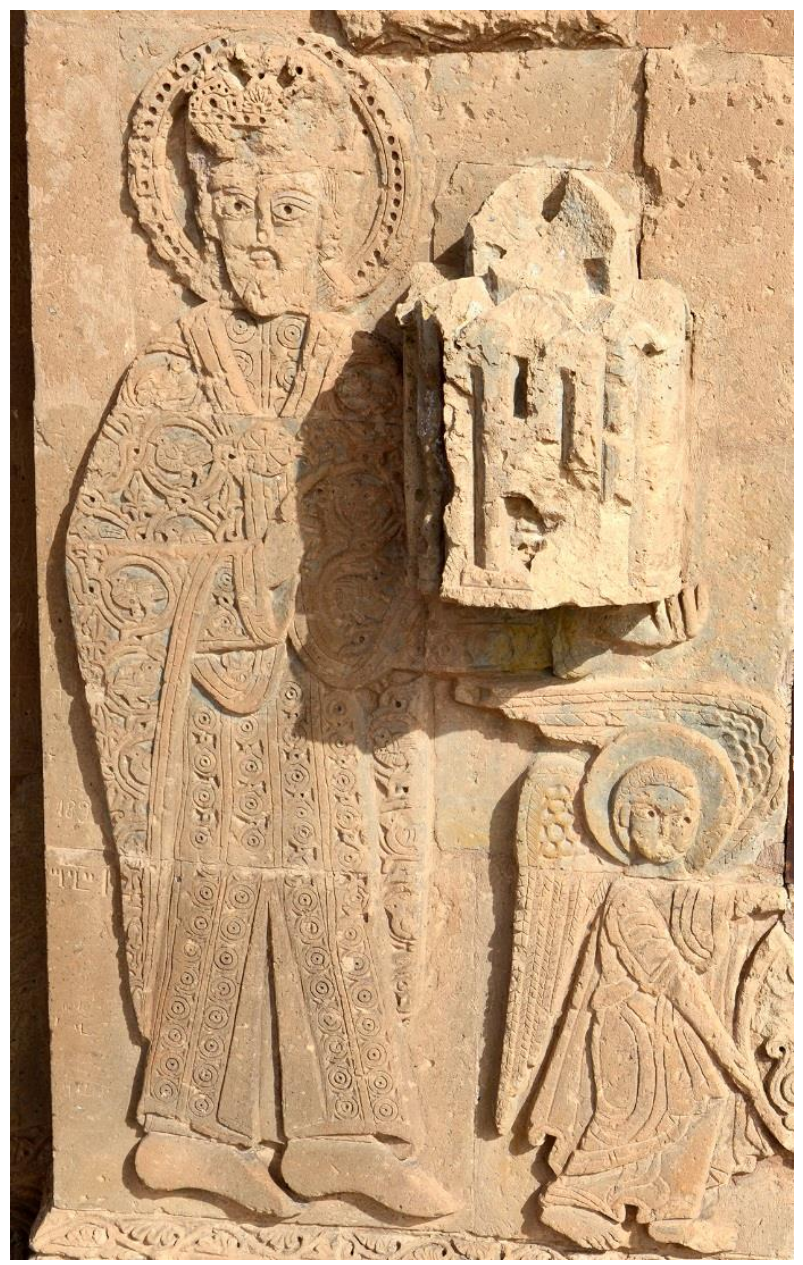

Fig. 21. Att'amar, Sainte-Croix (915-921). Façade O.

Le roi Gagik portant le modèle de l'église. Photo Hraïr H. Khatcherian.
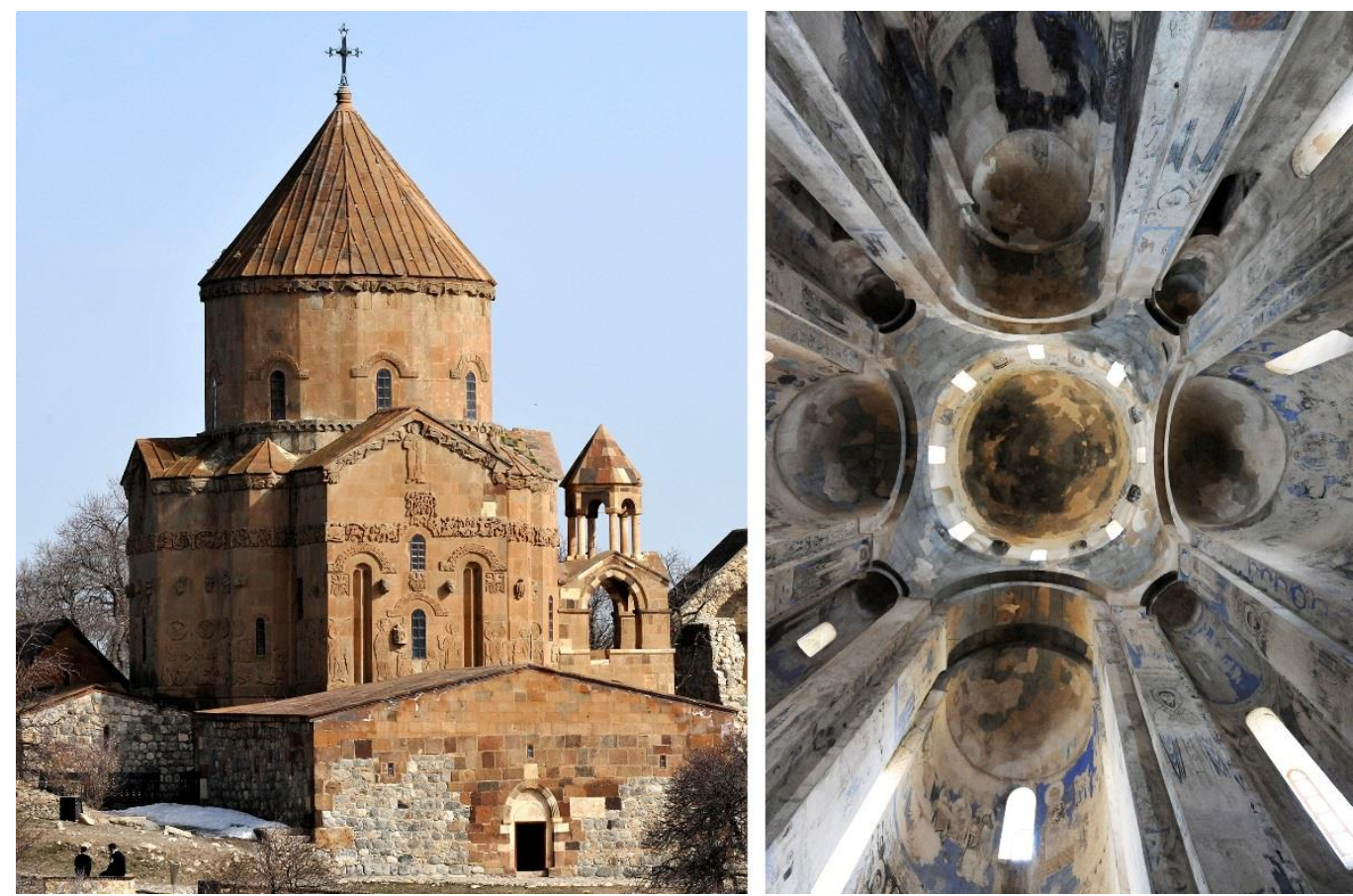

Fig. 22. Ałt'amar, Ste-Croix. A) Vue générale NO. Photo Hraïr H. Khatcherian. B) Vue zénithale intérieure. Photo Zaven Sargsyan. 


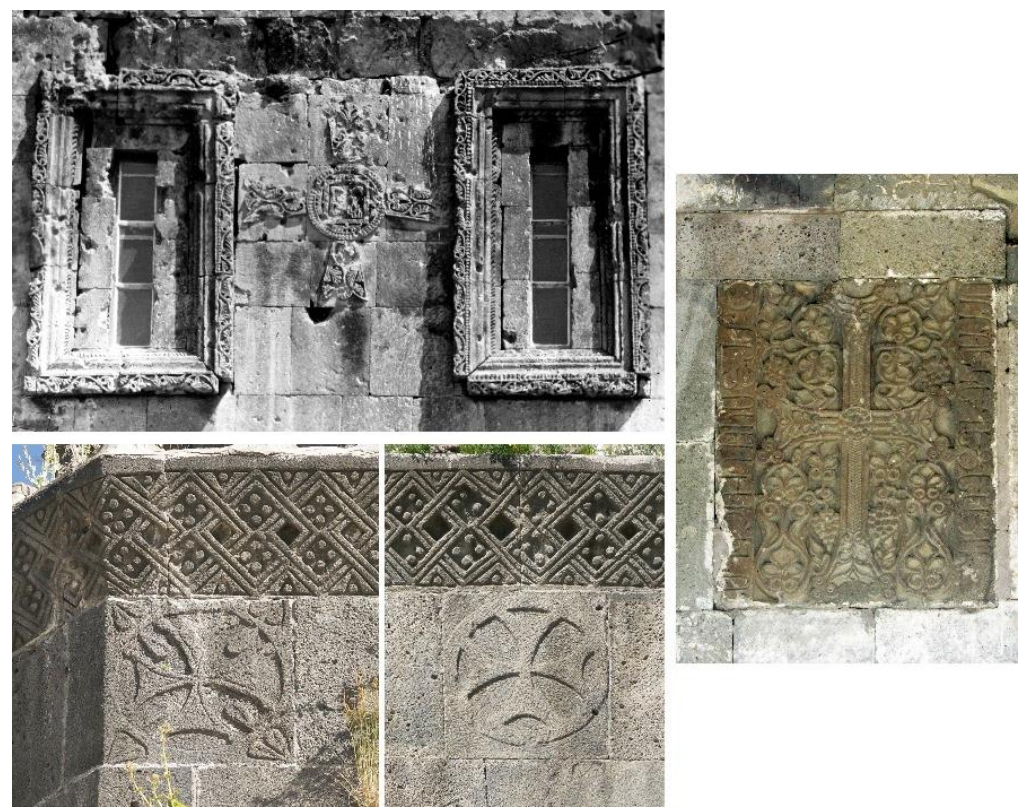

Fig. 23. Autres croix de la fin du IX $\mathrm{e}^{\mathrm{e}}-$ début du $\mathrm{X}^{\mathrm{e}} \mathrm{s}$.

A) Širakawan (fin IX ${ }^{\mathrm{e}}$ s.). Centre de la façade S. Archives Musée d'Histoire d'Arménie.

B) Kars, Saints-Apôtres (c. 930-943). Croix sous la corniche.

C) Tat'ew, Saints-Pierre et Paul (895-906). Plaque à croix sur la façade O.

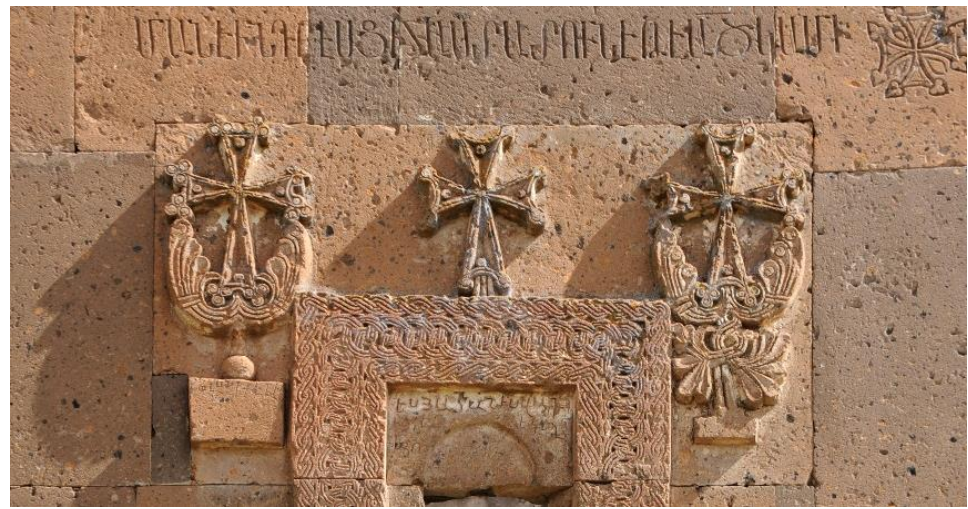

Fig. 24. Horomos, Saint-Georges (début du XI s. s.). Façade O. Photo Armen Kazarian.
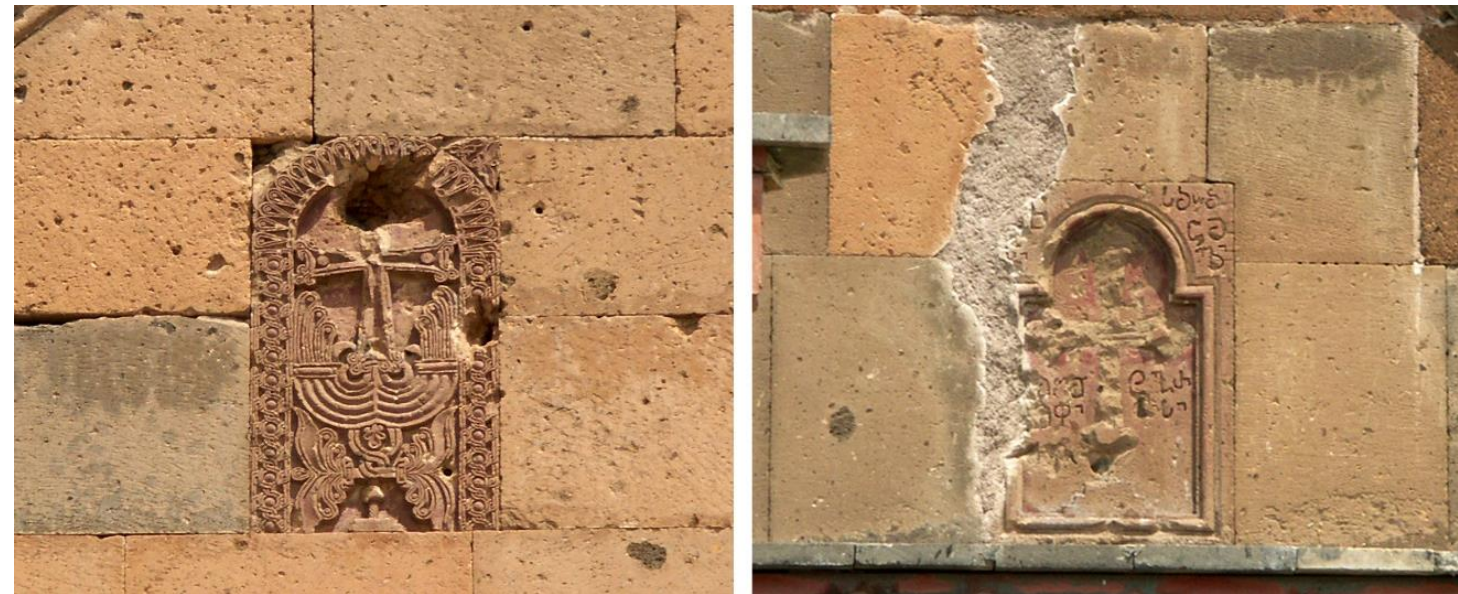

Fig. 25. Ani.

A) Cathédrale (989-1001). Pignon de la façade O. B) St-Grégoire de Tigran Honenc' (1215). Pignon O. $X a c^{\prime} k$ 'ar contemporain de la cathédrale. Plaque à croix (contemporaine de l'église ?). 

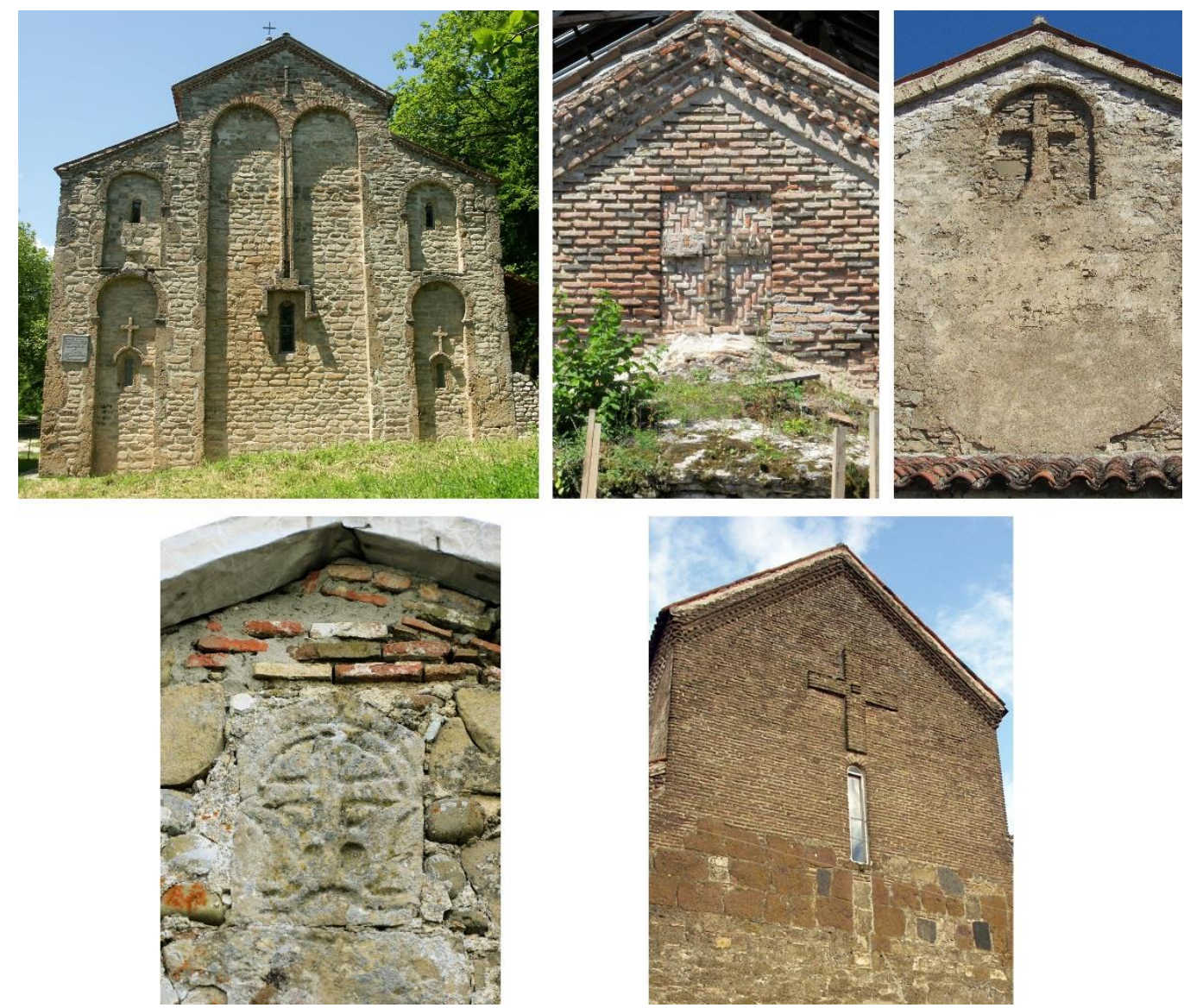

Fig. 26. Géorgie, $\mathrm{VIII}^{\mathrm{e}}-\mathrm{X}^{\mathrm{e}}$ siècle.

A) Gurjaani, façade E. B) Sanagire, façade E. C) Nekresi, basilique à trois salles, façade O.

D) Zedazeni, façade E. E) Urbnisi, façade O. [même croix à la faç. E.].
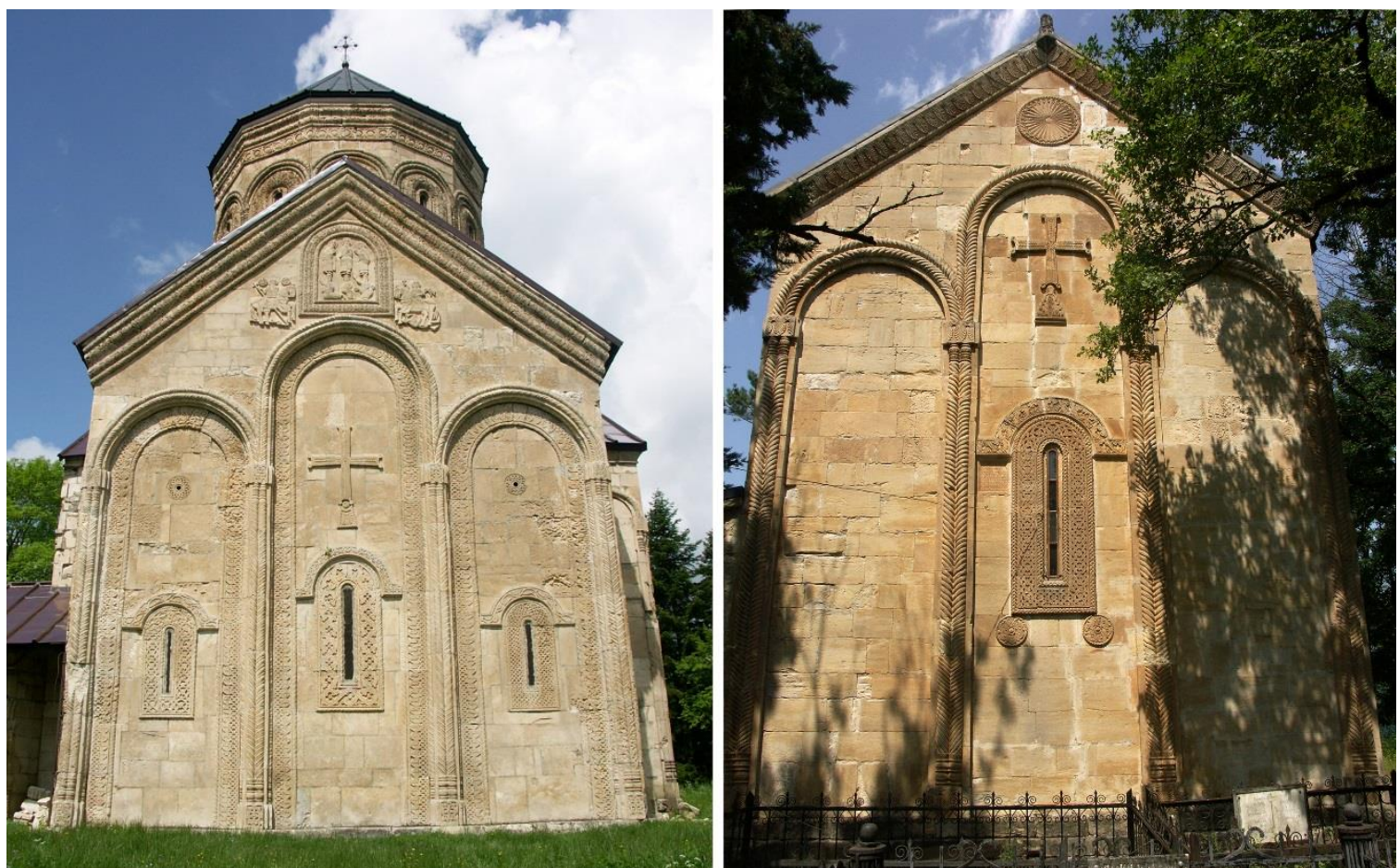

Fig. 27. Géorgie, $\mathrm{XI}^{\mathrm{e}}$ siècle.
A) Nikorc'minda (1014), façade E.
B) Savane (1046), façade E. 


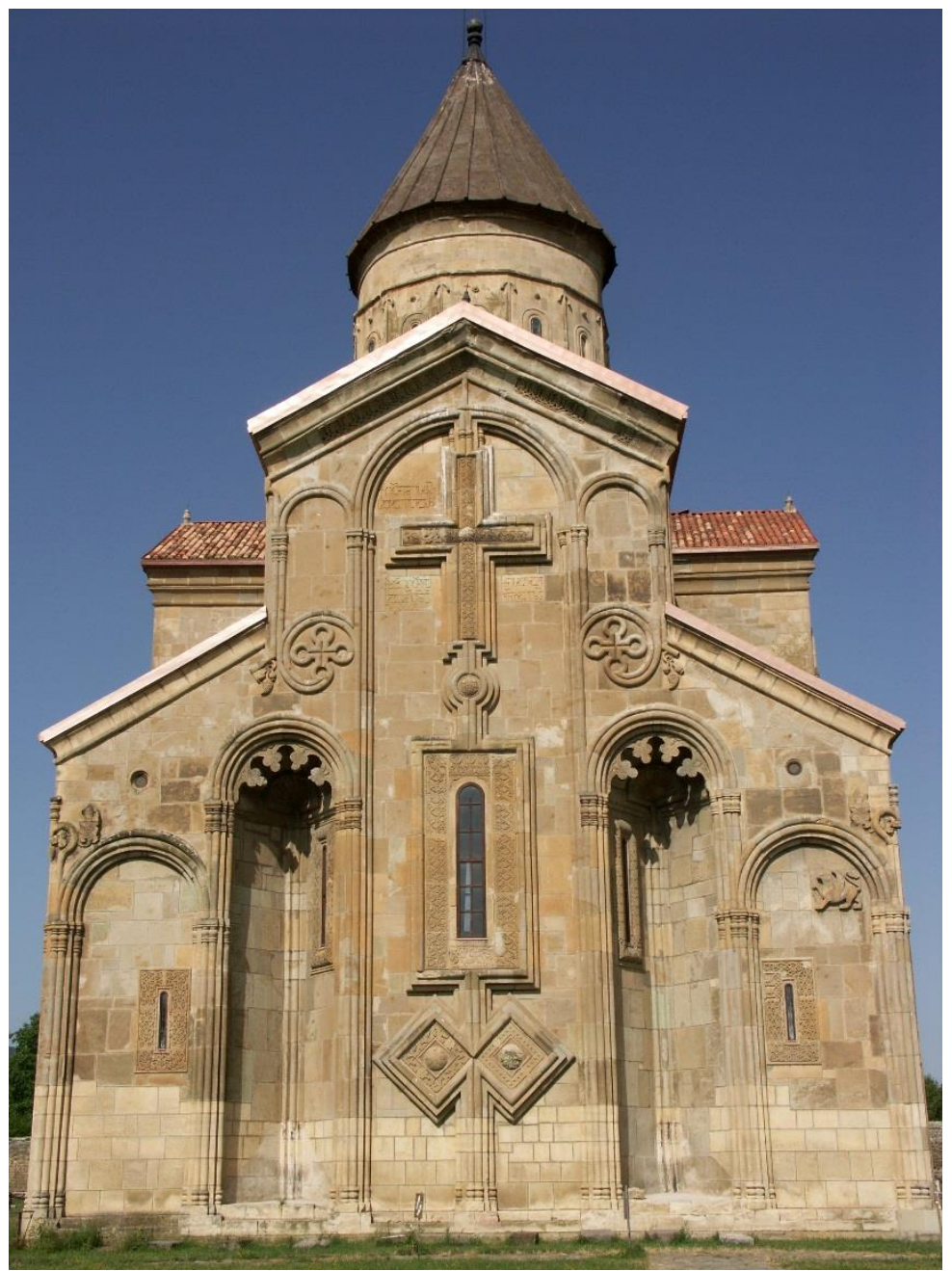

Fig. 28. Samtavisi (Géorgie - 1030). Façade E.
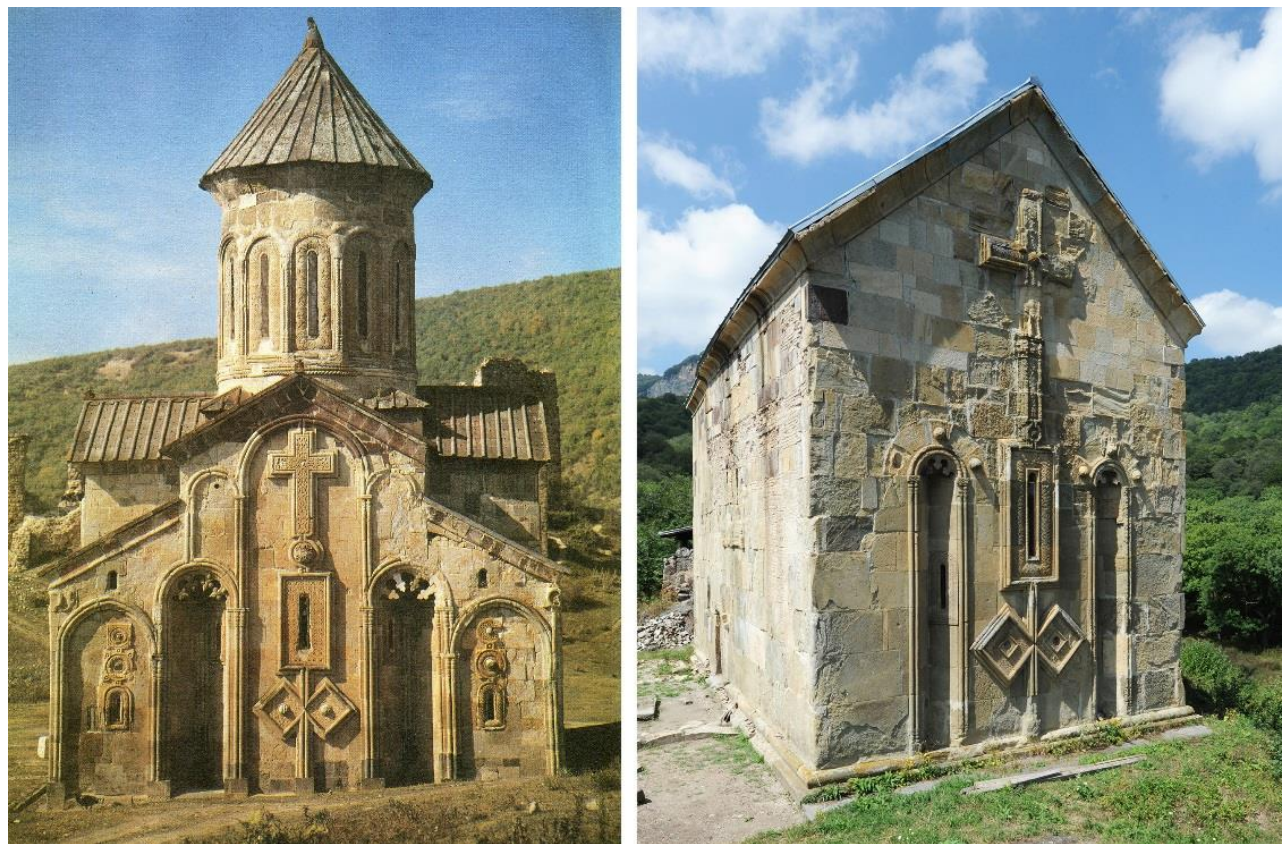

Fig. 29. Géorgie, façades orientales, XII ${ }^{\mathrm{e}}$-début XIII ${ }^{\mathrm{e}}$ siècle.

A) Ik’orta (1172). Photo Džanberidze et Cicišvili 1996, 244.

B) Gudarexi (début XIII ${ }^{\mathrm{e}}$ s.). Photo Ch. et J.-Cl. Hotellier. 

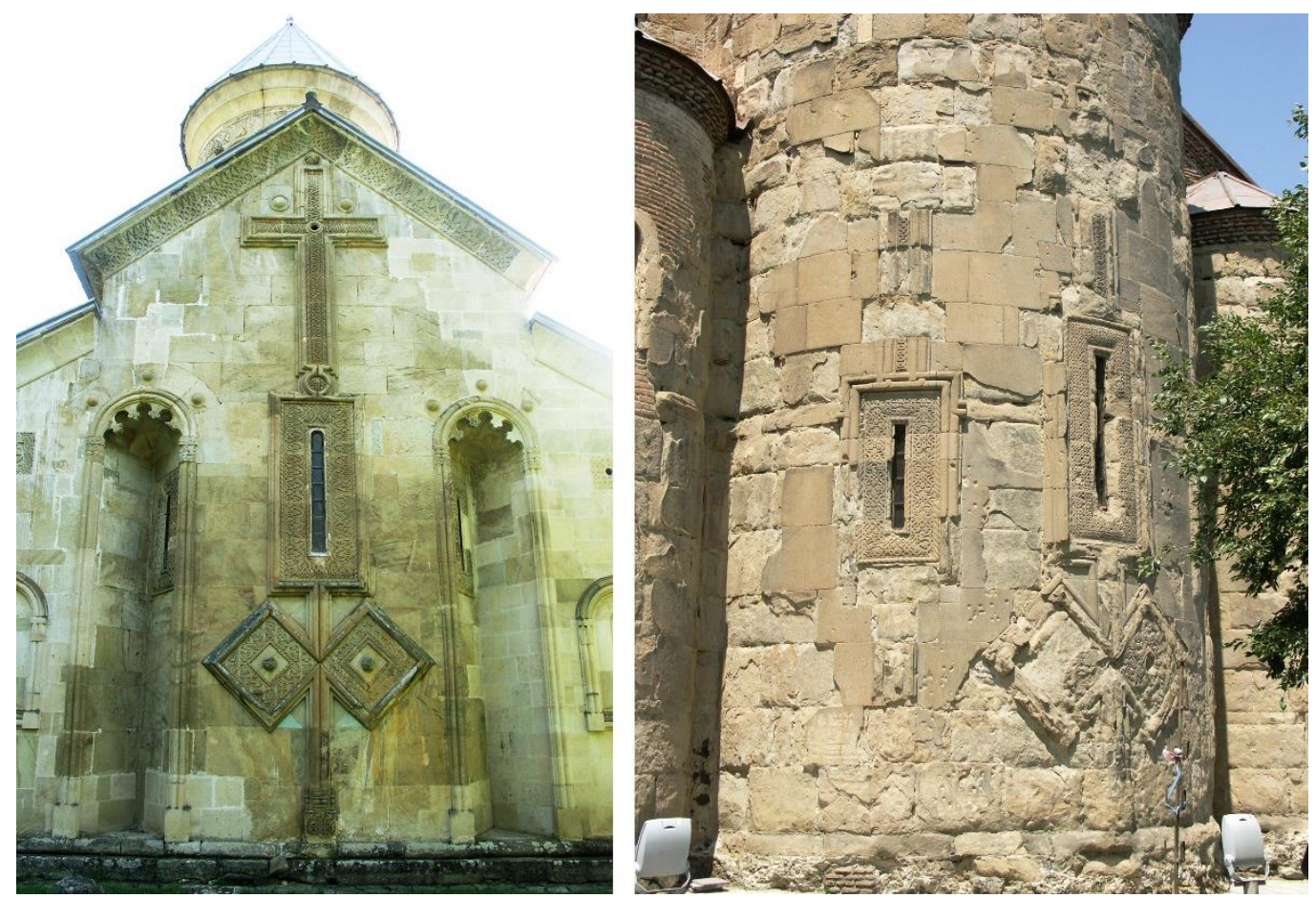

Fig. 30. Géorgie, façades orientales, XIII ${ }^{\mathrm{e}}$ siècle.

A) Kvataxevi (début XIII ${ }^{\mathrm{e}} \mathrm{s}$.).

B) Metexi (Tbilisi, 1272-1289).
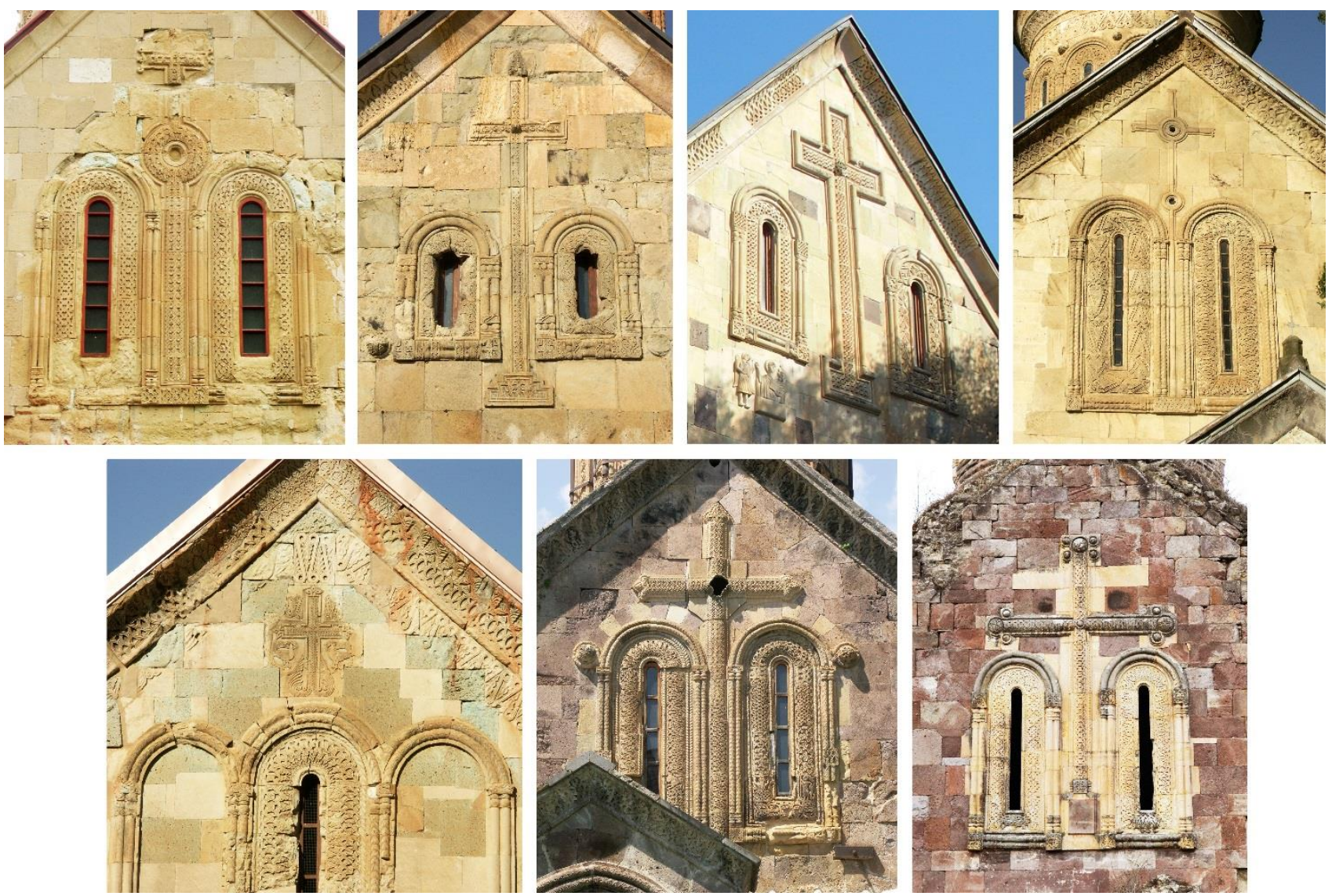

Fig. 31. Géorgie, façades autres qu'orientale, fin XII ${ }^{\mathrm{e}}$ - début XIII ${ }^{\mathrm{e}}$ siècle.

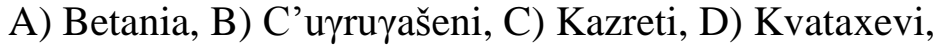

E) Mayalaant ek'lesia, F) Pit'areti ; G) Xučap (Arménie). 


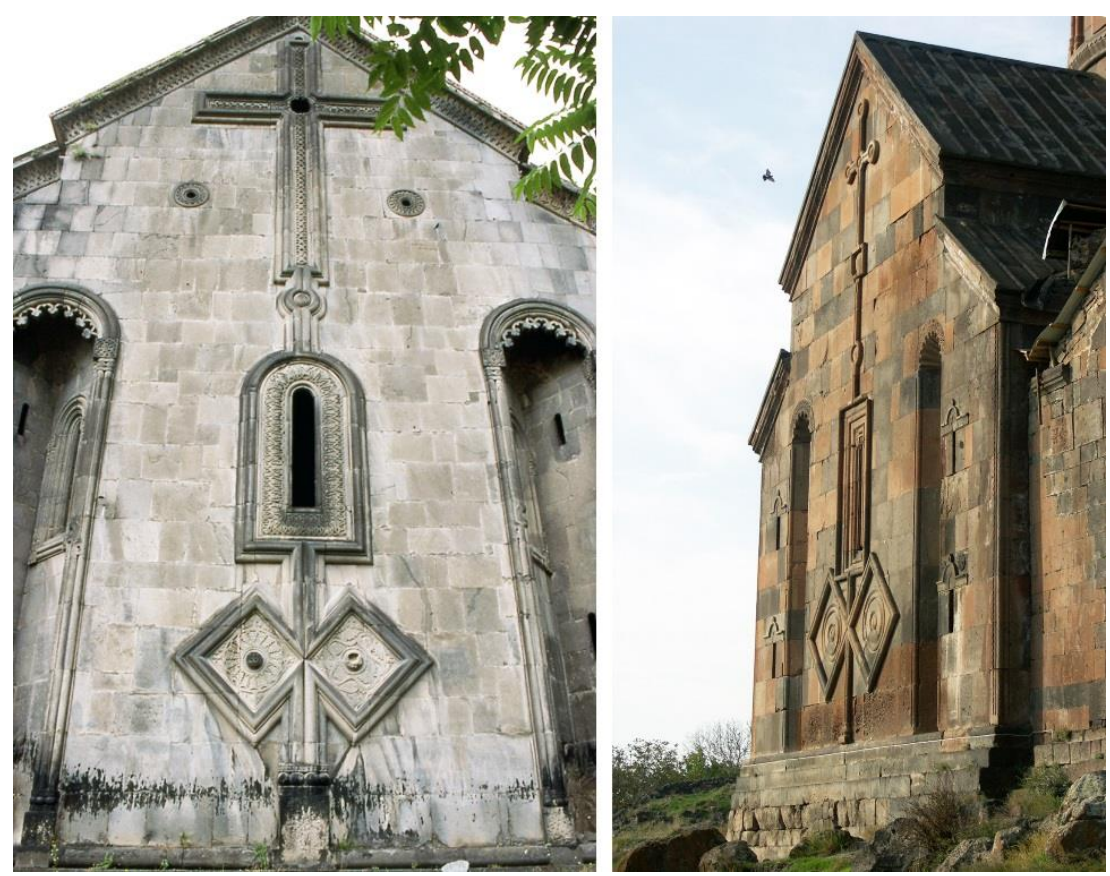

Fig. 32. Arménie, façades orientales, début du XIII siècle.
A) Płnjahank'/Axt'ala.
B) Yovhannavank' (1216-1221).
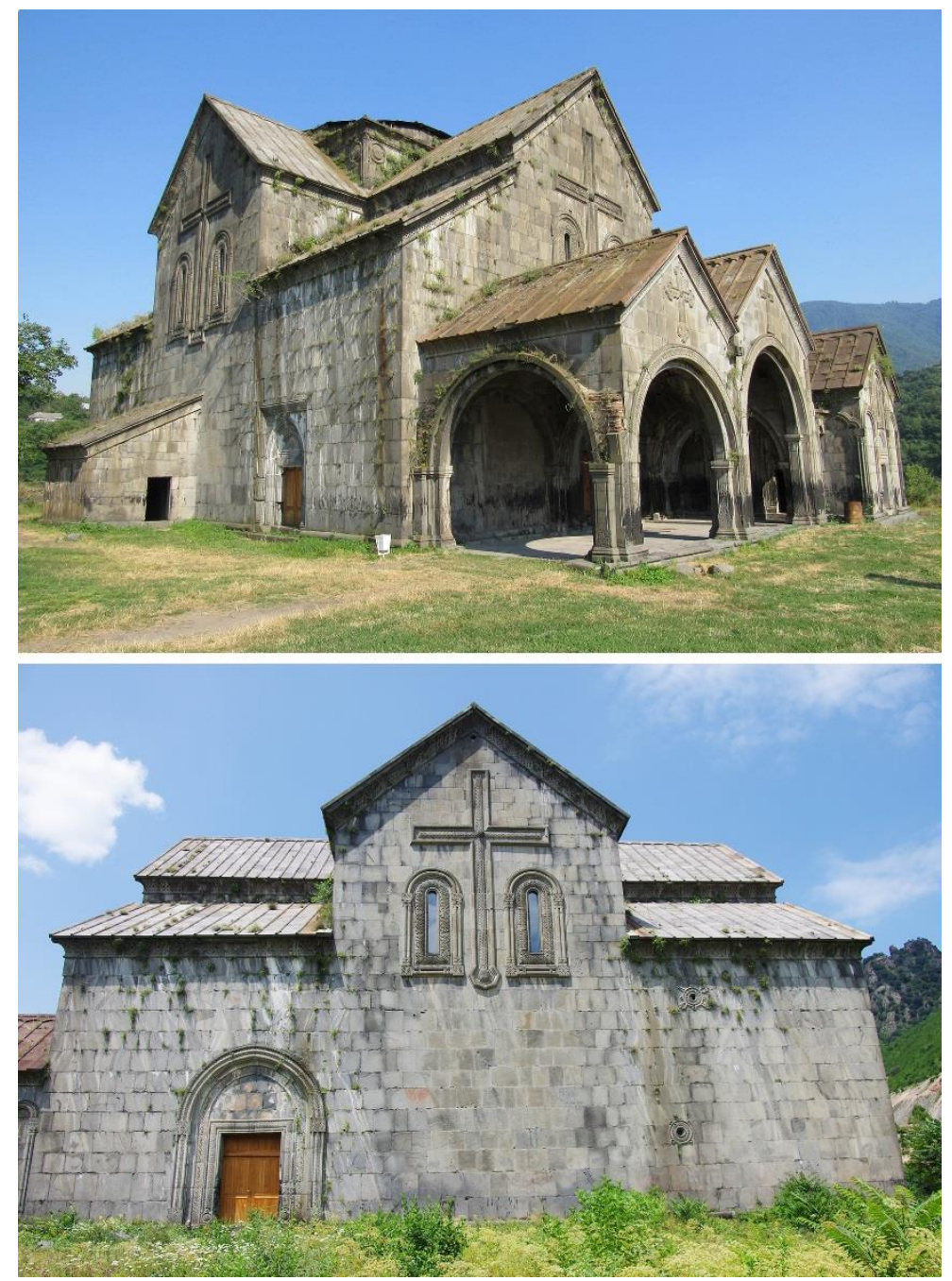

Fig. 33. Płnjahank'/Axt'ala (début XIII ${ }^{\mathrm{e}}$ s.). Vue NO et façade $\mathrm{S}$. 

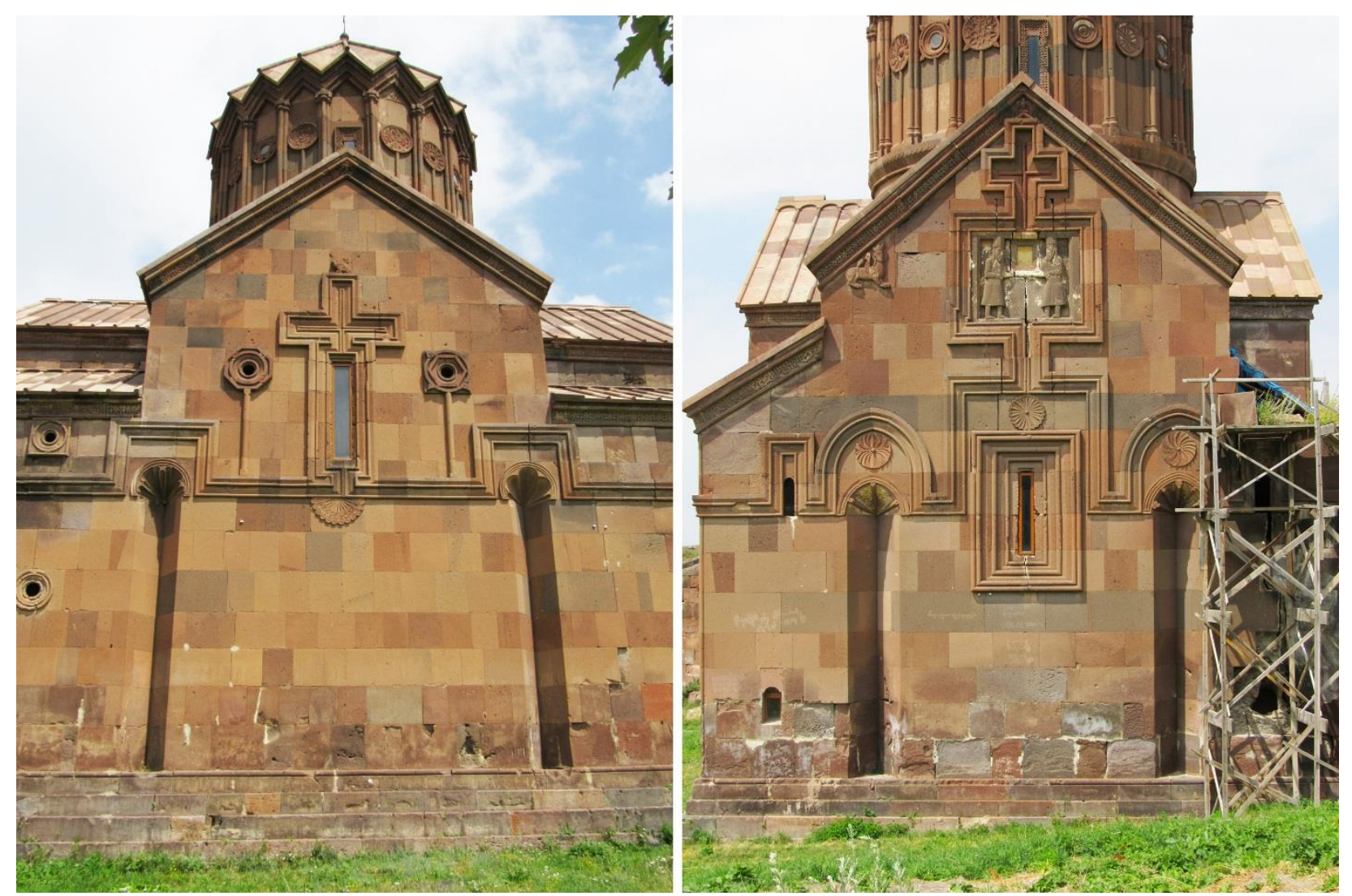

Fig. 34. Har̈ič (1201). Façades S et E.

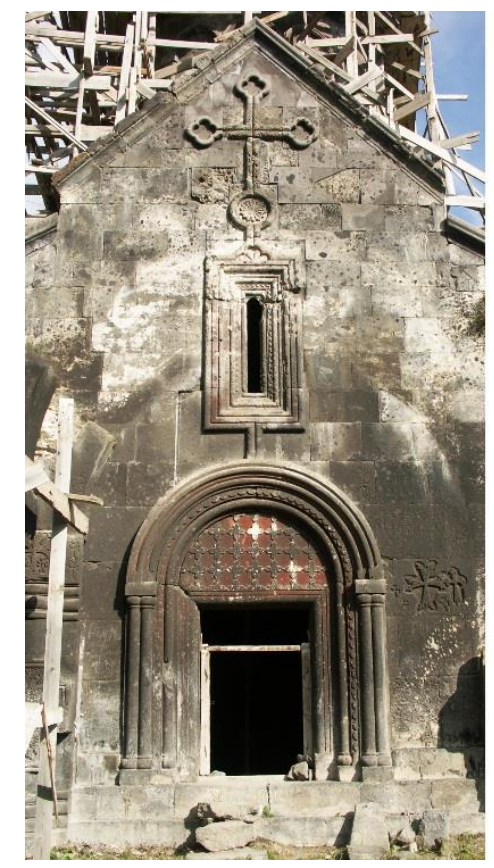

A) Astuacənkal (1244), façade O.
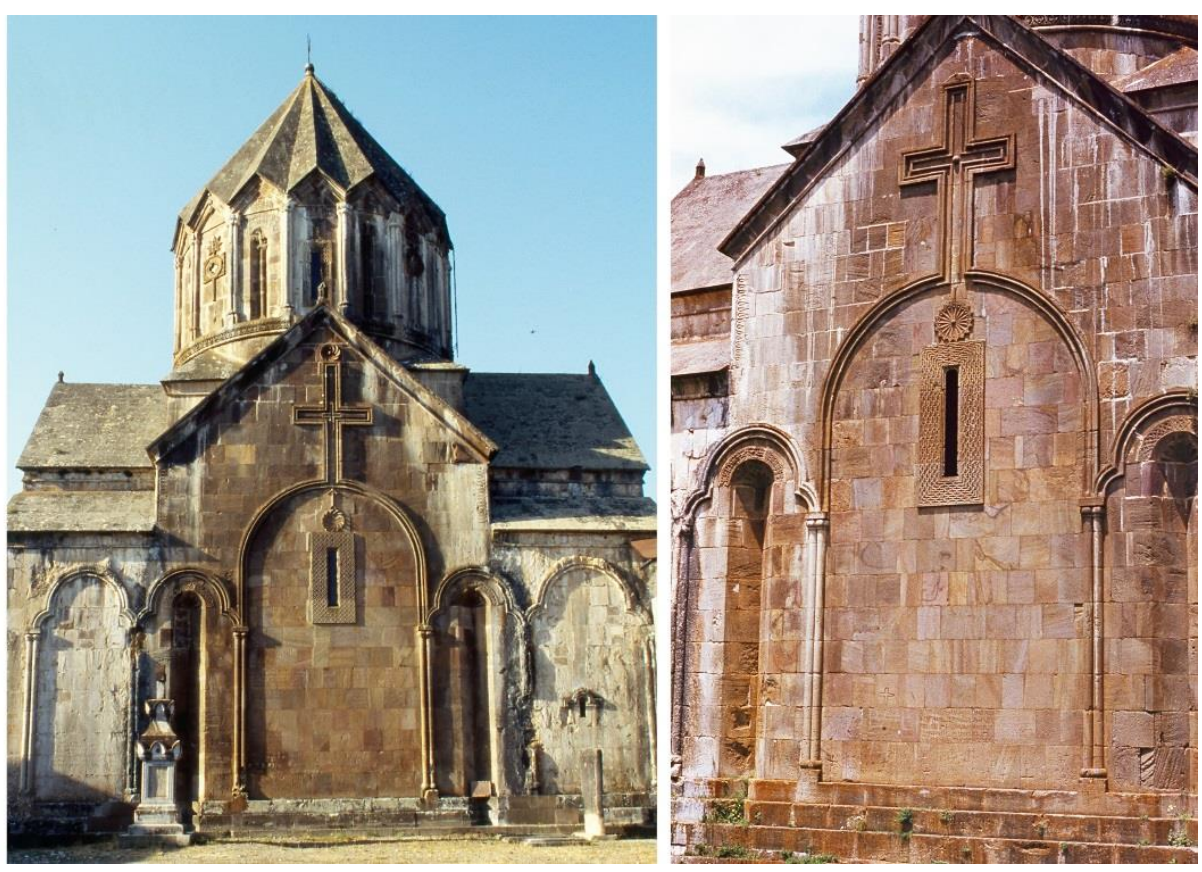

Fig. 35 .

B) et C) Ganjasar (1216-1238), façades $\mathrm{N}$ et $\mathrm{S}$. 


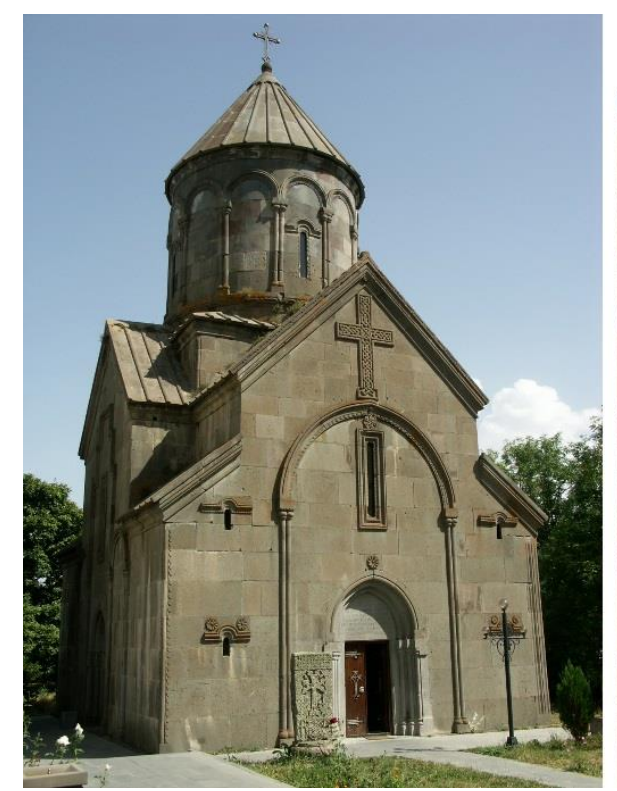

A) Keč‘ariis (déb. XIII ${ }^{e}$ ), façade $\mathrm{O}$.

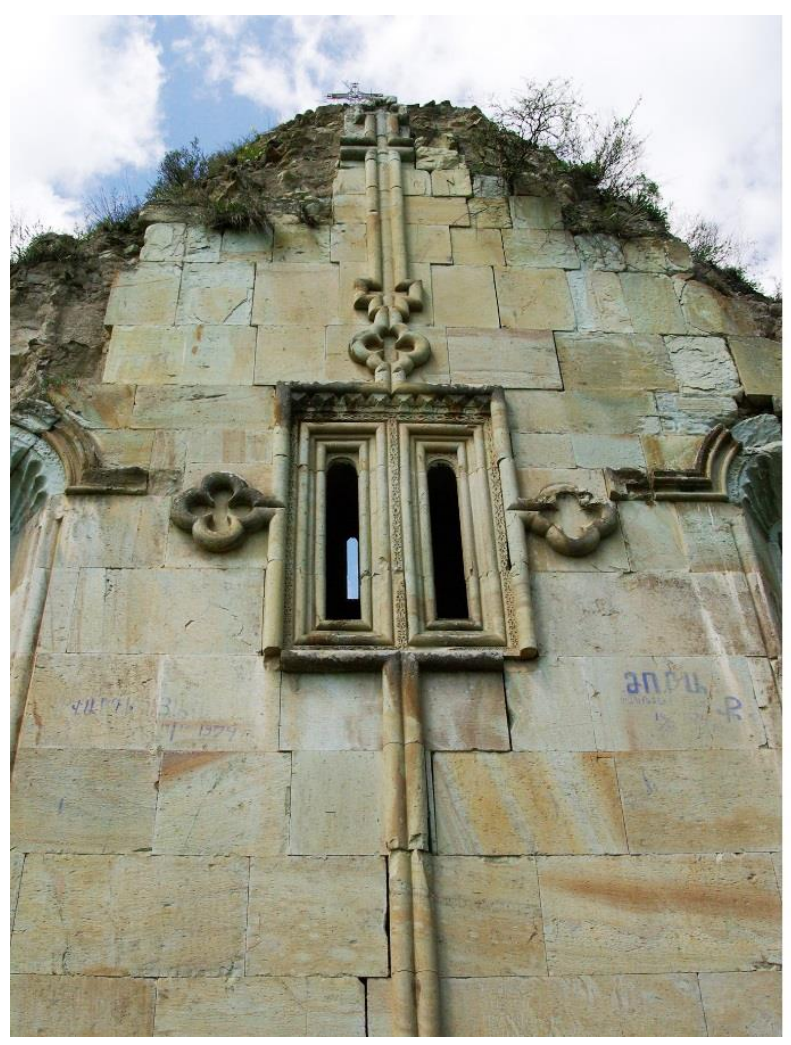

A) Nor Varagavank‘ (1224-1237), façade E.
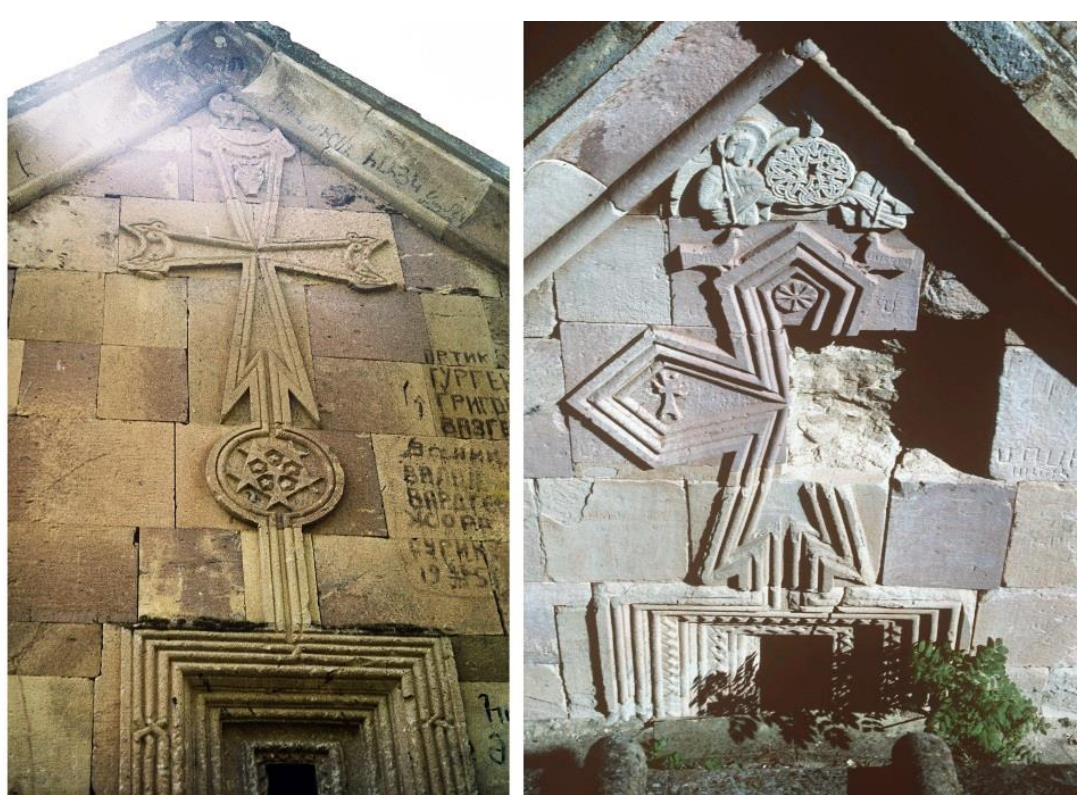

Fig. 36.

B) et C) Mškavank` (déb. XIII ${ }^{e}$, façades E et O.

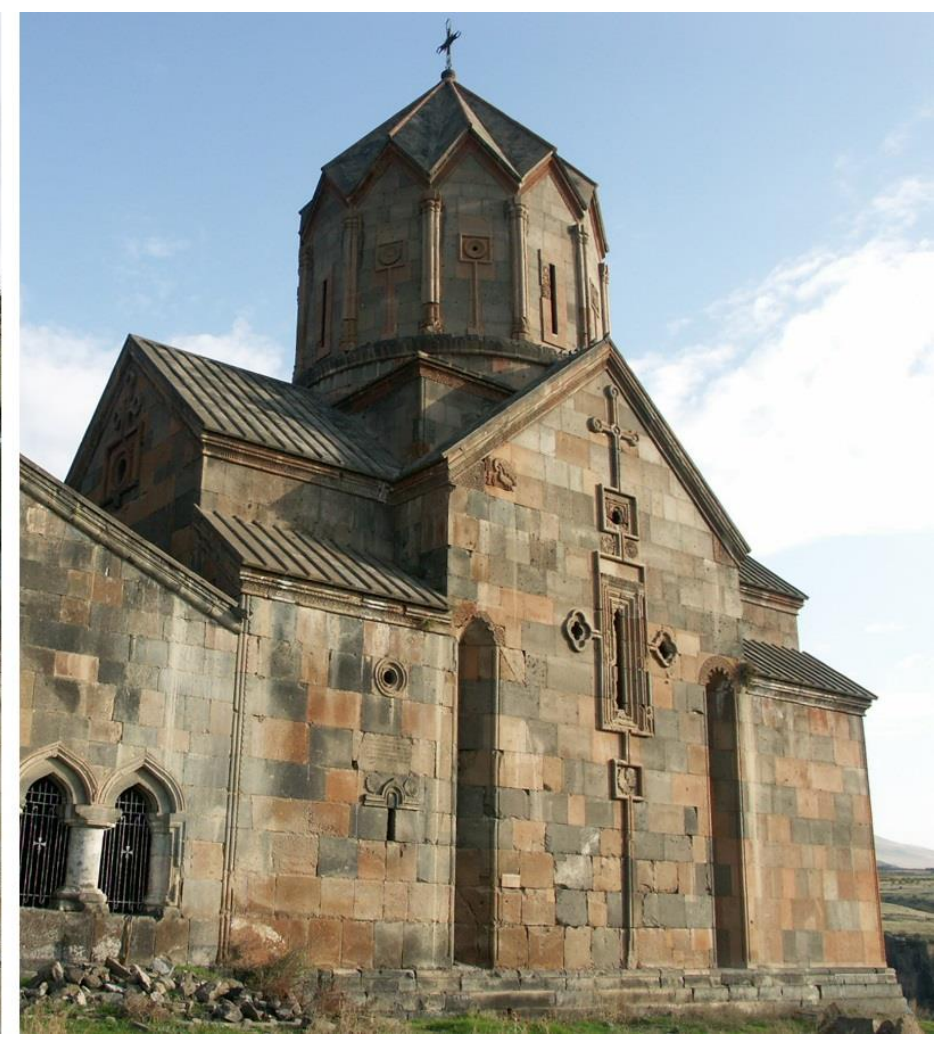

Fig. 37.

B) Yovhannavank' (1216-1221), façade S. 

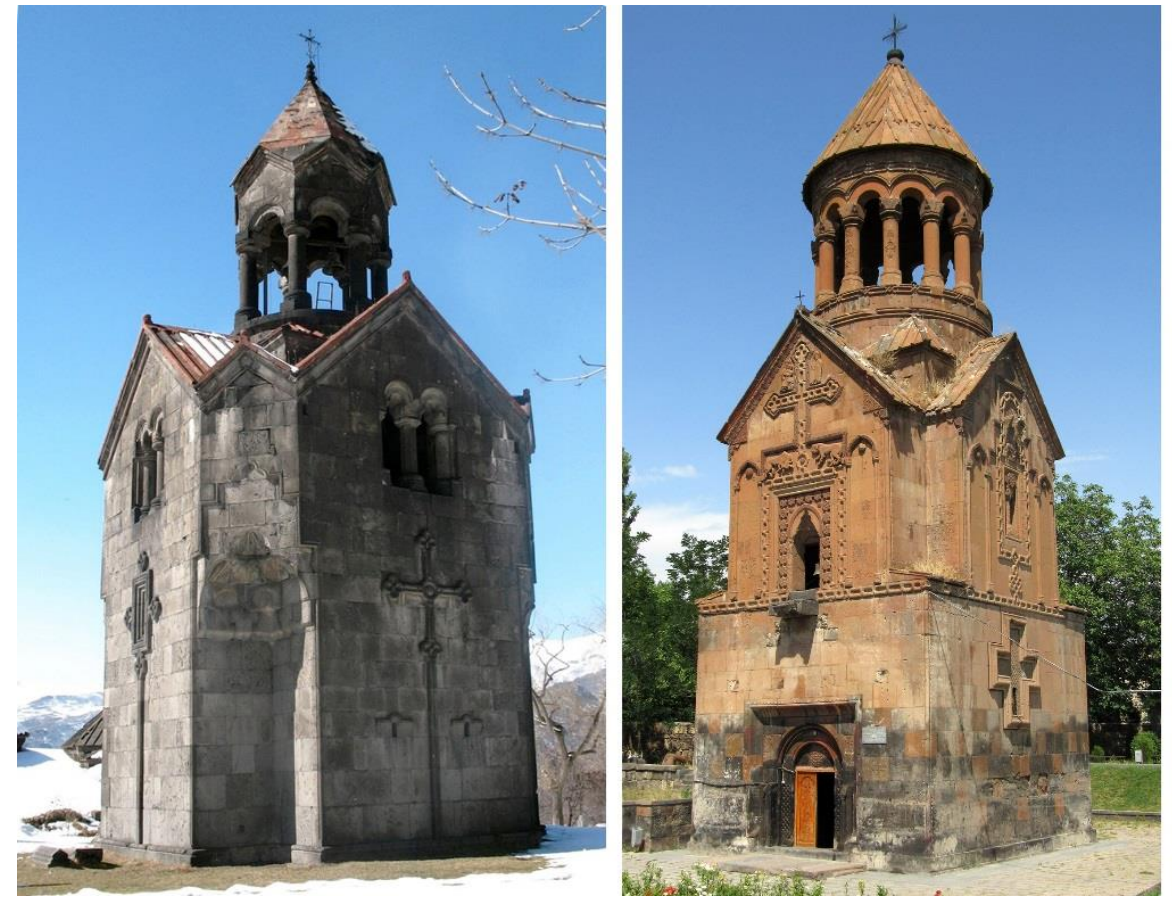

Fig. 38.

A) Hałbat, campanile (1245), vue S-E. B) Ełvard (déb. XIVe), vue S-O. C) Spitakawor (1321), vue S-E. 